Aus dem Zentrum für klinische Tiermedizin der Tierärztlichen Fakultät

der Ludwig-Maximilians-Universität München

Arbeit angefertigt unter der Leitung von Prof. Dr. Johannes Hirschberger

\title{
Lebensqualität und Lebenserwartung am malignen Lymphom erkrankter Hunde unter Chemotherapie - eine Besitzerumfrage
}

\author{
Inaugural-Dissertation \\ zur Erlangung der tiermedizinischen Doktorwürde \\ der Tierärztlichen Fakultät der Ludwig-Maximilians-Universität \\ München
}

von Michele Marie-Julie Dominique Bergmann

aus Fürth/Bayern

München 2011 
Gedruckt mit der Genehmigung der Tierärztlichen Fakultät der Ludwig-Maximilians-Universität München

Dekan: Univ.-Prof. Dr. Braun

Berichterstatter: Univ.-Prof. Dr. Hirschberger

Korreferent: Univ.-Prof. Dr. Klee

Tag der Promotion: 30. Juli 2011 
Meiner Familie 


\section{INHALTSVERZEICHNIS}

I.

EINLEITUNG 1

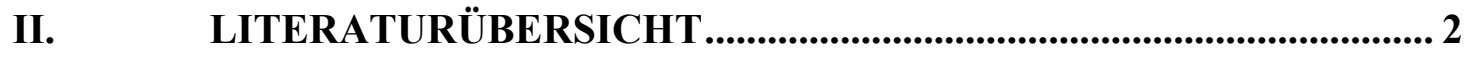

2.1. Das maligne Lymphom des Hundes.................................................... 2

2.1.1. Inzidenz und Ätiologie .................................................................. 2

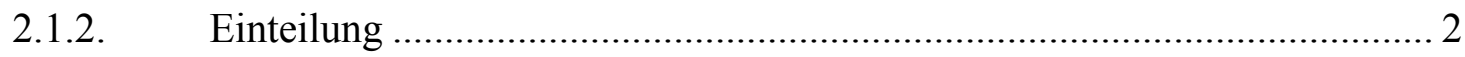

2.1.2.1. Anatomische Formen ..................................................................... 3

2.1.2.2. Klinische Stadieneinteilung .................................................................. 4

2.1.2.3. Histologische Einteilung und Immuntypisierung ..................................... 5

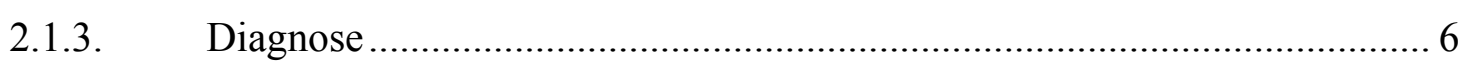

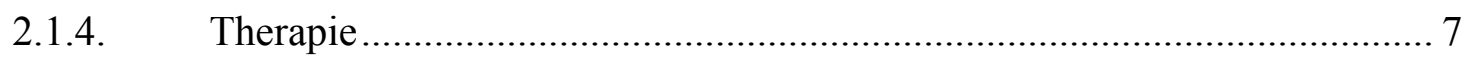

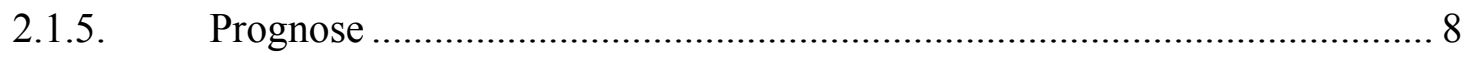

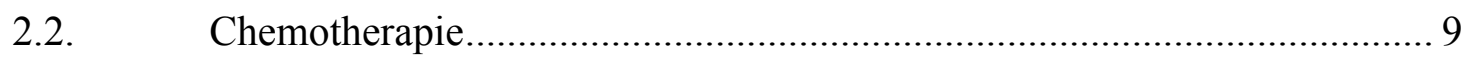

2.2.1. Komplikationen der Chemotherapie.................................................... 10

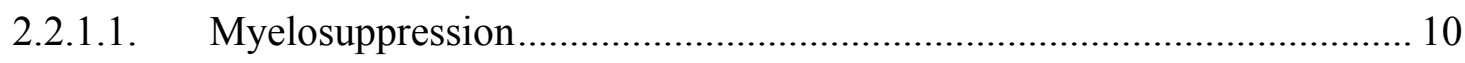

2.2.1.2. Gastrointestinale Toxizität ................................................................. 11

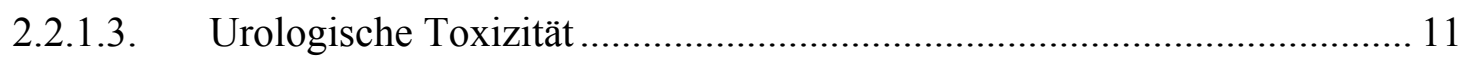

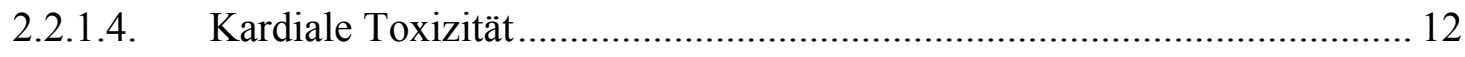

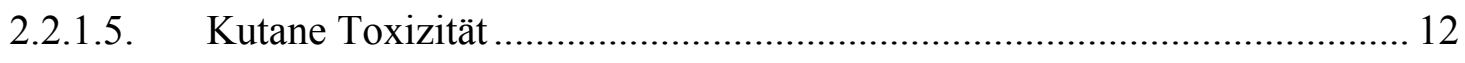

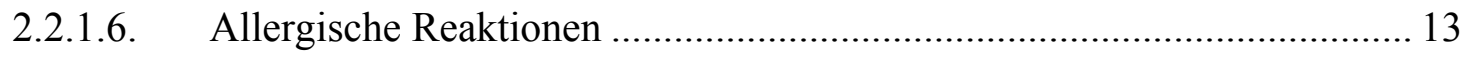

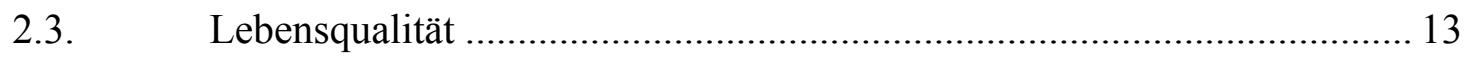

2.3.1. Instrumente zur Erfassung der Lebensqualität ....................................... 14

2.3.2. Aktueller Stand der Lebensqualitäts-Forschung .................................... 16

III. KAPITEL I: ERSTE PUBLIKATION_......................................... 18

IV. KAPITEL II: ZWEITE PUBLIKATION ........................................ 32

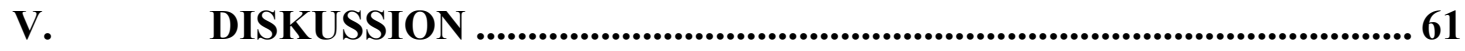

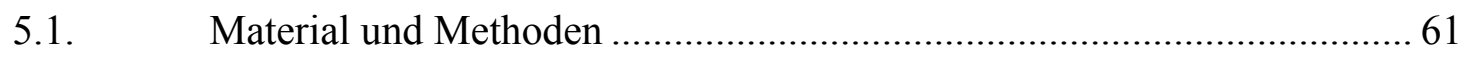

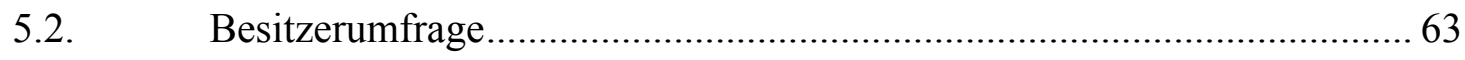

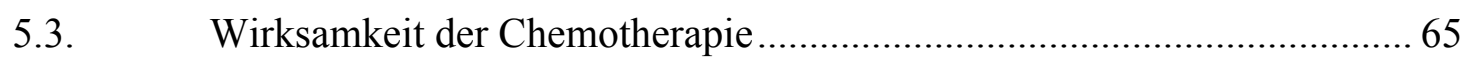

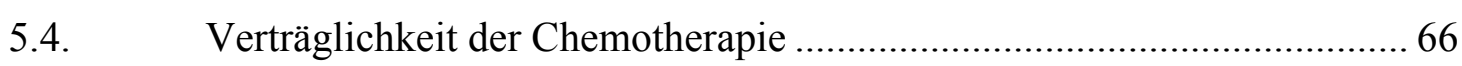


5.5. Wirksamkeit und Verträglichkeit - Vergleich mit der subjektiven

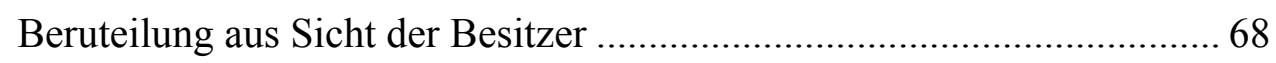

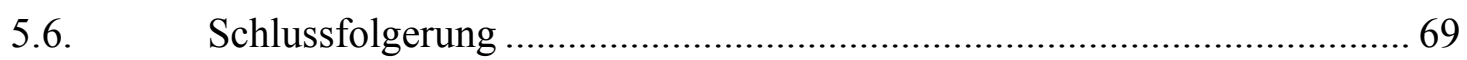

VI. ZUSAMMENFASSUNG ................................................................ 70

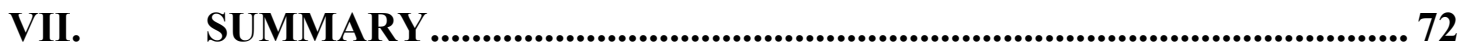

VIII. LITERATURVERZEICHNIS .........................................................73

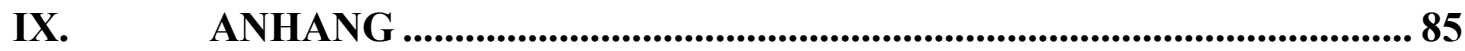

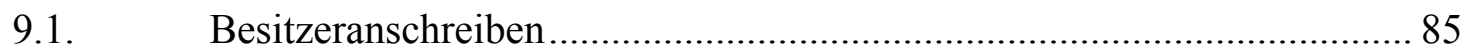

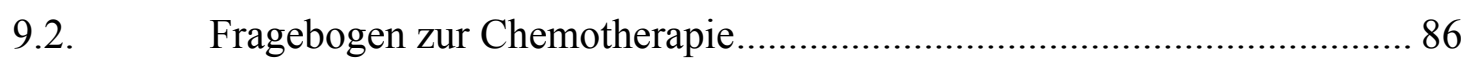

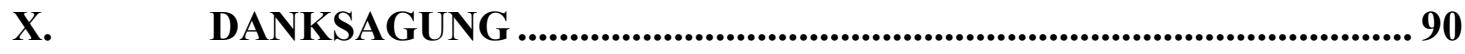




\section{ABKÜRZUNGSVERZEICHNIS}

AgNORs

BCR

CD

COP

CR

CTCAE

DISC

DNA

DVG

EORTC-QLQ C30

FIV

ggf.

HRQOL

IU

i. v.

$\mathrm{KC}$

MDR

NCI

PARR

PCR

RNA

s. c.
Argyrophilic Nucleolar Organizer Regions

B Cell Receptor

Cluster of Differentiation

Cyclophosphamid, Vincristin, Prednisolon

Complete Remission

Common Terminology Criteria for Adverse Events

Dose Intensifying Simultaneous Combination

Chemotherapy

Desoxyribonukleinsäure

Deutsche Veterinärmedizinische Gesellschaft

European Organisation for Research and Treatment

of Cancer Quality of Life Questionnaire

Felines Immundefizienz-Virus

gegebenenfalls

Health Related Quality of Life

International Units

intravenös

Kombinations-Chemotherapie

Multi Drug Resistance

National Cancer Institute

PCR for Antigen Receptor Rearrangement

Polymerasekettenreaktion

Ribonukleinsäure

subkutan 
SD

TCR

u. a.

VCOG

WHO

z. B.

ZNS
Stable Disease

T Cell Receptor

unter anderem

Veterinary Co-operative Oncology Group

World Health Organization

zum Beispiel

Zentralnervensystem 


\section{EINLEITUNG}

Das maligne Lymphom ist eine der am häufigsten diagnostizierten kaninen Neoplasien. Bezüglich der Behandlung liegt der Schwerpunkt in der Literatur auf Chemotherapie-Protokollen, die Parameter wie die mediane Überlebenszeit, die Remissionszeit und das Auftreten von Nebenwirkungen auswerten (BRONDEN et al., 2003; MELLANBY et al., 2003). In der Humanmedizin hingegen stellt die Lebensqualität bei der Bewertung palliativer Chemotherapien schon lange einen zentralen Bestandteil dar (OSOBA, 1992; GUNNARS et al., 2001).

Allmählich wird dem Konzept „Lebensqualität von Patienten” auch in der Tiermedizin mehr Aufmerksamkeit geschenkt (VON WETHERN et al., 1999; BRONDEN et al., 2003; MELLANBY et al., 2003; YAZBEK \& FANTONI 2005; TZANNES et al., 2008; YEATES \& MAIN, 2009; BOWLES et al., 2010). Bislang gibt es aber nur eine Studie, die die Lebensqualität von Hunden mit malignem Lymphom unter Chemotherapie krankheitsspezifisch evaluiert. In dieser Studie vertritt die Mehrzahl der Besitzer trotz vorhandener Komplikationen die Meinung, dass die Lebensqualität ihrer Hunde während der Behandlung so gut war wie vor der Entwicklung des Lymphoms. Bestimmte Faktoren, die die Lebensqualität beeinflussten, konnten die Autoren jedoch aufgrund des kleinen Patientenkollektivs und der unzureichenden Befragung nicht aufzeigen (MELLANBY et al., 2003).

Die vorliegende Arbeit beurteilt den Erfolg der Chemotherapie von Hunden mit malignem Lymphom anhand von zwei Kriterien: Zum einen wurden objektive Parameter der Chemotherapie, wie Überlebens-, Remissionszeiten und Nebenwirkungen ausgewertet. Der Schwerpunkt lag aber auf der subjektiven Bewertung der Therapie aus Sicht der Besitzer, insbesondere in Bezug auf die Lebensqualität der Tiere. Der Vergleich dieser Auswertungen zeigt, inwiefern die subjektive Beurteilung der Therapie durch den Tierhalter von der tierärztlichen Sicht abweicht. Zudem wurden Faktoren erfasst, die für die Besitzer bei der Einschätzung der Lebensqualität ihrer Tiere sowie für ihre Gesamtbewertung der Therapie eine entscheidende Rolle spielten. 


\section{LITERATURÜBERSICHT}

\subsection{Das maligne Lymphom des Hundes}

Das maligne Lymphom ist ein hämatopoetischer Tumor. Es zeichnet sich durch die klonale Proliferation von Lymphozyten aus, die in den meisten Fällen primär in Lymphknoten, Leber und Milz ihren Ursprung nimmt, jedoch können auch andere Organe, wie z. B. Niere, ZNS oder Haut betroffen sein (MADEWELL, 1985; MELLANBY et al., 2003).

\subsubsection{Inzidenz und Ätiologie}

Beim Hund gehört das maligne Lymphom zu den am häufigsten diagnostizierten neoplastischen Erkrankungen (ETTINGER, 2003). In der Literatur wird die jährliche Inzidenz mit 24 bis 114 Erkrankungen pro 100.000 Hunde angegeben (DORN et al., 1968; DORN et al., 1970; DOBSON et al., 2002). Allerdings sind zuverlässige Aussagen über die Häufigkeit schwierig zu treffen, da es kaum möglich ist, jeden am malignen Lymphom erkrankten Hund zu erfassen. Demnach ist es möglich, dass die wahre Inzidenz unterschätzt wird (TESKE, 1994; ETTINGER, 2003).

Das kanine maligne Lymphom ist ein aggressiver Tumor (FOURNEL-FLEURY et al., 2002). Die Ätiologie ist bislang weitgehend unbekannt (HAYES et al., 1991; TESKE, 1994; FOURNEL-FLEURY et al., 2002). Es gibt keine Geschlechts-, jedoch eine Rassedisposition (ETTINGER, 2003). Insbesondere größere Hunderassen, wie Deutscher Schäferhund, Boxer, Basset, Bulldogge, Golden Retriever, Pudel, Bernhadiner, Scottish Terrier, Chow Chow und Beagle scheinen vermehrt betroffen zu sein (DORN et al., 1967; ROSENTHAL, 1984; COUTO, 1985; KELLER et al., 1993; TESKE, 1994). Hunde aller Altersstufen können erkranken, besonders häufig sind jedoch mittelalte bis ältere Hunde betroffen. Das durchschnittliche Alter beträgt bei Diagnosestellung 6 bis 9 Jahre (PARODI et al., 1968; VAIL et al., 2001).

\subsubsection{Einteilung}

Für das maligne Lymphom sind mehrere Einteilungsschemata möglich, die auf unterschiedlichen Kriterien beruhen. Die Einteilung kann anhand der anatomischen Lokalisation, zytologisch-histologisch sowie durch 
Immuntypisierung erfolgen.

\subsubsection{Anatomische Formen}

In Abhängigkeit von der anatomischen Lokalisation des Lymphoms unterscheidet man die multizentrische $(80 \%)$, die mediastinale $(5 \%)$, die gastrointestinale (5 7 \%) Form sowie extranodale Formen (MADEWELL \& THESEN, 1987; ETTINGER, 2003).

Bei der multizentrischen Form sind vor allem die peripheren Lymphknoten betroffen. Weiterhin können Leber und Milz sowie das Knochenmark oder auch andere extranodale Lokalisationen befallen werden (ETTINGER, 2003). Klinisch dominiert eine generalisierte Lymphadenomegalie. In etwa 20 - $40 \%$ der Fälle treten unspezifische Symptome wie Gewichtsverlust, Lethargie, Anorexie oder Fieberschübe auf (KELLER et al., 1993; VAIL et al., 1996; ETTINGER, 2003).

Das mediastinale Lymphom geht mit einer Vergrößerung mediastinaler Lymphknoten und/oder des Thymus einher (VAIL et al., 2001). Betroffene Tiere sind oft noch sehr jung und zeigen Symptome wie Husten, Leistungsabfall oder Dyspnoe (DAY, 1997). Polyurie und Polydypsie können bei circa $40 \%$ der Patienten als Folge einer PTHrP (Parathormon-ähnliches Protein) induzierten Hyperkalzämie auftreten (OGILVIE \& MOORE, 1995).

Beim gastrointestinalen Lymphom liegt oftmals eine multifokale oder diffuse Infiltration neoplastischer Zellen der Submukosa und Lamina propria des Gastrointestinaltrakts mit neoplastischen Zellen vor (VAIL et al., 2001). In der Regel leiden betroffene Hunde bei Diagnosestellung bereits an mindestens einem der folgenden Symptome: Gewichtsverlust, Lethargie, Erbrechen, Durchfall oder Anorexie (RASSNICK et al., 2009). Generell ist diese Form mit einer schlechten Prognose verbunden (MADEWELL \& THESEN, 1987). Einige Autoren zählen das gastrointestinale Lymphom deshalb zu den extranodalen Formen (RASSNICK et al., 2009).

Bei den extranodalen Formen können die Tumorzellen primär verschiedene Organe wie beispielsweise Haut, Nieren, Hoden, Nasen- und Nasennebenhöhlen befallen. Zudem können neoplastische Lymphozyten auch primär das Nervensystem oder die Augen befallen, obwohl diese Formen im allgemeinen häufiger als Folge einer metastatischen Beteiligung bei einem multizentrischen Lymphom vorliegen (KALDRYMIDOU et al., 2000; VAIL et al., 2001; VONDERHAAR \& MORRISON, 2002; FAN, 2003; VAIL \& YOUNG, 2007). 
Das klinische Bild und die Symptome bei der Diagnose extranodaler Lymphome sind stark von der Lokalisation abhängig und unterscheiden sich normalerweise nicht erheblich von denen anderer maligner Erkrankungen, welche dieses spezifische Organ befallen. Hunde mit kutanem Lymphom werden oft wegen chronischer Dermatitis oder nodulären Hautveränderungen vorgestellt. Da der Verlauf sehr schleichend sein kann, wird die Diagnose oftmals erst sehr spät gestellt (FONTAINE et al., 2009). So besteht bei einigen Formen, wie etwa dem epitheliotropem T-Zell-Lymphom, die Gefahr, dass sich die Lymphomzellen über das Blut verbreiten oder das Knochenmark und innere Organe befallen (MORRISON, 2001; SCOTT, 2001; GROSS et al., 2005). Insgesamt stellen die extranodalen Formen einen geringen Anteil der malignen Lymphome dar. Generell besitzen sie eine eher schlechte Prognose (COUTO et al., 1984; FONTAINE et al., 2009).

\subsubsection{Klinische Stadieneinteilung}

Die World-Health-Organisation (WHO) gibt ein klinisches Staging-System des malignen Lymphoms vor, das auch beim Hund angewendet wird. Mit diesem lässt sich die klinische Ausbreitung des Tumors im Patienten standardisiert evaluieren (OWEN, 1980). Tabelle 1 stellt die verschiedenen klinischen Stadien dar.

Tabelle 1: Klinische Stadien des kaninen malignen Lymphoms nach WHO (OWEN, 1980).

\begin{tabular}{|c|c|}
\hline Klinisches Stadium* & Kriterien \\
\hline Stadium I & ein Lymphknoten betroffen \\
\hline Stadium II & mehrere regionäre Lymphknoten betroffen \\
\hline Stadium III & generalisierte Lymphknotenvergrößerung \\
\hline Stadium IV & Leber oder Milz (+/- Lnn.) betroffen \\
\hline Stadium V & $\begin{array}{l}\text { Knochenmark, peripheres Blut, andere } \\
\text { Organe betroffen }\end{array}$ \\
\hline \multicolumn{2}{|c|}{$\begin{array}{l}\text { * Die Stadien werden weiter unterteilt in Substage a und Substage b; Substage } \\
\text { bei ungestörtem, b bei gestörtem Allgemeinbefinden oder paraneoplastischer } \\
\text { Hyperkalzämie. }\end{array}$} \\
\hline
\end{tabular}




\subsubsection{Histologische Einteilung und Immuntypisierung}

In der Vergangenheit sind zahlreiche histologische Klassifikationssysteme für das kanine Lymphom erarbeitet worden. $\mathrm{Zu}$ den gebräuchlichsten gehören die Kiel Klassifikation in Europa und die Working Formulation in Nordamerika (CARTER et al., 1986; GREENLEE et al., 1990; FOURNEL-FLEURY et al., 2002; ETTINGER, 2003; FRY et al., 2003; MORRISON, 2005).

Die Kieler Klassifikation teilt Lymphome in sogenannte „low-grade“ und „highgrade" Lymphome ein und basiert sowohl auf morphologischen als auch immunologischen Kriterien (VAIL et al., 2001). Die „National Cancer Institute Working Formulation“" hingegen lässt den spezifischen Zelltyp außer Acht und stellt einen Zusammenhang zwischen den mikroskopischen Eigenschaften und dem klinischen Verlauf her (LENNERT \& FELLER, 1990). Die Einteilung erfolgt hierbei mit Hilfe des mitotischen Index und des Zelltyps in low-, intermediate- und high-grade Lymphome (Tabelle 2) (WORKING FORMULATION, 1982). Niedriggradige Tumoren verhalten sich klinisch weniger aggressiv, wohingegen hochgradige Lymphome oft einen sehr aggressiven klinischen Verlauf aufweisen (MORRISON, 2005). Neben den typischen Non-Hodgkin-Lymphomen sind beim Hund noch die sogenannten indolenten Lymphome beschrieben. Sie kommen vornehmlich in Milz und Lymphknoten vor, verhalten sich jedoch klinisch meist nicht sehr aggressiv (VALLI et al., 2006).

Tabelle 2: Histologische Einteilung des malignen Lymphoms anhand der NCIWorking Formulation (WORKING FORMULATION, 1982).

\begin{tabular}{|l|l|}
\hline \multicolumn{1}{|c|}{ Malignitätsgrad } & \multicolumn{1}{|c|}{ Kriterien } \\
\hline Low-grade & $\begin{array}{l}\text { kleinzellig lymphozytär } \\
\text { follikulär kleinzellig, gekerbt } \\
\text { follikulär gemischt kleinzellig, gekerbt und } \\
\text { großzellig }\end{array}$ \\
\hline Intermediate-grade & $\begin{array}{l}\text { follikulär großzellig } \\
\text { diffus kleinzellig, gekerbt } \\
\text { diffus gemischt klein- und großzellig } \\
\text { diffus großzellig, gekerbt oder nicht gekerbt }\end{array}$ \\
\hline High-grade & großzellig immunoblastisch \\
\hline
\end{tabular}




\begin{tabular}{|l|l|}
\hline & $\begin{array}{l}\text { lymphoblastisch } \\
\text { kleinzellig, nicht-gekerbt (Burkitt- und nicht } \\
\text { Burkitt-Lymphome) }\end{array}$ \\
\hline
\end{tabular}

Entsprechend des Immunphänotyps können maligne Lymphome des Weiteren in B- und T-Zell-Lymphome eingeteilt werden. Der Großteil der kaninen Lymphome gehört zum Immunphänotyp der B-Zellen (circa $70 \%$ ). In nur $20-25 \%$ aller Fälle kommen T-Zell-Lymphome vor. Diese verhalten sich allerdings klinisch meist aggressiver und sind auch häufiger mit einer paraneoplastischen Hyperkalzämie vergesellschaftet als Lymphome vom B-Zell-Typ (GREENLEE et al., 1990; TESKE et al., 1994; RUSLANDER et al., 1997). Bei den meisten mediastinalen und epidermotropen Lymphomen handelt es sich um T-ZellLymphome (MOORE et al., 1994; VAIL et al., 1996; RUSLANDER et al., 1997). In seltenen Fällen können weder B- noch T-Zell-Oberflächenmarker nachgewiesen werden. Solche Lymphome werden als Null-Zell-Typ bezeichnet (FAN, 2003).

\subsubsection{Diagnose}

Die Diagnose eines malignen Lymphoms kann anhand zytologischer und/oder histologischer Untersuchungen erfolgen. Zytologisch sind beim Hund die meisten hochgradigen Lymphome mit einer Feinnadelspiration eines Lymphknotens oder eines anderen vergrößerten Organs (z. B. Leber, Milz) sicher zu diagnostizieren. Bei den mittelgradigen und niedriggradigen Subtypen ist jedoch eine histologische Untersuchung einer Gewebebiopsie (z. B. Leber, Milz, Niere) oder eines gesamten Lymphknotens notwendig (DUNCAN \& PRASSE, 1979; CHUN et al., 2007; VAIL \& YOUNG, 2007; DICKINSON, 2008). Auch die indolenten Lymphome können nur histologisch sicher diagnostiziert werden (VALLI et al., 2006). Sollte die Histologie kein schlüssiges Ergebnis liefern, kann mit Hilfe einer Polymerase-Kettenreaktion (PCR) auf Klonalität des Antigen-Rezeptors untersucht werden (PARR $=$ PCR for Antigen Receptor Rearrangement). Hiermit kann auch gleichzeitig zwischen B- und T-Zell-Lymphom differenziert werden (KELLER et al., 2004).

Die Unterscheidung des Immunphänotyps kann des Weiteren mittels monoklonaler Antikörper durchgeführt werden (CHABANNE et al., 2000a; CULMSEE et al., 2001). Diese Immuntypisierung kann sowohl mit 
Lymphknotenaspiraten als auch mit peripherem Blut durchgeführt werden (WINNICKA et al., 2002; MINISCALCO et al., 2003; GIBSON et al., 2004). Hierbei werden bestimmte Antigene der Lymphozyten, die sogenannten „Cluster of Differentiation“ (CD), mit fluoreszenzgekoppelten monoklonalen Antikörpern markiert und bestimmt (MÜLLER, 1998). Der CD3 ist ein Komplex aus fünf Polypeptiden, der an den T-Zell-Rezeptor (TCR) gebunden ist und dessen Identifizierung das Vorliegen eines T-Zell-Lymphoms aufzeigt. Der CD79 ist ebenfalls ein Heterodimer, der an den B-Zell-Rezeptor (BCR) gebunden ist und dessen Identifizierung auf ein B-Zell-Lymphom hinweist (FAN, 2003).

\subsubsection{Therapie}

Da es sich beim malignen Lymphom um einen hämatopoetischen Tumor handelt, ist die systemische Chemotherapie die am besten geeignete Behandlung erkrankter Hunde (MACEWEN et al., 1981; ETTINGER, 2003; SIMON et al., 2006). Andere Therapien, wie Chirurgie oder Bestrahlung können in einzelnen Fällen (z. B. bei massiver Splenomegalie, Milzrupturen, nasalen oder lokalisierten ZNS-Lymphomen sowie bei einem Ileus) zur raschen Reduzierung der Tumorzellen und Linderung der klinischen Symptome zusätzlich zur zytostatischen Behandlung angebracht sein (MOLDOVANU et al., 1966; BROOKS et al., 1987; MELEO, 1997; ETTINGER, 2003).

Bei Hunden mit Lymphom wird die Chemotherapie in erster Linie palliativ zur Erhaltung oder Verbesserung der Lebensqualität und zur Verlängerung der Überlebenszeit der Patienten eingesetzt (ETTINGER, 2003; MELLANBY et al., 2003; SIMON et al., 2006). Der Therapieerfolg hängt unter anderem vom Einsatz verschiedener zytostatischer Wirkstoffe in einem festgelegten Protokoll ab. Durch die Kombination mehrerer Chemotherapeutika mit einem unterschiedlichem Wirkungs- und Nebenwirkungsspektrum können viele Tumorzellen abgetötet werden und eine bessere Verträglichkeit erzielt werden; zudem kann einer Medikamentenresistenz der Tumorzellen vorgebeugt werden (CHUN et al., 2007). $\mathrm{Zu}$ den wirksamsten Chemotherapeutika beim malignen Lymphom zählen Doxorubicin, Vincristin, Cyclophosphamid, L-Asparaginase und Prednisolon (ETTINGER, 2003). So konnten mit Doxorubicin-haltigen PolychemotherapieProtokollen Remissionsraten zwischen $76 \%$ und $92 \%$ und eine mediane Überlebenszeit von rund einem Jahr erreicht werden (MOORE et al., 2001; GARRETT et al., 2002; SIMON et al., 2006). 
Ist eine intensive Polychemotherapie aufgrund äußerer Umstände der Besitzer nicht durchführbar, kann eine Behandlung mit kostengünstigeren, weniger zeitintensiven Protokollen, wie z. B. Doxorubicin-freien Protokollen erfolgen. Diese enthalten meist verschiedene Alkylanzien, wie z. B. Cyclophosphamid und Chlorambucil, und andere Zytostatika, wie Vincristin oder Metothrexat, (MACEWEN et al., 1981; COTTER \& GOLDSTEIN, 1983; CARTER et al., 1987). Die Remissionsraten sind mit Doxrubicin-haltigen Protokollen vergleichbar und reichen von $70 \%-90 \%$, allerdings liegen die medianen Überlebenszeiten mit rund 6 bis 7,5 Monaten deutlich unter denen Doxorubicinhaltiger Protokolle (MACEWEN et al., 1981; COTTER \& GOLDSTEIN, 1983; CARTER et al., 1987).

Des Weiteren können beim malignen Lymphom Mono-Chemotherapien vorgenommen werden (PIEK et al., 1999; CHUN, 2009). Dabei ist Doxorubicin das bisher effektivste Monotherapeutikum, mit dem mediane Überlebenszeiten von bis zu 9 Monaten erreicht werden konnten (CR 76 \%) (CARTER et al., 1987).

Falls persönliche Gründe des Tierhalters (z. B. Schwangerschaft der Besitzerin, Kleinkinder im Haus) den Einsatz von Zytostatika nicht ratsam erscheinen lassen, kann eine Einzelmedikation mit L-Asparaginase und/oder einem Kortikosteroid vorgenommen werden. Hardy und Mitarbeiter (1970) konnten bei der Therapie mit L-Asparaginase eine Ansprechrate von 82 \% nachweisen. Zudem ist bekannt, dass bereits eine alleinige Behandlung mit einem Kortikosteroid eine Vollremissionsrate von $43 \%$ bewirken kann, jedoch rezidivieren die Tumoren zum Großteil innerhalb von 1 bis 2 Monaten (SQUIRE et al., 1973; CHUN et al., 2007; VAIL \& YOUNG, 2007; CHUN, 2009). Unterbleibt eine Behandlung, versterben die Hunde zumeist nach 4 bis 6 Wochen (ETTINGER, 2003).

\subsubsection{Prognose}

Mittlerweile wurden einige Faktoren untersucht, die die Prognose eines Hundes mit malignem Lymphom beeinflussen und bei der Aufklärung der Patientenbesitzer hinsichtlich des Therapieerfolges ihres Hundes hilfreich sein können. So ist bei Hunden, die bereits mit gestörtem Allgemeinbefinden (Susbtage b) vor der chemotherapeutischen Behandlung vorgestellt werden ebenso wie bei Hunden mit speziellen Lymphom-Lokalisationen (mediastinales, 
gastrointestinales, ZNS-, oder epitheliotropes Lymphom) generell von einer schlechteren Prognose auszugehen (COUTO et al., 1984; GREENLEE et al., 1990; KELLER et al., 1993; VALERIUS et al., 1997; ZEMANN et al., 1998; BASKIN et al., 2000; FONTAINE et al., 2009; RASSNICK et al., 2009). Auch labordiagnostische Veränderungen (z. B. paraneoplastische Hyperkalzämie, Anämie, Thrombozytopenie) können sich negativ auf die Prognose auswirken (KELLER et al., 1993; ZEMANN et al., 1998; MOORE et al., 2001; ABBO \& LUCROY, 2007). Vorbehandlungen mit Glukokortikoiden oder Zytostatika können zu Medikamentenresistenzen (MDR $=$ Multi Drug Resistance) bei betroffenen Hunden führen (PRICE et al., 1991; KHANNA et al., 1998; BERGMAN, 2003). Hunde, die im Verlauf der Behandlung keine komplette Remission erreichen, haben nachweislich kürzere Überlebenszeiten (MOORE et al., 2001; SIMON et al., 2006). Generell ist bekannt, dass Hunde mit B-ZellLymphomen häufiger vollständige und längere Remissionen erreichen und somit eine günstigere Prognose haben als Hunde mit T-Zell-Lymphomen (GREENLEE et al., 1990; TESKE et al., 1994; PONCE et al., 2004). Außerdem sind T-ZellLymphome häufiger mit einer paraneoplastischen Hyperkalzämie vergesellschaftet als Lymphome vom B-Zell-Typ (GREENLEE et al., 1990).

Dem histologischen Grad nach verhalten sich Lymphome mit höherer Malignität aggressiver als Lymphome mit niedrigerer Malignität (MORRISON, 2005). High-

grade Lymphome, die höhere Wachstumsfraktionen besitzen, reagieren zwar sensibler auf die Chemotherapie, allerdings ergeben sich schneller Mutationen, die ebenfalls zu Resistenzen führen (TESKE et al., 1994). Ebenfalls prognostisch von Bedeutung ist die Proliferationsrate des Tumors, die mittels AgNORs (Argyrophilic Nucleolar Organizer Regions) bestimmt werden kann (KIUPEL et al., 1999).

\subsection{Chemotherapie}

Die meisten Chemotherapeutika sind nicht selektiv und greifen unspezifisch Zellen an, die eine schnelle Zellteilung aufweisen - auch gesunde Zellen, wie z. B. Zellen des Knochenmarks oder des Gastrointestinaltrakts. Daraus resultieren die wichtigsten Toxizitäten einer zytostatischen Therapie (COUTO, 1990; CHUN et al., 2007; SORENMO et al., 2010). Das Ausmaß an Nebenwirkungen ist dabei abhängig von der Art, der Dosis und der zeitlichen Abfolge des verabreichten 
Medikaments; zusätzlich können individuelle Faktoren wie z. B. das Alter des Patienten (geriatrische Patienten), das Körpergewicht (leichte Patienten) oder Begleiterkrankungen (Organfunktionsstörungen) zu einer intensivierten Wirkung der Zytostatika führen und diesen so für Nebenwirkungen der Therapie anfälliger werden lassen (COUTO, 1990; HIRSCHBERGER et al., 2000; SORENMO et al., 2010).

\subsubsection{Komplikationen der Chemotherapie}

Bei den in der Literatur aufgeführten Angaben zur Verträglichkeit der Chemotherapie des malignen Lymphoms ist $\mathrm{zu}$ berücksichtigen, dass unterschiedliche Beschreibungen hinsichtlich der Toxizitäten und ihrer Schweregrade bestehen, was den Vergleich der beobachteten Komplikationen zwischen verschiedenen Studien erschwert (MELLANBY et al., 2003). Seit Dezember 2004 hat allerdings die „Veterinary Co-operative Oncology Group“ (VCOG) eine gemeinsame Abstimmung zur Bezeichnungsweise der Komplikationen der Chemotherapie bei Hund und Katze („Common Terminology Criteria for Adverse Events“ - CTCAE) herausgegeben (VAIL, 2004).

\subsubsection{Myelosuppression}

Die Myelosuppression gilt als eine der wichtigsten Komplikationen der Chemotherapie (PIZZO \& YOUNG, 1985; CHUN et al., 2007; SORENMO et al., 2010). Mit Ausnahme von Kortikosteroiden kommt es bei fast allen Medikamenten, die bei der Therapie des malignen Lymphoms eingesetzt werden $\mathrm{zu}$ einer Beeinträchtigung der blutbildenden Zellen im Knochenmark (MORRISON, 2005). Besonders betroffen sind hiervon die neutrophilen Granulozyten, da ihre Reifungszeit im Knochenmark nur 6 Tage beträgt und auch die Halbwertszeit in der Blutbahn sehr kurz ist (4 - 8 Stunden) (PIZZO \& YOUNG, 1985; HAMMER, 1992; RUSLANDER, 1999; NORTHRUP et al., 2002; MORRISON, 2005; CHUN et al., 2007; SORENMO et al., 2010). Bei den meisten Protokollen erholt sich allerdings das Knochenmark und es werden genügend Zellen bis zur nächsten Therapiesitzung nachgebildet (MORRISON, 2005). Dennoch können insbesondere in der Induktionsphase Neutropenien den Patienten gefährden, weshalb in dieser Therapiephase prophylaktisch regelmäßige Blutbildkontrollen durchgeführt werden müssen, um schwerwiegenden Komplikationen (z. B. Fieber infolge bakterieller Infektionen, Sepsis) vorzubeugen oder diese rechtzeitig behandeln zu können (HIRSCHBERGER et 
al., 2000; SORENMO et al., 2010).

Obwohl die Sepsis in der Tiermedizin als eine seltene Komplikation der Chemotherapie gilt, besteht einer neuen Studie zufolge bei Hunden mit malignem Lymphom nachweislich eine größere Gefahr, eine Sepsis zu entwickeln, als bei jenen, die aufgrund eines soliden Tumors chemotherapiert werden (CHUN et al., 2007; SORENMO et al., 2010). SORENMO und Mitarbeiter (2010) vermuten, dass dies mit der Immunsuppression Lymphom-kranker Hunde in Zusammenhang steht. So erkrankten Lymphom-Patienten vor allem im frühen Therapieverlauf der Induktionsphase, wenn zumeist noch keine Remission erreicht war, insbesondere nach der Gabe von Doxorubicin und Vincristin. Eine Immundysfunktion konnte von Fowler und Mitarbeitern (2010) kürzlich bei Hunden mit malignem Lymphom nachgewiesen werden.

Thrombozyten haben eine längere Halbwertszeit als neutrophile Granulozyten (Halbwertszeit 4-6 Tage), so dass Thrombopenien als Folge der Chemotherapie weniger häufig vorkommen als Neutropenien (COUTO, 1990; HIRSCHBERGER et al., 2000).

Eine Beeinträchtigung der Erythropoese ist aufgrund der langen Lebensdauer von Erythrozyten in der Regel nur bei einer Langzeitgabe von Chemotherapeutika gegeben. Betroffene Patienten weisen meist nur milde Anämien auf (COUTO, 1990; HIRSCHBERGER et al., 2000; MORRISON, 2005).

\subsubsection{Gastrointestinale Toxizität}

Gastrointestinale Nebenwirkungen, wie Anorexie, Erbrechen und Durchfall können häufiger als Komplikationen einer Chemotherapie auftreten, wobei es sich in der Regel um milde, zumeist selbstlimitierende Nebenwirkungen handelt (MORRISON, 2005). Sie sind insbesondere nach der Gabe von Vincristin beschrieben (ROWINSKY, 2006; CHUN et al., 2007). Als Ursache wird unter

anderem die periphere neurotoxische Wirkung von Vincristin im Gastrointestinaltrakt vermutet (RUSLANDER, 1999; NAGEL, 2003). Darüber hinaus sind gastrointestinale Beschwerden auch gehäuft nach Doxorubicin-Gaben beschrieben (CHUN et al., 2007).

\subsubsection{Urologische Toxizität}

Eine sterile hämorrhagische Zystitis ist eine spezielle Nebenwirkung, die vor allem nach der Gabe von Cyclophosphamid auftritt. Der dafür verantwortliche 
Cyclophosphamid-Metabolit Acrolein wird renal ausgeschieden und kann sowohl nach einer einmaligen Gabe wie auch nach chronischer Applikation direkt zur Schädigung des Harnblasenepithels führen (CROW et al., 1977; PETERSON et al., 1992; CHARNEY et al., 2003). Durch die gleichzeitige Gabe eines Diuretikums, z. B. Furosemid, kann die Inzidenz einer sterilen hämorrhagischen Zystitis drastisch gesenkt werden. Laut Literatur zeigen nur 1,2\% aller mit Cyclophosphamid plus Furosemid behandelten Hunde Symptome einer hämorrhagischen Zystitis im Gegensatz zu 9 \% der Furosemid-unbehandelten Hunde (CHARNEY et al., 2003).

\subsubsection{Kardiale Toxizität}

Kardiotoxische Komplikationen können durch Zytostatika, wie Doxorubicin und Epirubicin während deren Applikation in Form von akuten Arrhythmien auftreten. Diese sogenannten Anthrazyklin-Antibiotika hemmen die Topoisomerase II und führen zur Interkalation der DNA (Desoxyribonukleinsäure), was wiederum die Proteinsynthese hemmt und zur Bildung von eisenabhängigen freien Radikalen führt. Diese verursachen oxidative Zell-Schäden (CHABNER \& MYERS, 1993). Zusätzlich kann Doxorubicin beim Hund auch nach chronischer Applikation zu einer dilatativen Kardiomyopathie führen, die ebenfalls durch oxidative Schädigung der Myozyten bedingt ist. Dies kann insbesondere ab kumulativen Dosen von $180-240 \mathrm{mg} / \mathrm{m}^{2}$ erfolgen (MAULDIN et al., 1992).

\subsubsection{Kutane Toxizität}

Reaktionen der Haut (Alopezie, Hyperpigmentation, Hypersensitivität) sind insbesondere nach der Gabe von Doxorubicin beschrieben. In der Regel handelt es sich dabei um seltene, reversible Veränderungen (BRISTOW et al., 1980; VAN VLEET \& FERRANS, 1980; DECORTI et al., 1989; MAULDIN et al., 1992; MORISSON, 2002). Die Alopezie tritt vornehmlich bei Hunden mit einem permanenten Fellwuchs auf (Pudel, Bobtail, et cetera). Bei kurzhaarigen Hunderassen können die Tasthaare betroffen sein (COUTO, 1990). Selten kommt es insbesonders im Inguinalbereich zu Verfärbungen der Haut (VAN VLEET \& FERRANS, 1980; NAGEL, 2003).

Gewebenekrosen können infolge paravenöser Applikation eines jeden Zytostatikums mit gewebereizendem Charakter (z. B. Doxorubicin, Vincristin, Vinblastin) hervorgerufen werden (MAULDIN et al., 1992; MORRISON, 2005; 
ROWINSKY, 2006). Doxorubicin und Vincristin sind jedoch sehr potente vesikante Arzneimittel, deren Gabe daher streng intravenös erfolgen muss (ROWINSKY, 2006; CHUN et al., 2007).

\subsubsection{Allergische Reaktionen}

Durch die Gabe von L-Asparaginase, ein bakterielles Enzym und somit Fremdeiweiß werden Antikörper gebildet, die zu allergischen Reaktionen führen können (MASETTI \& PESSION, 2009). Die subkutane Applikation der LAsparaginase ist mit weniger Komplikationen verbunden als die intramuskuläre Gabe (VALERIUS et al., 1999).

Doxorubicin kann durch die Degranulation von Mastzellen mit Histaminfreisetzung ebenfalls zu Überempfindlichkeitsreaktionen führen (HAMMER, 1992). Mit langsamen Doxorubicin-Infusionen können diese Hypersensitivitätsreaktionen weitestgehend vermieden werden (CHUN et al., 2007).

\subsection{Lebensqualität}

In der Literatur zeigt sich, dass für den Begriff "Lebensqualität" bis heute sowohl in der Human- als auch in der Veterinärmedizin keine allgemein akzeptierte und verbindliche Definition vorliegt (MCMILLAN, 2000; GUNNARS et al., 2001; WOJCIECHOWSKA \& HEWSON, 2005). Da aus medizinischer Sicht hauptsächlich ein Instrument interessiert, das den Erfolg einer Behandlung misst, sollte man zwischen dem Begriff "Lebensqualität" und der "gesundheitsbezogenen Lebensqualität" (Health Related Quality of Life, HRQOL) unterscheiden (PATRICK \& DEYO, 1998). Die Präambel der Weltgesundheitsorganisation definierte Gesundheit 1947 als einen Zustand vollkommenen körperlichen, seelischen und sozialen Wohlbefindens. Dies führte dazu, dass neben objektiven Aspekten der Gesundheit, wie die klinische Symptomatik und mediane Überlebenszeiten auch explizit die Verbesserung des subjektiven Befindens für Therapieerfolge von Bedeutung ist. Im Zusammenhang mit der Entwicklung eines internationalen Fragebogens zur Erfassung der Lebensqualität beschrieb die WHO diese wie folgt: "Quality of Life is defined as an individual's perception of their position in life in the context of the culture and value systems in which they live and in relation to their goals, expectations, standards and concerns. It is a broad ranging concept affected in a complex way 
by the person's physical health, psychological state, level of independence, social relationship, and their relationship to salient features of their environment" (THE WHOQOL-GROUP, 1998). Demnach lässt sich Lebensqualität als die individuelle Wahrnehmung der eigenen Lebenssituation im Kontext der jeweiligen Kultur und des jeweiligen Wertesystems und in Bezug auf die eigenen Ziele, Erwartungen, Beurteilungsmaßstäbe und Interessen definieren. Lebensqualität ist also keine immer konstant bleibende Größe, sondern ein in den klinischen Phasen wechselndes Konstrukt (BERNHARD et al., 2004). Humanund Veterinärmediziner sind sich einig, dass sie ein subjektives und multidimensionales Konzept beinhaltet, das zumindest physische, psychologische, soziale und funktionelle Aspekte einschließt (GUNNARS et al., 2001; WOJCIECHOWSKA \& HEWSON, 2005). So sind die zentralen Bestandteile, die laut WOJCIECHOWSKA und HEWSON (2005) die Lebenqualität eines Hundes ausmachen Zufriedenheit in Hinblick auf physische Bedürfnisse (z. B. Fressen, Trinken), Zufriedenheit in Hinblick auf weitere Bedürfnisse, die in der Natur des Tieres liegen und zu dessen mentalen Wohlbefinden beitragen (z. B. soziale Interaktionen, Erkundung der Umgebung) und körperliche Gesundheit.

\subsubsection{Instrumente zur Erfassung der Lebensqualität}

Einschätzungen der Lebensqualität anhand von Selbstbewertungen vorzunehmen, wie es in der Humanmedizin als Goldstandard erachtet wird, ist von Seiten unserer Haustiere nicht möglich (MCMILLAN, 2009). Aber nicht selten wird eine Fremdeinschätzung von Patienten, die selbst nicht in der Lage zur Selbstbewertung sind, z. B. Neonaten, Kleinkindern oder geistig erkrankten Menschen durch Familienangehörige, häufig auch durch Ärzte oder das Pflegepersonal vorgenommen (MCMILLAN, 2000; MCMILLAN, 2009). Diese sogenannten Proxy-Erhebungen sind aufgund nachgewiesener Differenzen zwar umstritten, bieten jedoch die beste Methode zur Einschätzung der Lebensqualität bei Tieren (THEUNISSEN et al., 1998; MCMILLAN, 2000; MCMILLAN, 2009). Bei Hunden eignet sich dafür mit Sicherheit am besten die Person, die dem Hund am nächsten steht - in den allermeisten Fällen der Besitzer selbst (MCMILLAN, 2000).

Es existieren verschiedene Methoden, gesundheitsbezogene Lebensqualitätsuntersuchungen durchzuführen. Die älteste Form ist der Karnofsky-Index, der allerdings nur funktionelle Dimensionen der Lebensqualität 
berücksichtigt (GUNNARS et al., 2001). Er wurde 1998 von HARTMANN und KUFFER adaptiert, um Lebensqualitätseinschätzungen bei FIV-infizierten (Felines Immundefizienz-Virus) Katzen vorzunehmen (KARNOFSKY \& BURCHENAL, 1949; HARTMANN \& KUFFER, 1998). Weitere Methoden sind das Interviewverfahren und der Fragebogen. Häufig wird die gesundheitsbezogene Lebensqualität mit Hilfe von Fragebögen ermittelt, die von den Patienten oder Patientenbesitzern ausgefüllt werden (GUNNARS et al., 2001). Man unterscheidet zwischen krankheitsübergreifenden (generischen) und krankheitsspezifischen Messinstrumenten. Generische Fragebögen erfassen die allgemeine gesundheitsbezogene Lebensqualität unabhängig von bestimmten Krankheitsbildern. Sie sind daher für die Erfassung der Lebensqualität bei bestimmten Erkrankungen weniger geeignet als krankheitsspezifische Fragebögen (PATRICK \& DEYO, 1998). GUNNARS und Mitarbeiter (2001) führen gewisse Grundvorraussetzungen für ein ideales Messinstrument zur Erfassung der Lebensqualität auf. Instrumente, die zum Einsatz kommen, sollen speziell für den jeweiligen Bereich entwickelt und möglichst sensitiv in Hinblick auf Veränderungen sein. Zur Gewährleistung einer hohen Compliance ist es wichtig, dass verwendete Fragen leicht verständlich und nicht zu akademisch formuliert sind. Fragebögen sollen zwar vollständig, aber möglichst kurz gehalten werden. GUNNARS und Mitarbeiter (2001) betonen die Notwendigkeit nicht nur nach der Quantität verschiedener Symptome zu fragen, sondern auch die Bedeutsamkeit dieser Symptome für jeden Einzelnen zu ermitteln.

Mittlerweile gibt es in der Humanmedizin mehrere nationale und internationale Arbeitsgruppen, die es sich zum Ziel gesetzt haben, Richtlinien zur Messung der Lebensqualität zu erarbeiten. GUNNARS und Mitarbeiter (2001) geben einen Überblick über die Arbeitsgruppen, die im onkologischen Feld eine herausragende Rolle spielen, wie z. B. The European Organisation for Research and Treatment of Cancer Quality of Life Questionnaire (EORTC-QLQ C-30) (GUNNARS et al., 2001). Der entsprechende Fragebogen erfasst die wichtigsten Dimensionen der gesundheitsbezogenen Lebensqualität sowie die häufigsten Symptome der Tumorpatienten. Er ist beim Menschen bereits validiert, findet aber aufgrund der Natur der Fragen geringe Anwendbarkeit beim Hund (z. B. Einschränkungen bei der Arbeit, Konzentrations- oder Schlafstörungen). Bewährte validierte Messinstrumente zur Bestimmung der Lebensqualität von Hunden, die an Krebs 
erkrankt sind, würden in der onkologischen Veterinärmedizin von großem Nutzen sein.

\subsubsection{Aktueller Stand der Lebensqualitäts-Forschung}

In der Medizin nimmt die Erfassung der Lebensqualität gerade bei der Bewertung palliativer Therapieformen zunehmend eine zentrale Stellung ein. Dem Konzept "Lebensqualität von Patienten" ist immer mehr Aufmerksamkeit geschenkt worden, da bei der Behandlung schwerstkranker Patienten nicht mehr allein die Überlebenszeit das entscheidende Kriterium sein sollte (BADIA \& HERDMANN, 2001). So ist es wichtiger, dass z. B. Patienten im Endstadium einer Tumorerkrankung über ein möglichst hohes Maß an Lebensqualität verfügen (GUNNARS et al., 2001). Allmählich wird dem Konzept „Lebensqualität von Patienten" nun auch in der Tiermedizin mehr Aufmerksamkeit geschenkt (VON WETHERN et al., 1999; BRONDEN et al., 2003; MELLANBY et al., 2003; YAZBEK \& FANTONI, 2005; TZANNES et al., 2008; YEATES \& MAIN, 2009; BOWLES et al., 2010).

Bislang wurden in der veterinärmedizinischen Onkologie Lebensqualitätsumfragen in England, in den Niederlanden und in den USA durchgeführt (BRONDEN et al., 2003; MELLANBY et al., 2003; TZANNES et al., 2008; BOWLES et al., 2009).

MELLANBY und Mitarbeiter (2003) evaluierten die Lebensqualität von 25 Hunden mit multizentrischem Lymphom, die von 1994 bis 2001 im Queen's Veterinary School Hospital der Universität Cambridge eine Polychemotherapie erhalten haben. In dieser Studie vertritt die Mehrzahl der Besitzer (86 \%) trotz vorhandener Komplikationen die Meinung, dass die Lebensqualität ihrer Hunde während der Behandlung so gut war wie vor der Entwicklung des Lymphoms. Bestimmte Faktoren, die die Lebensqualität beeinflussten, konnten MELLANBY und Mitarbeiter (2003) jedoch aufgrund des kleinen Patientenkollektivs und der unzureichenden Befragung nicht aufzeigen.

Vergleichbare Ergebnisse zeigen auch andere Studien (BRONDEN et al., 2003; TZANNES et al., 2008; BOWLES et al., 2009). TZANNES und Mitarbeiter (2008) analysierten die Lebensqualität Lymphom-kranker Katzen, die mit dem COP-Protokoll (Cyclophosphamid, Vincristin, Prednisolon) behandelt wurden. In der Auswertung zeigt sich eine deutliche Verbesserung der Lebensqualität bei fast 
allen Katzen während der Chemotherapie, auch wenn das Niveau der Lebensqualität unter dem vor Krankheitseintritt liegt. Entsprechend den Ergebnissen ihrer Studie, erachteten Tzannes und Mitarbeiter (2008) es für sinnvoll, in größeren Studien mit multivariaten Analysen eventuelle Korrelationen zwischen Lebensqualität und Nebenwirkungen der Chemotherapie zu ermitteln.

BRONDEN und Mitarbeiter (2003) sowie BOWLES und Mitarbeiter (2009) entwickelten jeweils einen Fragebogen, der krankheitsunspezifisch die Lebensqualität chemotherapierter Hunde oder Katzen erfasste. Die Ergebnisse dieser Studien lassen darauf schliessen, dass Besitzer in gewisser Weise eine Reduktion der Lebensqualität tolerieren, solange das Leben ihrer Hunde dabei verlängert werden kann (BRONDEN et al., 2003; BOWLES et al., 2009). 


\section{Kapitel I: ERste Publikation}

11-Jan-2011

Sehr geehrte Frau Kollegin Bergmann,

ich freue mich, Ihnen mitteilen zu können, dass Ihr Manuskript mit dem Titel "Lebensqualität und Lebenserwartung am malignen Lymphom erkrankter Hunde unter Chemotherapie - Eine Besitzerumfrage" in der vorliegenden Fassung zur Publikation in der Zeitschrift Tieraerztliche Praxis angenommen wurde. Die Kommentare der Gutachter, die Ihr Manuskript beurteilt haben, finden Sie am Ende dieser E-Mail, ferner gegebenenfalls einen Kommentar des für Ihre Arbeit zuständigen Sektionsschriftleiters.

Vielen Dank für Ihren hervorragenden Beitrag. Die Schriftleitung der Zeitschrift Tieraerztliche Praxis sieht weiteren Artikeln von Ihnen mit Freude entgegen.

Mit freundlichen Grüßen

Prof. Andreas Moritz

Verantwortlicher Schriftleiter, Tieraerztliche Praxis

Andreas.Moritz@vetmed.uni-giessen.de

Kommentare der Gutachter für die Autoren:

Reviewer: 1

Comments to the Author

(There are no comments.)

Kommentar des Sektionsschriftleiters

Associate Editor: Nolte, Ingo

Comments to the Author:

(There are no comments.)

11-Jan-2011

Dear Miss Bergmann:

It is a pleasure to accept your manuscript entitled "Lebensqualität und Lebenserwartung am malignen Lymphom erkrankter Hunde unter Chemotherapie - Eine Besitzerumfrage" in its current form for publication in the Tieraerztliche Praxis. The comments of the reviewer(s) who reviewed your manuscript and possibly comments of the associate editor are included at the foot of this letter.

Thank you for your fine contribution. On behalf of the Editors of the Tieraerztliche Praxis, we look forward to your continued contributions to 
the Journal.

Sincerely,

Prof. Andreas Moritz

Editor in Chief, Tieraerztliche Praxis

Andreas.Moritz@vetmed.uni-giessen.de

Reviewer(s)' Comments to Author:

Reviewer: 1

Comments to the Author

(There are no comments.)

Comments of the Associate Editor to Author:

Associate Editor: Nolte, Ingo

Comments to the Author:

(There are no comments.) 


\title{
Originalartikel
}

M. Bergmann et al.: Chemotherapie und Lebensqualität/-erwartung beim Hund

\section{Lebensqualität und Lebenserwartung am malignen Lymphom erkrankter Hunde unter Chemotherapie}

\author{
Eine Besitzerumfrage
}

\author{
M. Bergmann; C. Sauter-Louis; J. Hirschberger \\ Medizinische Kleintierklinik der Ludwig-Maximilians-Universität München
}

\author{
Schlüsselwörter \\ Hund, malignes Lymphom, palliative Chemotherapie, Fragebogen, Besitzer
}

\section{Zusammenfassung}

Gegenstand und Ziel: Der Erfolg palliativer Chemotherapien bei Hunden mit malignem Lymphom wurde insbesondere in Bezug auf die Lebensqualität der Tiere evaluiert. Zudem wurden Faktoren erfasst, die für die Besitzer bei der Einschätzung der Lebensqualität ihrer Tiere sowie für ihre Gesamtbewertung der Therapie eine entscheidende Rolle spielten. Material und Methoden: Die retrospektive Befragung mittels eines Fragebogens bezüglich Krankheitsverlauf und Therapie ihrer Tiere richtete sich an 207 Hundebesitzer, deren Hunde in den letzten 13 Jahren zur Chemotherapie in der Medizinischen Kleintierklinik der LudwigMaximilians-Universität München vorgestellt worden waren. Ergebnisse: 123 Besitzer $(59,4 \%)$ beantworteten den Fragebogen. Bei 64 Hunden $(53,3 \%)$ ließ sich aus Sicht der Besitzer mit der Chemotherapie eine Verbesserung der Lebensqualität erreichen. Nur bei 24 Hunden $(20,0 \%)$ kam es zu einer Verschlechterung der Lebensqualität, die in direktem Zusammenhang mit dem Remissionsstatus und Nebenwirkungen der Chemotherapie stand. Die Remissionsrate der Hunde lag bei 83,7\%. Schlussfolgerung: Der Großteil der Besitzer $(65,0 \%)$ war zufrieden mit der Chemotherapie. 90 Besitzer $(73,2 \%)$ würden sich erneut für eine solche Behandlung entscheiden, wobei insbesondere die Lebensverlängerung ein wichtiges Entscheidungskriterium darstellte. Klinische Relevanz: Bei Tumorpatienten, die eine palliative Chemotherapie erhalten, muss die Lebensqualität konstant überwacht werden. Nur so kann sie bei der Auswahl geeigneter Chemotherapie-Protokolle helfen und zusätzlich Besitzer und Tierarzt die Entscheidung für den weiteren Verlauf der Therapie erleichtern.

Key words

Dog, malignant lymphoma, palliative chemotherapy, questionnaire, owner

\section{Summary}

Objective: The outcome of palliative chemotherapy in dogs with lymphoma was evaluated. Special emphasis was placed on quality of life during chemotherapy. Besides factors, which are important for the owners by estimating their dogs' quality of life and the assessment of therapy, were comprehended. Material and methods: In a retrospective study the owners of 207 dogs, that had undergone chemotherapy at the Clinic of Small Animal Medicine, University of Munich during the last 13 years, were asked about their dogs' course of disease and therapy by using a specially designed questionnaire. Results: A total of 123 owners $(59.4 \%)$ responded to the questionnaire. Quality of life improved in 64 dogs $(53.3 \%)$ during chemotherapy. In only 24 dogs $(20.0 \%)$ a decline in quality of life was recorded, that directly correlated with remission status and side effects. The overall remission rate in dogs undergoing chemotherapy was $83.7 \%$. Conclusion: Despite treatment complications the majority of the owners $(65.0 \%)$ was satisfied by the chemotherapy of their dogs. Ninety owners $(73.2 \%)$ would have treated their animal with chemotherapy again; for this decision prolonged survival was an important factor. Clinical relevance: In dogs with cancer quality of life needs to be monitored constantly during palliative chemotherapy. This assessments helps to choose the appropriate chemotherapy protocol and facilitates the decision on further treatment options by the owner and the veterinarian. 
Dog's quality and prospects of life during chemotherapy for canine lymphoma. An owner survey

Tierärztl Prax 2011; 39 (K):

Eingegangen: 31. August 2010

Akzeptiert nach Revision: 11. Januar 2011

Korrespondenzadresse

Prof. Dr. Johannes Hirschberger

Medizinische Kleintierklinik

der Ludwig-Maximilians-Universität München

Veterinärstraße 13

80539 München

E-Mail: hirschberger@Imu.de

\section{Einleitung}

Das maligne Lymphom ist eine der am häufigsten diagnostizierten kaninen Neoplasien (6). Bezüglich der Behandlung liegt der Schwerpunkt in der Literatur auf Protokollen, die Parameter wie die mediane Überlebenszeit, die Remissionszeit und das Auftreten von Nebenwirkungen auswerten $(3,12)$. In der Humanmedizin hingegen stellt die Lebensqualität bei der Bewertung palliativer Chemotherapien schon lange einen zentralen Bestandteil dar $(8,13)$. Allmählich wird dem Konzept "Lebensqualität von Patienten” auch in der Tiermedizin mehr Aufmerksamkeit geschenkt (2, 3, 12, 18, 20, 22, 23). Bislang gibt es aber nur eine Studie, die die Lebensqualität von Hunden mit malignem Lymphom unter Chemotherapie krankheitsspezifisch evaluiert. In dieser Studie vertritt die Mehrzahl der Besitzer trotz vorhandener Komplikationen die Meinung, dass die Lebensqualität ihrer Hunde während der Behandlung so gut war wie vor der Entwicklung des Lymphoms. Bestimmte Faktoren, die die Lebensqualität beeinflussten, konnten die Autoren jeodch aufgrund des kleinen Patientenkollektivs und der unzureichenden Befragung nicht aufzeigen (12).

Die vorliegende Arbeit beurteilt den Erfolg der Chemotherapie von Hunden mit malignem Lymphom anhand von zwei Kriterien: Zum einen wurden objektive Parameter der Chemotherapie, wie Überlebens- und Remissionszeiten, ausgewertet. Der Schwerpunkt lag aber auf der subjektiven Bewertung der Therapie aus Sicht der Besitzer, insbesondere in Bezug auf die Lebensqualität der Tiere. Statistische Tests sollten schließlich Aufschluss über Faktoren geben, die für die Besitzer bei der Einschätzung der Lebensqualität ihrer Tiere sowie für ihre Gesamtbewertung der Therapie eine entscheidende Rolle spielten.

\section{Material und Methoden}

\section{Patientengut}

Das Patientenkollektiv umfasste alle an einem malignen Lymphom erkrankten Hunde, die zwischen dem 01.01.1997 und dem 01.08.2009 in der Medizinischen Kleintierklinik der Ludwig-Maximilians-Universität München vorgestellt wurden. Alle Hunde mit zytologisch oder histologisch gesicherter Diagnose "malignes Lymphom” wurden in die Studie eingeschlossen, sofern sie eine oder mehrere Dosen an Chemotherapie erhalten hatten. Aufnahme in die Studie fanden ferner Hunde, die zum Zeitpunkt der Datenerfassung noch mit Chemotherapie behandelt wurden. Hunde, deren Besitzer sich aus einem bestimmten Grund (z. B. Schwangerschaft der Besitzerin oder schlechtes Allgemeinbefinden des Hundes) nur für eine einmalige oder mehrfache Asparaginaseinjektion und gegen jede weitere chemotherapeutische Maßnahme entschieden hatten, blieben von der Studie ausgeschlossen.

Erhebungen zu den Patienten und ihren chemotherapeutischen Behandlungen stammten aus der Datenbank der Medizinischen Kleintierklinik München, dem Klinikverwaltungsprogramm Vetera (G\&P Software, Eltville, Deutschland). Das Ansprechen auf die Therapie wurde als komplette Remission (Reduktion der Tumormasse um 100\%), partielle Remission (Reduktion der Tumormasse um mindestens 50\%, aber weniger als 100\%) oder keine Remission (stationäres Tumorverhalten oder Progression) beurteilt. 


\section{Besitzerumfrage}

Zur Bewertung der Therapie aus Sicht der Besitzer diente ein Fragebogen, der sich in seinen Grundzügen an den Fragebogen von Bronden et al. (3) anlehnte und mithilfe der DiplomPsychologin Susanne Braun, Center for Leadership and People Management der LudwigMaximilians-Universität München, überarbeitet wurde. Um eine hohe Resonanz zu gewährleisten, wurden die verwendeten Fragen leicht verständlich und alltagssprachlich formuliert. Die Verständlichkeit des erarbeiteten Fragebogens wurde an 20 zufällig ausgewählten Besitzern überprüft, die der Befragung im Vorfeld telefonisch zugestimmt hatten. Der Fragebogen erwies sich als leicht verständlich und konnte von den Hundehaltern problemlos beantwortet werden, sodass alle weiteren Besitzer diese Version per Post erhielten. Bei fehlenden Rückmeldungen der Patientebesitzer erfolgte eine telefonische Kontaktaufnahme. Besitzer, die auch danach den Fragebogen nicht zurücksandten, wurden nicht erneut angeschrieben

Im Fragebogen wurden neben Angaben zur individuellen Krankheitsgeschichte des Tieres auch Angaben zu persönlichen Erfahrungen der Hundebesitzer erfasst. Da es sich um einen krankheitsspezifischen Fragebogen handelte, fanden bei den Angaben zur Krankheitsgeschichte die häufigsten Symptome lymphomkranker Hunde Berücksichtigung. Im ersten Teil des Fragebogens wurden die Besitzer zur Symptomatik und Lebensqualität inrer Hunde in der prätherapeutischen Phase befragt, ferner zur Dauer bis zum Abklingen der Symptome ab Beginn der Chemotherapie.

Der zweite Teil erfasste die Einstellung der Besitzer gegenüber Chemotherapie, bevor inre Hunde behandelt wurden. Zudem konnten die Befragten angeben, ob sie im Vorfeld schon einmal Kontakt zu Chemotherapiepatienten hatten und in welchem Bezug sie zu diesen standen.

Im dritten Abschnitt des Fragebogens wurden die Erwartungen der Besitzer an die Chemotherapie erhoben. Die Aufklärung durch den betreuenden Tierarzt der Abteilung Onkologie in Bezug auf Prognose, Nebenwirkungen und Kosten konnte von den Besitzern jeweils als "gut" (1), „mittelmäßig“ (2) oder „schlecht" (3) bewertet werden. Neben der Frage nach positiven Effekten wurden Nebenwirkungen erfasst, die die Besitzer von der Chemotherapie erwarteten („Haarverlust", „Gewichtsverlust“, „schlechtes Allgemeinbefinden“, „Durchfall/Erbrechen“, „Fieber“, „keine zu erwartenden Nebenwirkungen“). Weitere Nebenwirkungen konnten unter dem Punkt „Andere“ vermerkt werden.

Der vierte Teil des Fragebogens bezog sich auf die Chemotherapie selbst. Ermittelt wurde, welche Effekte die Chemotherapie auf die Erkrankung hatte, wie sie sich auf die Lebensqualität auswirkte und ob Nebenwirkungen auftraten. Letztgenannte konnten die Besitzer als "selten“, „häufig“, „unbedeutend“ und „schwerwiegend“ bewerten. Um welche Nebenwirkungen es sich dabei handelte, wurde nicht erfragt. Zur Erfassung der Lebensqualität war eine fünfstufige Skala von "sehr gut" (1) bis „sehr schlecht“ (5) vorgegeben. Schließlich wurden die Besitzer gefragt, ob und aus welchen Gründen („kein Ansprechen“, „Zu starke Nebenwirkungen“, „Zu hohe Kosten“, „Zu hoher Zeitaufwand“, „Anderes“) ein vorzeitiger Abbruch der Therapie erfolgte. Zusammenfassend sollte die Einstellung der Besitzer gegenüber Chemotherapie entsprechend ihren Erfahrungen bei der Behandlung des eigenen Hundes erfasst werden. Hierzu wurden den Besitzern folgende Fragen gestellt: „Welche Aussage repräsentiert am besten Ihre Gefühle gegenüber Chemotherapie heute?" und „Würden Sie sich heute wieder dafür entscheiden, Ihr Tier/eines Ihrer Tiere mit Chemotherapie behandeln zu lassen?". Zum Schluss hatten die Besitzer die Möglichkeit, ein freies Textfeld für Anmerkungen und Kommentare zu nutzen („Haben Sie weitere Anmerkungen?").

\section{Statistische Auswertung}

Alle statistischen Auswertungen wurden mit dem Statistikprogramm SPSS, Version 17.0 (SPSS Inc., Chicago, USA) vorgenommen. Die Auswertung der gesammelten Daten erfolgte zunächst rein deskriptiv mithilfe von Häufigkeitsanalysen. Die Remissionsrate war definiert als Anzahl der Hunde mit kompletter oder partieller Remission dividiert durch die Anzahl der behandelten Hunde. Als Remissionszeit galt die Zeitspanne in Tagen vom Erreichen einer 
kompletten oder partiellen Remission bis zur Diagnose eines Tumorrezidivs bzw. einer Tumorprogression oder bis zum Datum des Todes. Die Überlebenszeit war festgelegt als die Zeitspanne von der ersten Chemotherapie bis zum Zeitpunkt des Todes. Die Remissionsund Überlebenszeiten der Hunde wurden wie oben beschrieben ausgewertet und mittels Kaplan-Meier-Kurven dargestellt.

Bei der Ermittlung der Überlebensdauer wurden Patienten, die nicht an einem malignen Lymphom verstorben waren oder deswegen euthanasiert wurden, zensiert. Gleiches galt für Hunde, die zum Zeitpunkt des letzten Kontakts mit dem Besitzer noch am Leben waren.

Mithilfe des Rangkorrelationskoeffizienten nach Spearman wurde auf Faktoren (Nebenwirkungen und Remissionsstatus) getestet, die für die Besitzer bei der Einschätzung der Lebensqualität ihrer Hunde während der Chemotherapie eine entscheidende Rolle gespielt haben. Zur Analyse der Aspekte, die die Einstellung der Besitzer gegenüber Chemotherapie nach der Behandlung beeinflussten, kamen ebenfalls der Rangkorrelationskoeffizient nach Spearman (Einflussnahme durch Nebenwirkungen) sowie der Log-Rank-Test (Einflussnahme durch Remissions- und Überlebenszeit) zum Einsatz. Das Signifikanzniveau wurde bei allen Analysen auf $5 \%$ festgelegt.

\section{Ergebnisse}

\section{Patientengut}

Insgesamt ließen sich 207 Hunde mit malignem Lymphom ermitteln, die zwischen dem 01.01.1997 und dem 01.08.2009 in der Medizinischen Kleintierklinik der Ludwig-MaximiliansUniverstät München behandelt worden waren. Die Besitzer von 123 dieser Tiere $(59,4 \%)$ sandten die Fragebögen beantwortet zurück.

Das Durchschnittsalter der Hunde bei Diagnosestellung lag bei 8 Jahren und variierte zwischen 2 und 14 Jahren. Neben 48 Mischlingen umfasste das Kollektiv Vertreter von 36 Hunderassen, davon am häufigsten Berner Sennenhund $(n=13)$ und Deutscher Schäferhund $(n=9)$. Das Verhältnis von Hündinnen zu Rüden betrug 1:1,4. Bei 40 Hunden $(32,5 \%)$ hatte im Vorfeld bereits eine Behandlung mit Glukokortikoiden durch den Haustierarzt stattgefunden. Insgesamt waren alle anatomischen Formen des Lymphoms vertreten (Abb. 1). 84 Hunde (68,3\%) hatten ein multizentrisches, $20 \quad(16,3 \%)$ ein mediastinales Lymphom und neun Patienten $(7,3 \%)$ ein gastrointestinales Lymphom. Die bei 10 Hunden $(8,1 \%)$ vorliegenden extranodalen Formen befanden sich in der Haut $(n=7)$ sowie jeweils einmal nasal, perianal und okulär. 32 Hunde $(26,0 \%)$ zeigten bei Diagnosestellung in der Klinik ein ungestörtes Allgemeinbefinden und wurden dem Substadium a zugeordnet. Bei 91 Hunden $(74,0 \%)$ erfolgte eine Zuteilung zum Substadium b. Als Behandlungen kamen vorwiegend Polychemotherapien mit konventionellen KurzzeitKombinationstherapien („DISC-Protokoll“, „12-Wochen-DVG-Protokoll“), bei fünf Tieren die Doxorubicin-Monotherapie zum Einsatz $(17,19,24)$.

Bei 80 Patienten $(65,0 \%)$ konnte eine komplette Remission und bei $23(18,7 \%)$ eine partielle Remission erzielt werden. Die mediane Überlebenszeit lag bei 275 Tagen (Min.: 1 Tag; Max.: 2922 Tage). Hunde mit kompletter Remission erreichten sogar eine mediane Überlebenszeit von 424 Tagen (Min.: 7 Tage; Max.: 2922 Tage).

\section{Auswertung des Fragebogens}

\section{Symptome der Erkrankung}

Fast die Hälfte der Besitzer $(n=57)$ hatte zu Beginn der Erkankung ihrer Hunde eine Lymphknotenvergößerung bemerkt und aus diesem Grund einen Tierarzt konsultiert. Bei drei Hunden stellte der Haustierarzt im Rahmen einer Routineuntersuchung eine Lymphadenomegalie fest. Außerdem fiel 51 Besitzern (41,5\%) ein reduziertes Allgemeinbefinden ihres Hundes auf. Bei jedem sechsten Tier lagen Übelkeit und Inappetenz vor.

Nach Besitzereinschätzung bestand bei 13 Hunden (10,6\%) kurz vor der Chemotherapie trotz Krankheit eine "sehr gute“ Lebensqualität (Abb. 2). Diese Hunde wiesen laut ihren Besitzern als einziges Symptom eine generalisierte Lymphknotenvergrößerung $(n=7)$, 
Hautveränderungen $(n=2)$ oder Augenveränderungen $(n=1)$ auf. Drei Teilnehmer empfanden die Lebensqualität ihres Hundes trotz vorhandener respiratorischer Störungen $(n=1)$, eines reduzierten Allgemeinbefindens $(n=1)$ sowie Übelkeit und Inappetenz $(n=1)$ als „sehr gut“. Demgegenüber schätzten 19 Besitzer (15,4\%) die Lebensqualität als „sehr schlecht" ein. Die betroffenen Hunde litten im Durchschnitt unter zwei bis drei verschiedenen Symptomen gleichzeitig.

Mit Beginn der Chemotherapie zeigte der Großteil der Hunde $(70,7 \%)$ eine Besserung der Symptome, die mehrheitlich spätestens nach 1-4 Wochen eintrat. Bei 19 Hunden $(15,4 \%)$ konnte keine Besserung erzielt werden. 17 Besitzer $(13,8 \%)$ machten zu dieser Frage keine Angaben.

\section{Persönliche Einstellung gegenüber Chemotherapie vor der Behandlung}

Mehr als die Hälfte der Besitzer $(n=79)$ wussten bis vor der Behandlung ihres Hundes nicht, dass Chemotherapien bei Haustieren durchgeführt werden. Die meisten Hundebesitzer mit Erfahrungen bezüglich Chemotherapie $(n=46)$, hatten diese Behandlung bei einem engen Freund oder Verwandten erlebt $(n=28)$. Nur acht Besitzer $(6,5 \%)$ wussten von chemotherapeutisch behandelten Haustieren.

\section{Erwartungen an die Chemotherapie}

Die Aufklärung bezüglich Prognose, Nebenwirkungen und Kosten der Chemotherapie des malignen Lymphoms durch den betreuenden Tierarzt der Abteilung Onkologie empfanden die meisten Hundebesitzern $(n=75)$ als "gut". 80 Befragte $(65,0 \%)$ gaben an, sich zur Behandlung entschlossen zu haben, da sie die Chemotherapie für die beste Therapiemöglichkeit hielten. So stand auch der mehrheitliche Teil der Besitzer $(n=88)$ der ersten Behandlung erwartungsvoll gegenüber.

An erhofften Vorteilen wurde noch vor der „Verbesserung des Allgemeinbefindens und der Lebensqualität" $(n=94)$ die "Lebensverlängerung" genannt $(n=104) .74$ Besitzer $(60,2 \%)$ erwarteten eine „Verkleinerung der Lymphknoten“, 32 (26,0\%) sogar eine „Heilung“. Von den 100 Teilnehmern (81,3\%), die angaben, mit Nebenwirkungen gerechnet zu haben, wurde 73-mal $(59,3 \%)$ das "schlechte Allgemeinbefinden“ genannt, 61-mal (49,6\%) „Durchfall, Erbrechen“, 39-mal (31,7\%) „Haarausfall“, 31-mal (25,2\%) „Gewichtsverlust“, 14mal $(11,4 \%)$ „Fieber“ und 4-mal $(3,3 \%)$ „Anderes“. 22 Besitzer (17,9\%) gaben an, keine Nebenwirkungen erwartet zu haben.

\section{Verlauf der Chemotherapie}

Bei 67 Hunden (54,5\%) erzielte die Chemotherapie laut Besitzern eine „Besserung des Allgemeinbefindens und der Lebensqualität", bei $61 \quad(49,6 \%)$ eine „Verkleinerung der Lymphknoten“, bei $43(35,0 \%)$ die „Lebensverlängerung“ und bei fünf $(4,1 \%)$ die „Heilung“. Im Fall von 32 Hunden $(26,0 \%)$ ergab sich „keine Besserung“.

Bei 85 Hunden $(73,3 \%)$ traten Nebenwirkungen auf (Abb. 3), die jedoch überwiegend $(n=47)$ als „selten und unbedeutend“ eingestuft wurden.

Abbildung 4 zeigt die Lebensqualität der Hunde unter Chemotherapie. Bei 64 Tieren $(53,3 \%)$ verbesserte sich die Lebensqualität, bei $32(26,7 \%)$ blieb sie unverändert und bei 24 Patienten $(20,0 \%)$ verschlechterte sie sich trotz Behandlung. Zum Zeitpunkt der Diagnosestellung bewerteten die Besitzer die Lebensqualität auf der fünfstufigen Skala im Median mit „3“, während der Chemotherapie mit „2“.

Fast die Hälfte der Besitzer $(n=52)$ kreuzte an, dass die Therapie ihres Hundes vorzeitig abgebrochen wurde. Angegebene Gründe hierfür waren „kein Ansprechen mehr auf die Chemotherapie“ ( $n=31)$, hohe Nebenwirkungen“ $(n=9)$ und „Kosten“ $(n=3)$. Drei Besitzer nannten freitextlich „Tod/Euthanasie infolge einer anderen Erkrankung", sechs Besitzer "Tod/Euthanasie infolge der Tumorerkrankung".

Nach der Chemotherapie waren 80 Besitzer $(65,0 \%)$ froh darüber, ihren Hund dieser Behandlung unterzogen zu haben. $29(23,6 \%)$ Besitzer beantworteten diese Frage mit „ich bin unsicher, weil...". Freitextlich angegebene Gründe hierfür waren „das Ausbleiben des erhofften Therapieerfolges“, „die große Belastung durch die vielen Therapiesitzungen“, „die zu starken Nebenwirkungen der Therapie“, „der zu späte Therapiebeginn“, „die hohen 
Kosten“, und „der ständige Wechsel behandelnder Tierärzte in der Klinikabteilung“. Nichtsdestoweniger würden sich insgesamt 90 Besitzer $(73,2 \%)$ heute erneut dazu entschließen, ihr(e) Tier(e) mit Chemotherapie behandeln zu lassen.

Am Ende des Fragebogens machten knapp die Hälfte der Hundebesitzer $(n=48)$ von der Möglichkeit freitextlicher Anmerkungen Gebrauch. Diese Kommentare stellten eine zum Teil ausführlichere Beschreibung der bereits im Fragebogen erfassten Meinungen dar. Vier Besitzer betonten zudem die Notwendigkeit einer fürsorglichen tierärztlichen Betreuung von Hund und Besitzer und drei die persönliche Erleichterung, die eine gute Zusammenarbeit zwischen den verschiedenen Tierärzten und Kliniken mit sich brachte.

Zum Zeitpunkt der Auswertung der Umfrage waren 15 Hunde (12,2\%) noch am Leben. Von den $108(87,8 \%)$ verstorbenen Hunde wurden 92 (74,8\%) aufgrund ihres Lymphoms euthanasiert, bei 16 Hunden $(13,0 \%)$ waren andere Umstände für das Versterben ursächlich.

\section{Analyse der Lebensqualitäts- und Chemotherapiebewertung}

Um herauszufinden, welche Faktoren für Besitzer bei der Einschätzung der Lebensqualität ihrer Hunde eine entscheidende Rolle spielten, wurde der Korrelationskoeffizient nach Spearman bestimmt. Es zeigte sich ein signifikanter negativer Zusammenhang zwischen der Lebensqualität der Hunde und den aufgetretenen Nebenwirkungen der Chemotherapie $(r=-$ $0,471 ; p<0,001)$ sowie zwischen der Lebensqualität und dem erreichten Remissionsstatus $(r=-0,457 ; p<0,001)$. Demzufolge hatten die Hunde, bei denen es im Therapieverlauf zu keinen oder nur unbedeutenden Nebenwirkungen kam, und Tiere, die eine komplette Remission erreichten, eine bessere Lebensqualität. Ein Zusammenhang zwischen den aufgetretenen Nebenwirkungen während der Chemotherapie und der persönlichen Einstellung der Besitzer gegenüber Chemotherapie nach der Behandlung konnte nicht bestätigt werden $(r=-0,002 ; p=0,980)$. Allerdings bestand ein Zusammenhang zwischen der Einstellung der Befragten und den Überlebens- und Remissionszeiten der Hunde (Log Rank $=16,329, \mathrm{df}=2, p<0,001$; Log Rank =10,969 df =2, $p=0,004)$. So würden sich Besitzer, deren Hunde längere Remissions- und Überlebenszeiten aufwiesen, eher erneut für eine Chemotherapie entscheiden (Tab. 1). Ein signifikanter Unterschied zwischen den Besitzern, die diese Therapie nicht wieder wählen würden, und denen, die sich darüber unsicher sind, lag nicht vor.

\section{Diskussion}

Bei der Therapie des malignen Lymphoms handelt es sich um eine in erster Linie palliative Behandlung (6). Obwohl in der Literatur viele Angaben zu verschiedenen ChemotherapieProtokollen vorliegen, gibt es bisher nur eine Studie, die die Lebensqualität von Hunden mit malignem Lymphom unter Chemotherapie krankheitsspezifisch berücksichtigt (12). Erfahrungsberichte aus der Perspektive deutscher Hundehalter existieren diesbezüglich bislang nicht. Haustiere nehmen kulturell einen unterschiedlichen Stellenwert ein, sodass von unterschiedlichen Erwartungen der Halter an die medizinische Versorgung ihrer Tiere auszugehen ist, insbesondere im Rahmen einer Tumorbehandlung. Dies macht hierzulande eine entsprechende Analyse erforderlich. Eine Befragung per Telefon, wie sie Mellanby et al. (12) durchführten, hätte womöglich mehr beantwortete Fragebögen erbracht. Dennoch wurde die schriftliche Befragung dem Interviewverfahren vorgezogen. Sie hatte den Vorteil, dass die Hundebesitzer nicht unter Zeitdruck standen. Zusätzlich konnte eine hohe Anonymität gewährleistet werden und Antworten im Sinne der sozialen Erwünschtheit ließen sich so vermeiden $(11,16)$.

Die Rücklaufquote des Fragebogens betrug 59,4\% und findet sich somit im unteren Bereich von zuvor veröffentlichten Lebensqualitätsumfragen in der onkologischen Veterinärmedizin $(2,3,12,18)$. Ein Grund hierfür ist sicherlich die zum Teil schon lange zurückliegende Chemotherapie. Dennoch stellt sich die Frage, ob diese niedrige Rücklaufquote eine Unzufriedenheit etwa mit der durchgeführten Therapie widerspiegelt und ob Besitzer, deren Hunde erfolgreich behandelt wurden, womöglich motivierter waren, den Fragebogen zu beantworten $(1,5)$. Die unterschiedliche Resonanz zeigt allerdings, dass vielfältige Teilnehmer vertreten waren und lässt somit auf repräsentative Ergebnisse schließen $(2,12)$. 
Der Nachteil dieser Studie liegt in ihrem retrospektiven Charakter, denn einige Behandlungen lagen bis zu 13 Jahre zurück. In der Literatur wird der Einfluss des Befragungszeitpunkts auf die Patientenzufriedenheit kontrovers diskutiert $(14,20)$. Denkbar ist, dass manche Situationen stärker oder schwächer im Gedächtnis haften bleiben, eventuell verzerrte Sichtweisen vorliegen und dies die Qualität der Antworten beeinflusst (14, 18, 21). Tzannes et al. (18) konnten keinen statistisch signifikanten Zusammenhang zwischen dem Zeitpunkt der Diagnose am malignen Lymphom erkrankter Katzen und der retrospektiven Bewertung der Lebensqualität durch die Besitzer nachweisen. Inwiefern sich dies auf die Validität ihrer Daten auswirkt, wird nicht diskutiert. Bowles et al. (2) sehen einen Validitätsnachweis in dem Vergleich der Besitzerangaben mit den Krankenakten der Patienten. Aus Sicht der Autoren der vorliegenden Studie können auf diese Weise Einschätzungen zwar vorgenommen werden, doch ist zu bedenken, dass die subjektive Beurteilung der Therapie durch den Besitzer generell von der tierärztlichen Sicht abweichen könnte. Zudem stellt sich die Frage, ob es für Tierbesitzer womöglich schwierig ist, zwischen Nebenwirkungen der Therapie und krankheitsbedingten Symptomen zu unterscheiden. Die Möglichkeit einer eingeschränkten Erinnerung der Besitzer sowie potenziell abweichende Sichtweisen unterstreichen die Notwendigkeit prospektiver Studien, in denen die Beobachtungen der Hundebesitzer denen des Tierarztes gegenübergestellt werden. Die Erkenntnisse und Erfahrungen aus der vorliegenden Studie könnten für solch zukünftige Studien hilfreich sein.

85 Besitzer $(73,3 \%)$ gaben an, dass die Chemotherapie ihres Hundes mit Nebenwirkungen einherging. Auch wenn der mehrheitliche Teil der Besitzer diese als "selten" und "unbedeutend" einstufte, waren sie dennoch neben dem Remissionsstatus als signifikanter Faktor für die Beurteilung der Lebensqualität der Hunde unter Chemotherapie entscheidend. So konnte nur bei 64 Hunden $(53,3 \%)$ eine Steigerung der Lebensqualität erreicht werden, obwohl es bei 90 Hunden zu einer Besserung der Symptome kam. Diese Ergebnisse sind nicht vergleichbar mit den Erfolgen, von denen Mellanby et al. (12) berichten. Dabei ist aber zu berücksichtigen, dass in der vorliegenden Studie alle an einem malignen Lymphom erkrankten Hunde mit zytostatischer Therapie aufgenommen wurden, unabhängig von anatomischem Stadium oder eventueller Vorbehandlung mit Glukokortikoiden. Zudem lag der Anteil an Patienten mit Substadium b in der vorliegenden Studie weit über dem in der Studie von Mellanby et al. (12). Das eigene Patientengut wies somit einen deutlich höheren Anteil an Faktoren auf, die bekanntlich mit einer schlechteren Prognose einhergehen $(4,7,9,10,15)$. Zusätzlich fielen in der vorliegenden Studie bei der Auswertung der Lebensqualität widersprüchliche Angaben von 15 Besitzern (12,5\%) auf. Diese schätzten die Lebensqualität ihres Hundes vor und während der Chemotherapie zwar als gleichbleibend ein, gaben weiter unten im Fragebogen jedoch an, dass ihre Erwartungen an die Chemotherapie unter anderem durch eine „Verbesserung des Allgemeinbefindens und der Lebensqualität" ihres Tieres erfüllt wurden.

Folgende Erklärungen lassen sich hierfür in Betracht ziehen: Zum einen ist es denkbar, dass die Antwortmöglichkeiten nach Notenpunkten keine Feinabstimmung zuließ und sich die Lebensqualität der Hunde während der Chemotherapie im Vergleich zur Situation davor nur geringfügig veränderte, sodass diese als gleichbleibend gewertet wurde. Möglicherweise haben aber auch Schwankungen der Lebensqualität unter Chemotherapie die Beurteilung schwierig gestaltet. Hier stellt sich die Frage, ob eine einmalige Bewertung der Lebensqualität unter Therapie ausreichend war. Um die Lebensqualität möglichst genau zu evaluieren, müssen Befragungen prospektiv durchgeführt werden. Die therapiebegleitende Beurteilung der Lebensqualität sollte zudem konstant erfolgen und gegebenenfalls durch quantitative Erhebungen ergänzt werden (z. B. das Verhältnis von "guten“ und "schlechten Tage" zwischen den jeweiligen Therapiesitzungen).

Zusammenfassend lässt sich feststellen, dass sich die Lebensqualität der meisten Hunde durch die Therapie besserte. So lag die mediane Bewertung der Lebensqualität zum Zeitpunkt der Diagnosestellung bei „3“ und ist somit als „mittelmäßig“ zu betrachten. Während der Chemotherapie verbesserte sich dieser Wert auf "2" und ist demnach als "gut" zu bewerten.

Insgesamt war der Großteil der Besitzer (65,0\%) im Nachhinein zufrieden mit der palliativen Chemotherapie ihres Hundes und 90 Besitzer $(73,2 \%)$ würden sich heute erneut 
für eine solche Therapie entscheiden. Dies bestätigt die Ergebnisse anderer Umfragen in der veterinärmedizinischen Onkologie $(2,3,12,18,20)$. Zusätzlich zeigte die vorliegende Studie, dass sich vor allem Besitzer, deren Hunde sehr lange Remissions- und Überlebenszeiten erreichten, erneut zu einer Chemotherapie entschließen würden, unabhängig von den Nebenwirkungen der Behandlung. Diese Ergebnisse untermauern die Vermutungen von Tzannes et al. (18) und Bowles et al. (2): Besitzer tolerieren in gewisser Weise eine Reduktion der Lebensqualität ihrer Hunde, solange deren Leben durch die Behandlung verlängert werden kann.

\section{Fazit für die Praxis}

Die Ergebnisse dieser Studie zeigen, dass für Hundebesitzer besonders die Lebensverlängerung ihres Tieres ein wichtiges Kriterium bei der Entscheidung für eine palliative Chemotherapie darstellt. Dennoch beeinflussen Nebenwirkungen die Lebensqualität therapierter Hunde maßgeblich und sind dementsprechend auf ein minimales Maß zu reduzieren. Die Erfassung der Lebensqualität muss therapiebegleitend konstant erfolgen. Nur so kann sie bei der Auswahl geeigneter Chemotherapie-Protokolle helfen und zusätzlich Besitzer und Tierarzt die Entscheidung für den weiteren Verlauf der Therapie erleichtern. Dies erfordert die Entwicklung geeigneter Messinstrumente, die zusätzlich die Qualität der tierärztlichen Betreuung berücksichtigen. Hierzu könnte der in dieser Studie verwendete Fragebogen nach entsprechenden Modifikationen für zukünftige Umfragen nützlich sein.

\section{Danksagung}

Wir danken Frau Susanne Braun, Diplom-Psychologin aus dem Center for Leadership and People Management der Ludwig-Maximilians-Universität München, für ihre Hilfe bei der Optimierung des Fragebogens.

\section{Interessenskonflikt}

Die Autoren bestätigen, dass kein Interessenskonflikt besteht.

Abb. 1 Einteilung der am malignen Lymphom erkrankten Hunde nach der anatomischen Tumorform $(\mathrm{n}=123)$

Fig. 1 Anatomic forms of dog's with lymphoma

Abb. 2 Lebensqualität der am malignen Lymphom erkrankten Hunde vor Beginn der Chemotherapie $(\mathrm{n}=123)$

Fig. 2 Dog's quality of life before chemotherapy

Abb. 3 Nebenwirkungen der Chemotherapie $(n=116)$

Fig. 3 Adverse events of chemotherapy

Abb. 4 Lebensqualität der am malignen Lymphom erkrankten Hunde im Verlauf der Chemotherapie $(\mathrm{n}=120)$

Fig. 4 Dog's quality of life during chemotherapy

Tab. 1 Einflussnahme der Überlebens- und Remissionszeit der am malignen Lymphom erkrankten und zytostatisch behandelten Hunde auf die Einstellung ihrer Besitzer gegenüber Chemotherapie $(\mathrm{n}=120)$

Table 1 Influence of survival time and remission duration on the owner's attitude towards chemotherapy (statistically significant correlations are indicated in bold)

\section{Literatur}

1. Asch DA, Jedrziewski MK, Christakis NA. Response rates to mail surveys published in medical journals. J Clin Epidemiol 1997; 50: 1129-1136.

2. Bowles DB, Robson MC, Galloway PE, Walker L. Owner's perception of carboplatin in conjunction with other palliative treatments for cancer therapy. J Small Anim Pract 2010; 51: 104-112.

3. Bronden LB, Rutteman GR, Flagstad A, Teske E. Study of dog and cat owners' perceptions of medical treatment for cancer. Vet Rec 2003; 125: 77-80. 
4. Couto CG, Cullen J, Pedroia V, Turrel JM. Central nervous system lymphosarcoma in the dog. J Am Vet Med Assoc 1984; 184: 809-813.

5. Edwards P, Roberts I, Clarke M, DiGuiseppi C, Pratap S, Wenzt R, Kwan I, Cooper R. Methods to increase response rates to postal questionnaires. Cochrane Database Syst Rev 2007: 18: MR00008.

6. Ettinger SN. Principles of treatment for canine lymphoma. Clin Tech Small Anim Pract 2003; 18 : 92-97.

7. Fontaine J, Bovens C, Bettenay S, Mueller RS. Canine cutaneous epitheliotropic T-cell-lymphoma: a review. Vet Comp Oncol 2009; 7: 1-14.

8. Gunnars B, Nygren P, Glimelius B. Assessment of quality of life during chemotherapy. Acta Oncol 2001; 40: 175-184.

9. Keller ET, MacEwen EG, Rosenthal RC, Helfand SC, Fox LE. Evaluation of prognostic factors and sequential combination chemotherapy with doxorubicin for canine lymphoma. J Vet Intern Med 1993; 7: 289-295.

10. Lee JJ, Hughes CS, Fine RL, Page RL. P-glycoprotein expression in canine lymphoma: a relevant, intermediate model of multidrug resistance. Cancer 1996; 77: 1892-1898.

11. Mellanby RJ, Herrtage ME, Dobson JM. Treatment of canine Lymphoma by veterinarians in first opinion practice in England. J Small Anim Pract 2002; 43: 198-202.

12. Mellanby RJ, Herrtage ME, Dobson JM. Owners' assessments of their dog's quality of life during palliative chemotherapy for lymphoma. J Small Anim Pract 2003; 44: 100-103.

13. Osoba D. The Quality of Life Committee of the Clinical Trials Group of the National Cancer Institute of Canada: organization and functions. Qual Life Res 1992; 1: 211-218.

14. Priebe S, Gruyters T. The role of the helping alliance in psychiatric community care. A prospective study. J Nerv Men Dis 1993; 181: 552-557.

15. Rassnick KM, Moore AS, Collister KE, Northrup NC, Kristal O, Chretin JD, Bailey DB. Efficacy of combination chemotherapy for treatment of gastrointestinal lymphoma in dogs. J Vet Intern Med 2009; 23: 317-322.

16. Ruppaner R. Measurement of disease in animal populations based on interviews. J Am Vet Med Assoc 1972; 161: 1033-1038.

17. Simon D, Nolte I, Eberle N, Abbrederis N, Killich M, Hirschberger J. Treatment of dogs with Lymphoma Using a 12-Week, Maintenance-Free Combination Chemotherapy Protocol. J Vet Intern Med 2006; 20: 948-954.

18. Tzannes S, Hammond MF, Murphy S, Sparkes A, Blackwood L. Owners 'perception of their cats' quality of life during COP chemotherapy for lymphoma. J Feline Med Surg 2008; 10: 73-81.

19. Valerius K, Ogilvie G, Mallinckrodt C, Getzy D. Doxorubicin alone or in combination with asparaginase, followed by cyclophosphamide, vincristine, and prednisone for treatment of multicentric lymphoma in dogs: 121 cases (1987-1995). J Am Vet Med Assoc 1997; 210: 512-516.

20. Von Wethern CJ, Horst C, Schwarz G. Zur Gliedmaßenamputation bei Hund und Katze: Eine Besitzerbefragung. Kleintierprax 1999; 44: 169-176.

21. Walker A, Restuccia J. Obtaining information on patient satisfaction with hospital care: mail versus telephone. Health Serv Res 1984; 19: 291-306.

22. Yazbek KV, Fantoni DT. Validity of a health-related quality-of-life scale for dogs with signs of pain secondary to cancer. J Am Vet Med Assoc 2005; 226: 1354-1358.

23. Yeates J, Main D. Assessment of companion animal quality of life in veterinary practice and research. J Small Anim Pract 2009; 50: 274-281.

24. Zenker I, Meichner K, Steinle K, Kessler M, Hirschberger J. A 13-week Dose Intensifying Simultaneous Combination Chemotherapy (DISC) Protocol for Malignant Lymphoma in Dogs: 21 Cases. Vet Rec 2010; 167 (19): 744-748.

Tab. 1 


\begin{tabular}{|c|c|c|c|c|}
\hline & \multicolumn{3}{|c|}{ behandeln zu lassen?“ } & \\
\hline & ,ja“ & "nein“ & "unsicher" & \\
\hline $\begin{array}{l}\text { Mediane } \\
\text { Überlebenszeit } \\
\text { der Hunde } \\
\text { (Tage) }\end{array}$ & 393 & 187 & 64 & $<0,001^{*}$ \\
\hline $\begin{array}{l}\text { Mediane } \\
\text { Remissionszeit } \\
\text { der Hunde } \\
\text { (Tage) }\end{array}$ & 226 & 120 & 50 & $0,004^{*}$ \\
\hline
\end{tabular}




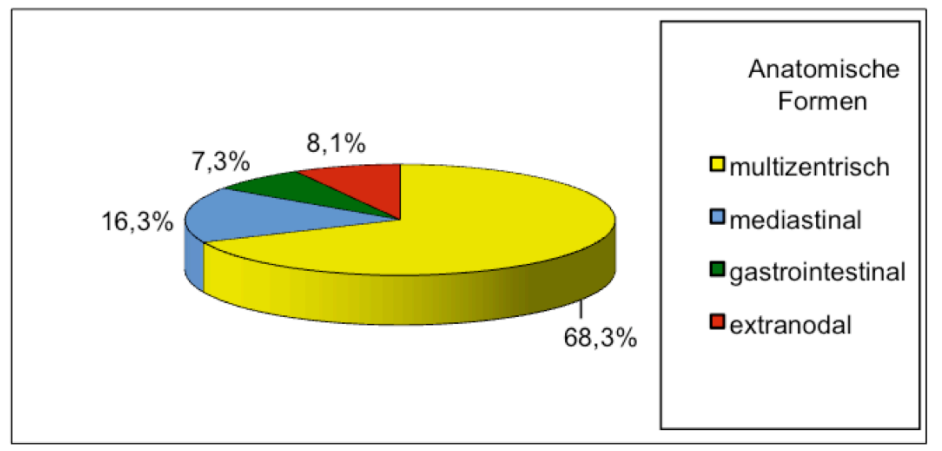

Abb. 1

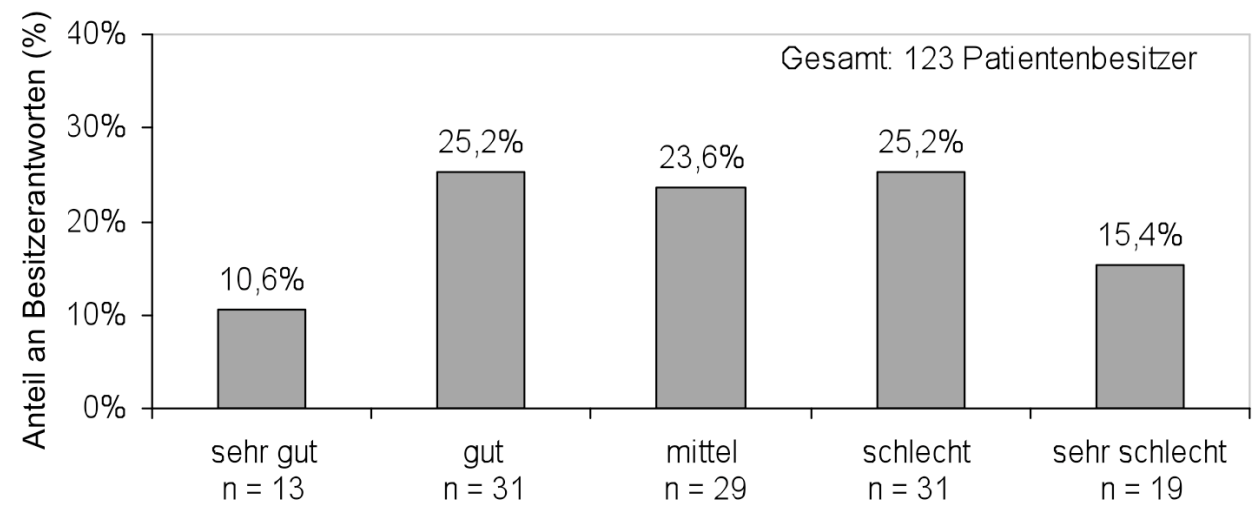

Abb. 2

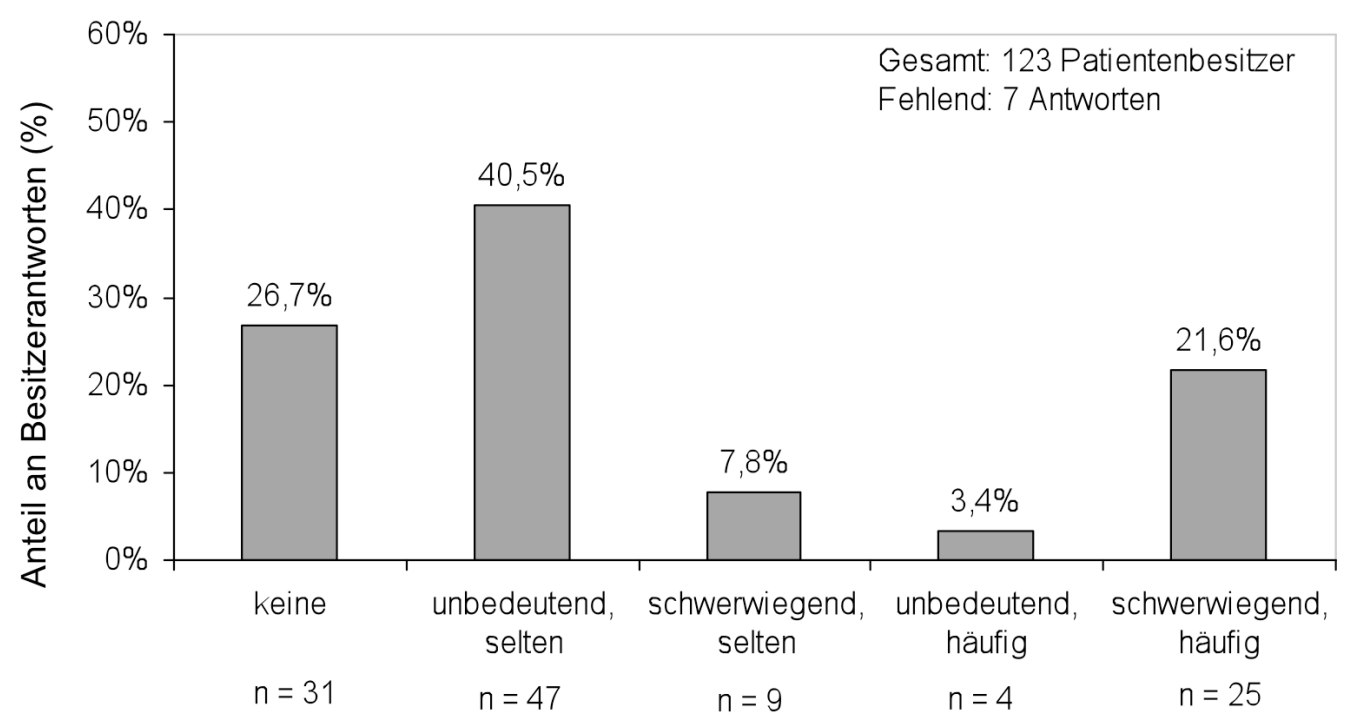

Abb. 3 


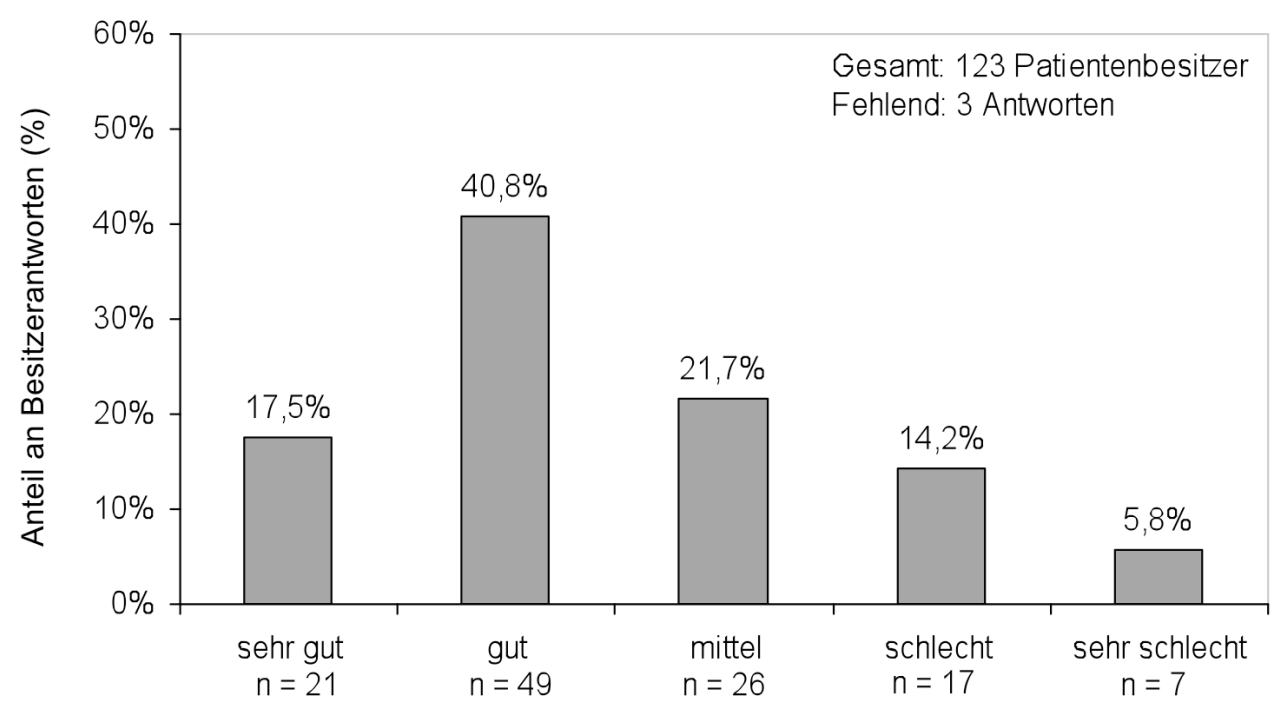

Abb. 4 


\section{KAPITEL II: ZWEITE PUblikAtion}

Sehr geehrte Frau Bergmann,

Ihre Originalarbeit "Chemotherapie Lymphom-kranker Hunde - Wirksamkeit und Verträglichkeit aus Sicht des Tierarztes und des Tierhalters" wurde von der Schriftleitung zur Publikation in der Kleintierpraxis angenommen. Wir freuen uns, das Manuskript in einer der nächsten Ausgaben zu veröffentlichen!

Vor Drucklegung werden wir Ihnen ein pdf des Artikels zur Autorkorrektur zusenden. Dann werden wir Sie auch bitten, die Formulare zur Rechteübertragung auszufüllen und zu unterzeichnen. Ein Teil liegt uns ja bereits vor.

Herzliche Grüße

i.A. Dr. med. vet. Gerda Bäumer Redaktion Veterinärmedizin

M.\& H. Schaper GmbH Postfach 54 29, 30054 Hannover Adresse: Bischofsholer Damm 2430173 Hannover

Mailto:baeumer@schluetersche.de Telefon +49 511 8550-2485 Telefax +49 511 85502411 www.schaper-verlag.de

Amtsgericht Hannover HRB 200529 Geschäftsführung: Klaus Krause USt-IdNr. DE 248954181 


\section{Chemotherapie Lymphom-kranker Hunde - Wirksamkeit und Verträglichkeit aus Sicht des Tierarztes und des Tierhalters}

Chemotherapy in dogs with lymphoma - efficacy and adverse effects from the veterinarian's and owner's perspective

Michele Bergmann ${ }^{1}$, Carola Sauter-Louis ${ }^{2}$, Johannes Hirschberger ${ }^{1}$

${ }^{1}$ Medizinische Kleintierklinik der Ludwig-Maximilians-Universität München

${ }^{2}$ Klinik für Wiederkäuer mit Ambulanz und Bestandsbetreuung der Ludwig-MaximiliansUniversität München 


\section{Chemotherapie Lymphom-kranker Hunde - Wirksamkeit und Verträglichkeit aus Sicht des Tierarztes und des Tierhalters}

\section{Zusammenfassung:}

Gegenstand und Ziel: Die Wirksamkeit und Verträglichkeit der Chemotherapie Lymphomkranker Hunde wurde evaluiert und den Beobachtungen der Hundebesitzer gegenübergestellt. Material und Methoden: Retrospektiv wurden Erhebungen zur Behandlung von 136 Lymphom-kranken Hunde, die in der Medizinischen Kleintierklinik München (MTK) der Ludwig-Maximilians-Universität München in den letzten 13 Jahren eine oder mehrere Dosen einer zytostatischen Chemotherapie erhielten und deren Besitzer sich zur Studienteilnahme bereit erklärten, aus der Datenbank, dem Klinikverwaltungsprogramm Vetera (G\&P Software, Eltville, Deutschland) entnommen. Die Beurteilung der Wirksamkeit erfolgte anhand von Remissionsstatus, Remissions- und Überlebenszeit der Patienten. Nebenwirkungen wurden mithilfe der Common Terminology Criteria for Adverse Events (CTCAE) ausgewertet (Vail, 2004). Die Beurteilung der Chemotherapie aus Sicht der Besitzer erfolgte anhand eines Fragebogens. Ergebnisse: 123 Hunde erhielten eine „Kombinations-Chemotherapie“. Die Remissionsrate dieser Hunde lag bei 83,7 \% (65,0\% komplette Remission, 18,7\% partielle Remission). Die mediane Überlebenszeit betrug 275 Tage. 69 Patienten (56,1\%) zeigten hämatologische $(n=52)$ und/oder klinische Nebenwirkungen $(n=49)$. Bei 48 Hunden (39,0 \%) waren diese mild (Grad I und II), bei 21 Patienten schwerwiegend (Grad III und IV). Aus Sicht der Tierhalter konnte die Therapie bei 90 Hunden (73,2 \%) eine Besserung erzielen. 85 Besitzer $(69,1 \%)$ berichteten von Nebenwirkungen. Schlussfolgerung: 60 Besitzer (70,6\%) empfanden Nebenwirkungen Grad I, II als „unbedeutend“, Nebenwirkungen Grad III, IV als „schwerwiegend“. Klinische Nebenwirkungen (gastrointestinale Nebenwirkungen Grad II) wurden von einigen Besitzern als „schwerwiegend“ empfunden ( $\mathrm{n}=7)$. Speziell Besitzer von Hunden mit sehr kurzen Überlebens- und Remissionszeiten bedauerten die Entscheidung zur Therapie $(\mathrm{n}=13)$. Klinische Relevanz: Regelmäßig zu erwartende Nebenwirkungen, die medizinisch nicht relevant erscheinen, wie Durchfall oder Erbrechen, können zu einer Belastung des Tierhalters führen und sollten vorbeugend behandelt werden. Die Dauer der Überlebenszeit ist als wichtiges Kriterium für die Zufriedenheit der Besitzer mit der erhaltenen Therapie zu berücksichtigen, insbesondere bei der Aufklärung von Patienten mit negativen prognostischen Faktoren.

Schlüsselwörter: Lymphom - Nebenwirkungen - CTCAE-Tabelle - Besitzer - Umfrage 


\section{Chemotherapy in dogs with lymphoma - efficacy and adverse effects from the veterinarian's and owner's perspective}

\section{Summary:}

Objective: Efficacy and adverse events of chemotherapy in dogs with lymphoma were evaluated and compared with the owners' observations. Material and methods: One hundred and thirty-six dogs with lymphoma that underwent chemotherapy at the Clinic of Small Animal Medicine, University of Munich, during the last 13 years were included in the study. Patient data was extracted from the clinic data base "Vetera" (G\&P Software, Eltville, Germany) in a retrospective study. Assessment of efficacy was made by remission status, remission duration and survival time. Adverse events were graded according to the CTCAEscale (Common Terminology Criteria for Adverse Events) (Vail, 2004). Owners' assessment of chemotherapy was obtained using a questionnaire. Results: One hundred and twenty-three dogs underwent "combination chemotherapy". The overall remission rate of dogs undergoing chemotherapy was $83.7 \%$ (65.0\% CR, 18.7\% PR). Median survival time was 275 days. Sixtynine patients $(56.1 \%)$ showed haematologic $(n=52)$ and/or clinical adverse events $(n=48)$. Among 48 dogs adverse events were mild (grade I und II), among 21 patients they were serious (grade III und IV). From the owners' perspective, therapy led to improvement in 90 dogs (73.2\%). Eighty-five owners (69.1\%) reported about adverse events. Conclusion: Sixty owners $(70.6 \%)$ felt grade I, II toxicoses to be minor to negligible, while grade III, IV toxicoses were considered serious complications. Clinical signs of toxicosis (grade I, II gastrointestinal toxicosis) were also regarded as "severe" $(n=7)$. Especially owners of dogs with short remission and survival times deplored the decision to treatment $(n=13)$. Clinical relevance: Even expected adverse events, which are medically irrelevant, such as diarrhea or emesis, can cause stress for the owners and should be treated preventively. It must be taken into consideration, that length of survival time is an important criterion for owners' satisfaction with administered therapy, in particular during informed consent of owners of animals with negative factors for prognosis.

Key words: Lymphoma - Side effects - CTCAE-Scale - Owner - Questionnaire 


\section{Einleitung}

Die in der Veterinärmedizin am häufigsten zytostatisch behandelte Krankheit ist das kanine maligne Lymphom. Diese Krankheit tritt beim Hund mit einer Inzidenz von 24 bis 114 Tieren je 100000 jährlich auf (Dorn et al., 1968; Dorn et al., 1970; Dobson et al., 2002). Eine palliative Behandlung mit verschiedenen zytostatischen Medikamenten, die so genannte Polychemotherapie, verläuft in den meisten Fällen erfolgreich (Myers et al., 1997; Zemann et al., 1998; Boyce und Kitchell, 2000; Moore et al., 2001; Simon et al., 2006). So können Remissionsraten zwischen $76 \%$ und $92 \%$ und eine mediane Überlebenszeit von rund einem Jahr erreicht werden (Moore et al., 2001; Garrett et al., 2002; Simon et al., 2006). Nach Literaturangaben zeigen nur wenige Patienten toxische Erscheinungen (Keller et al., 1993; Hirschberger, 2001; Vail et al., 2001).

Allerdings ist bei diesen Angaben zur Verträglichkeit der Chemotherapie des malignen Lymphoms $\mathrm{zu}$ berücksichtigen, dass unterschiedliche Beschreibungen hinsichtlich der Toxizitäten und ihrer Schweregrade bestehen. Dies erschwert den Vergleich der beobachteten Komplikationen zwischen verschiedenen Studien (Mellanby et al., 2003).

Bislang gibt es nur eine Studie, die speziell die Komplikationen der Chemotherapie Lymphom-kranker Hunde anhand der Common Terminology Criteria of Adverse Events (CTCAE) evaluiert (Vail, 2004; Tomiyasu et al., 2010). Inwieweit diese Nebenwirkungen den Hund und seinen Besitzer aus dessen subjektiver Sicht belasten, ist bislang allerdings noch nicht bekannt.

Ziel dieser Studie war es deshalb, die Wirksamkeit und die Verträglichkeit der palliativen Chemotherapie Lymphom-kranker Hunde anhand der CTCAE-Tabelle zu evaluieren. Der Vergleich dieser Auswertungen mit der subjektiven Beurteilung der Therapie aus Sicht der Besitzer zeigt darüber hinaus, inwiefern diese von der tierärztlichen Sicht abweicht.

Zudem soll die Studie dem Therapeuten die Möglichkeit geben, drohende oder auftretende Komplikationen der Chemotherapie leichter zu erkennen, diese gegebenenfalls rechtzeitig und korrekt zu behandeln und folglich den Therapieverlauf individuell so zu gestalten, dass eine bestmögliche Behandlung für Hund und Besitzer gegeben ist. 


\section{Material und Methoden}

Patientengut: Die vorliegende Arbeit wurde als retrospektive Studie angelegt. Das Patientenkollektiv umfasste alle an einem malignen Lymphom erkrankten Hunde, die in der Medizinischen Kleintierklinik der Ludwig-Maximilians-Universität München in den letzten 13 Jahren eine oder mehrere Dosen eines zytostatischen Chemotherapeutikums erhalten haben und deren Besitzer sich im Rahmen einer Umfrage zur Teilnahme an der Studie bereit erklärten.

Datenerhebungen: Alle Erhebungen $\mathrm{zu}$ den Patienten und ihren chemotherapeutischen Behandlungen stammten aus der Datenbank der Medizinischen Kleintierklinik München, dem Klinikverwaltungsprogramm Vetera (G\&P Software, Eltville, Deutschland).

Aufgrund der Tatsache, dass von den Besitzern verschiedene Therapieformen gewählt wurden, die vollkommen unterschiedlichen Erwartungen entsprachen, wurden entsprechend der „Intention-to-treat“ 2 verschiedene Gruppen erstellt. Die Gruppe „KombinationsChemotherapie“ (KC-Gruppe) umfasste alle Hunde von Besitzern, die sich im Voraus, d.h. bei Erstvorstellung für eine volle chemotherapeutische Behandlung entschlossen haben, auch wenn diese nach initialer Asparaginasegabe abgebrochen wurde oder werden musste. In die zweite Gruppe, die „Asparaginase-Monotherapie“ (AM-Gruppe), fielen die Hunde, deren Besitzer sich vorweg aus einem bestimmten Grund nur für eine einmalige oder mehrfache Asparaginase-Injektion und gegen jede weitere chemotherapeutische Maßnahme entschieden haben.

Die Therapieantwort wurde als komplette Remission (CR; Reduktion der Tumormasse um $100 \%$ ), partielle Remission (PR; Reduktion der Tumormasse um mindestens 50\% aber weniger als 100\%) oder keine Remission (stationäres Tumorverhalten oder Progression) beurteilt.

Hämatologische (Neutropenien, Thrombozytopenien) und klinische Nebenwirkungen wurden anhand der CTCAE-Tabelle ausgewertet (Vail, 2004). Einen Auszug aus der CTCAE-Tabelle zeigt Tabelle 1. Die Toxizitäten, die ein und derselbe Wirkstoff bei einem Patienten verursachte, wurden nicht einmalig, sondern entsprechend ihrer Häufigkeit gezählt. 
Wirksamkeit und Verträglichkeit - Beurteilung aus Sicht der Besitzer: Zur Bewertung der Therapie aus Sicht der Besitzer wurde ein Fragebogen entwickelt, der in seinen Grundzügen an den im Rahmen der Studie „Study of dog and cat owners perception of medical treatment of cancer“ entwickelten Fragebogen von Bronden et al. (2003) angelehnt war und mit Hilfe der Diplom-Psychologin Susanne Braun, Center for Leadership and People Management der Ludwig-Maximilians-Universität München, noch einmal überarbeitet wurde. Die Befragung erfolgte per Post und startete im August 2009. Jedem Schreiben lag ein frankierter Rückumschlag zur Rücksendung bei. Alle beantworteten Fragebögen wurden in einem Zeitraum von 3 Monaten gesammelt und anschließend gruppenabhängig ausgewertet. Bei den Auswertungen wurde berücksichtigt, ob und inwiefern die Sicht der Besitzer von der tierärztlichen Sicht abweicht. Da die Hälfte der Patienten $(n=6)$ der AM-Gruppe nur einmalig in der Tierklinik vorgestellt wurden, erfolgte dieser Vergleich nur bei Patienten der KC-Gruppe.

Der Fragebogen enthielt zumeist geschlossene Fragen, die nach dem Multiple-ChoiceVerfahren zu beantworten waren. Zur Beurteilung der Wirksamkeit wurde ermittelt, welche Effekte die Chemotherapie auf die Erkrankung der Hunde hatte (,Verkleinerung der Lymphknoten“, „Verbesserung des Allgemeinbefindens und der Lebensqualität“", „Lebensverlängerung“, „Heilung“, „keine Besserung“, „Anderes“). Zur Beurteilung der Verträglichkeit wurden die Besitzer gefragt, ob bei ihren Hunden Nebenwirkungen der Therapie auftraten. Um Nebenwirkungen näher zu beschreiben, konnten die Besitzer diese als „selten und unbedeutend“, „,selten aber schwerwiegend“, „häufig und unbedeutend “, oder „häufig und schwerwiegend“ bewerten. Um welche Nebenwirkungen es sich dabei handelte, wurde nicht erfragt. Zusammenfassend sollte die Einstellung der Besitzer gegenüber Chemotherapie entsprechend ihren Erfahrungen bezüglich der Behandlung des eigenen Hundes erfasst werden, mit Hilfe derer die unten aufgeführten statistischen Analysen durchgeführt wurden. Hierzu wurden die Besitzer gefragt, ob sie froh darüber sind, ihren Hund behandelt haben zu lassen oder, ob sie die Behandlung bedauern. Für Besitzer, die sich diesbezüglich „unsicher“ waren, stand zusätzlich ein freies Textfeld zur Verfügung. Schließlich wurden die Besitzer gefragt, ob ihr am malignen Lymphom erkrankter Hund noch lebt und wenn nicht, weshalb und seit wann nicht mehr.

Statistik: Alle statistischen Auswertungen erfolgten mit dem Statistikprogramm SPSS, Version 17.0 (SPSS Inc., Chicago, USA). Die Remissionsrate wurde definiert als die Anzahl an Hunden mit CR oder PR, dividiert durch die Anzahl aller Hunde, die behandelt wurden. 
Die Remissionszeit galt als die Zeitspanne in Tagen vom Erreichen einer kompletten oder partiellen Remission bis zur Diagnose eines Tumorrezidivs, einer Tumorprogression oder bis zum Datum des Todes. Bei den Angaben der Überlebenszeiten wurde die Zeitspanne von der ersten Chemotherapie bis zum Zeitpunkt des Todes gewählt. Patienten, die nicht an einem malignen Lymphom verstorben waren oder aus anderen Gründen euthanasiert wurden, wurden zensiert. Mithilfe des Rangkorrelationskoeffizienten nach Spearman wurde auf einen Zusammenhang zwischen den - laut Besitzerangaben - aufgetretenen Nebenwirkungen und der Zufriedenheit der Besitzer mit der Therapie ihrer Hunde getestet. Die Überlebens- und Remissionszeiten wurden mittels Log-Rank-Test zwischen den 3 Zufriedenheitsgruppen verglichen. Das Studienprotokoll wurde nicht in die Auswertung mit aufgenommen, da dazu nicht bei jedem Protokoll genügend Tiere vorhanden waren. Das Signifikanzniveau wurde auf fünf Prozent festgelegt. Aufgrund der geringen Anzahl an Hunden mit „AsparaginaseMonotherapie“ wurden letztgenannte Analysen nur für Hunde vorgenommen, die ein "Chemotherapieprotokoll" erhielten.

\section{Ergebnisse}

Patienten: Das Patientengut umfasste 136 Hunde mit malignem Lymphom. Das Durchschnittsalter der Hunde bei Diagnosestellung lag bei 8 Jahren und variierte zwischen 2 und 14 Jahren. Insgesamt waren 36 verschiedene Hunderassen vertreten. Die häufigsten Rassen waren der Berner Sennenhund $(n=14)$ und der Deutsche Schäferhund $(n=4) .55$ Hunde waren Mischlinge. Das Verhältnis weiblicher zu männlicher Patienten betrug 1:1,3. Bei 45 Hunden $(33,1 \%)$ fand im Vorfeld bereits eine Behandlung mit Glukokortikoiden durch den Haustierarzt statt. Insgesamt waren fast alle anatomischen Formen des Lymphoms vertreten. 94 Hunde $(69,1 \%)$ hatten ein multizentrisches, $21(15,5 \%)$ ein mediastinales Lymphom. 10 Patienten $(7,4 \%)$ wurden wegen eines gastrointestinalen Lymphoms behandelt. Von insgesamt 11 Hunden mit extranodalen Formen $(8,1 \%)$ waren 8 in der Haut, die restlichen jeweils einmal nasal, perianal und okulär lokalisiert.

37 Hunde $(27,2 \%)$ zeigten bei Diagnosestellung in der Klinik ein ungestörtes Allgemeinbefinden. Sie wurden dem Substadium a zugeordnet. 99 Hunde $(72,8 \%)$ wurden in das Substadium b eingeteilt. Alle Patienten mit gastrointestinalem und mit mediastinalem Lymphom sowie 64 Hunde mit multizentrischem und 4 Hunde mit extranodalem Lymphom wiesen ein gestörtes Allgemeinbefinden auf. 
„Kombinations-Chemotherapie“: Insgesamt handelte es sich bei der Chemotherapie aller Hunde um eine Erstlinienchemotherapie. Dabei kamen verschiedene Protokolle vorwiegend aber Polychemotherapien mit konventionellen Kurzzeit-Kombinationstherapien zum Einsatz.

Bei 123 Hunden wurden 5 verschiedene Therapieschemata, geordnet nach ihrer Häufigkeit eingesetzt: das „12-Wochen-DVG-Protokoll““ ( $\mathrm{n}=80$; Tab. 2) (Simon et al., 2006), das „DISC-Protokoll“, eine simultane Applikation dreier verschiedener Chemotherapeutika (Vincristin, Cyclophosphamid, Doxorubicin) aus unterschiedlichen Wirkstoffgruppen mit individueller Dosissteigerung $(n=26)$ (Zenker et al., 2009), die „orale Chemotherapie“ (Lomustin alle 3 Wochen oder die Kombination aus Cyclophosphamid plus Chlorambucil alle 2 Wochen im Wechsel; $\mathrm{n}=10$ ), die „Doxorubicin-Monotherapie“ (Doxorubicin alle 3 Wochen; $n=5)$ (Valerius et al., 1997) und das „modifizierte DVG-Protokoll“ ( $n=2$; Tab. 2). Prednisolon wurde bei fast allen Patienten eingesetzt. Gründe für einen Verzicht auf die Prednisolongabe waren unter anderem die regelmäßige Gabe nicht-steroidaler Antiphlogistika, Diabetes mellitus oder Hunde mit chronischer Niereninsuffizienz (CNI). Tabelle 3 zeigt die Dosierungen der verwendeten Therapeutika. Bei einem geriatrischen Patienten und 2 Hunden mit CNI wurden von Beginn an nur 70\% der Standarddosis gewählt, um ein Überschreiten der tolerablen Toxizität zu vermeiden.

Die mediane Anzahl der Chemotherapien des initialen Protokolls lag bei 12 Sitzungen pro Patient (25\%-Perzentil: 4 Sitzungen; 75\%-Perzentil: 12 Sitzungen). 38 Besitzer (30,9\%) haben die Chemotherapie ihrer Hunde zu unterschiedlichen Zeitpunkten innerhalb der ersten 12 Wochen vorzeitig abgebrochen. Vermerkte Ursachen hierfür waren kein Ansprechen auf die Chemotherapie bei 17 Hunden nach einer $(n=11), 2(n=3), 3(n=2)$ und $6(n=1)$ Behandlungen, PD (progressive disease) nach PR oder CR $(n=10)$ und Nebenwirkungen der Therapie $(n=3)$. Weitere Gründe waren zu hohe Kosten $(n=2)$, aggressives Verhalten $(n=$ 1) und 2 Besitzer verzichteten aufgrund des guten Allgemeinbefindens des Hundes auf weitere zytostatische Behandlungen. Ein Patient verstarb an den Folgen einer Überdosierung in einer anderen Klinik.

Wirksamkeit der „Kombinations-Chemotherapie “: Die Remissionsrate der Hunde aus der KC-Gruppe lag bei 83,7 \%. Bei 80 Patienten (65,0\%) konnte eine komplette Remission und bei $23(18,7 \%)$ eine partielle Remission erreicht werden. Median vergingen 14 Tage bis die 
Hunde ihren Remissionsstatus erlangten (25\%-Perzentil: 7 Tage; 75\%-Perzentil: 14 Tage). Von 20 Patienten, die nicht in Remission gingen waren 15 Hunde Substage b, 13 hatten vor Therapiebeginn labordiagnostische Veränderungen (7mal Thrombozytopenie, 5mal Anämie, $1 \mathrm{mal}$ Azotämie, 3mal Hyperkalzämie) und 4 Hunde waren mit Kortikosteroiden vorbehandelt. Bei 7 Hunden waren Lymphomformen vorhanden, welche allgemein als mit einer negativen Prognose assoziiert bewertet werden (3mal ZNS-Beteiligung, 2mal kutane epitheliotrope TZell-Lymphome, 3mal T-Zell-Lymphome) (Couto et al., 1984; Keller et al., 1993; Moore et al., 1995; Lee et al., 1996; Starrak et al., 1997; Zemann et al., 1998; Moore et al., 2001; Abbo und Lucroy, 2007; Fontaine et al., 2009). Tabelle 4 und 5 zeigen den Remissionsstatus der Patienten in Abhängigkeit von den Behandlungsprotokollen, der anatomischen Form, sowie dem Substage.

Die mediane Überlebenszeit der KC-Gruppe lag bei 275 Tagen. Hunde mit CR sowie solche mit Substage a hatten eine mediane Überlebenszeit von jeweils 424 Tagen. Patienten mit multizentrischem Lymphom lebten median 373 Tage.

Verträglichkeit der „Kombinations-Chemotherapie“: Die Nebenwirkungen der Therapie wurden von jeweils verschiedenen behandelnden Tierärzten schriftlich festgehalten. Insgesamt zeigten 69 Patienten $(56,1 \%)$ hämatologische $(\mathrm{n}=52)$ und/oder klinische Nebenwirkungen $(\mathrm{n}=49)$. Bei 48 Hunden $(39,0 \%)$ handelte es sich um milde (Grad I und II), bei 21 Patienten (17,1\%) um schwerwiegende (Grad III und IV) Komplikationen.

Bei 52 Patienten (42,3 \%) kam es in unterschiedlicher Häufigkeit und Ausprägung zu Neutround/oder Thrombozytopenien (Tab. 6). Dadurch mussten zahlreiche Therapieaufschübe vorgenommen werden $(\mathrm{n}=103)$. Bei 37 Hunden konnte die Therapie zumeist 3 Tage später nach erneuter Blutbildkontrolle durchgeführt werden. Bei 13 Patienten mit Neutropenie $(10,6 \%)$ wurde eine Dosisreduktion des jeweiligen Chemotherapeutikums vorgenommen. Lomustin wurde von ursprünglich $70 \mathrm{mg} / \mathrm{m}^{2}$ auf $60 \mathrm{mg} / \mathrm{m}^{2}$, alle anderen einzeln applizierten Medikamente von $100 \%$ der Standarddosis auf $80 \%$ reduziert. Hunde, die das „DISCProtokoll“ erhielten, wurden nicht weiter Dosis-eskaliert. Bei einem dieser Hunde wurde die $50 \%$ ige Dosis wieder auf die vorherige Stufe (40\%) reduziert.

Neutropenien wurden bei 48 Hunden $(39,0 \%)$ durch Vincristin (32mal) oder die simultane Gabe von Vincristin, Cyclophosphamid und Doxorubicin (31mal) hervorgerufen. 
Grad III und IV Neutropenien $(\mathrm{n}=17)$ wurden unter anderem bei alleiniger Applikation von Doxorubicin (6mal) und Lomustin (2mal) beobachtet. Betroffene Hunde $(n=13)$ waren klinisch unauffällig und hatten keine Anzeichen einer bakteriellen Infektion, sodass sie prophylaktisch mit Amoxicillin/Clavulansäure ambulant behandelt werden konnten.

Thrombozytopenien wurden bei 14 Patienten (11,4\%) im Verlauf des DISC-Protokolls (8mal), durch Doxorubicin (3mal), Lomustin (2mal), Vincristin (2mal) sowie einmalig nach Cyclophosphamid und Asparaginase hervorgerufen. Grad I und II Thrombozytopenien wurden bei 11 Hunden insgesamt $15 \mathrm{mal}$, Grad III und IV Thrombozytopenien bei 3 Hunden jeweils einmalig beobachtet. Diejenigen Hunde, die eine Thrombozytopenie infolge des DISC-Protokolls entwickelten, waren zudem neutropenisch $(n=8)$. Klinische Anzeichen einer Blutungsneigung zeigte keiner der betroffenen Patienten. Die Besitzer schonten ihre Hunde, welche sich komplikationslos erholten.

Gastrointestinale Komplikationen wie Vomitus, Diarrhoe oder Anorexie wurden insgesamt 56mal (42mal Grad I, 9mal Grad II) beobachtet. Keiner der 36 betroffenen Patienten (29,3\%) musste aufgrund dieser Beschwerden hospitalisiert werden. Die Komplikationen fanden sich insbesondere nach Vincristin- (21mal) und Cyclophosphamidgaben (9mal) sowie bei Kombinationen dieser 2 Medikamente mit Doxorubicin im Verlauf des „DISC-Protokolls“ (15mal). Patienten, mit Durchfall (Grad II) wurden dem jeweiligen Protokoll folgend therapiert und zusätzlich prophylaktisch mit Metronidazol ( 2 x täglich $15 \mathrm{mg} / \mathrm{kg}$ über 5 Tage) behandelt. Dosisreduktionen auf $70 \%$ wurden bei 2 Patienten vorgenommen, die wiederholt Durchfall Grad II entwickelten.

Ein gestörtes Allgemeinbefinden trat in Form von milder Apathie/Lethargie bei 4 Hunden (3\%) auf. Eine Grad III-Toxizität wurde bei einem Hund ein paar Tage nach therapieeinleitender Asparaginasegabe beobachtet. Dieser Hund war eine Woche später in kompletter Remission und klinisch unauffällig.

Insgesamt 8 Hunde $(6,5 \%)$ hatten im Verlauf ihrer Therapie eine erhöhte Körpertemperatur. 5 von diesen 8 Patienten hatten zusätzlich eine Neutropenie, Anorexie, ein hochgradig gestörtes Allgemeinbefinden und wurden hospitalisiert. 2 dieser Patienten wiesen zusätzlich eine disseminierte intravasale Koagulopathie (Grad II) auf. Diese beiden Patienten wurden mit Amoxicillin/Clavulansäure, Enrofloxacin und Metronidazol sowie mit Infusionstherapie behandelt. Ein Hund wurde nach 5 Tagen entlassen. Das Protokoll wurde abgebrochen und der Hund im Weiteren mit dem Tyrosinkinaseinhibitor Masivet behandelt. Der zweite Patient verstarb an Komplikationen einer Bluttransfusion im Rahmen seiner 
Sepsis-Behandlung. Die übrigen 3 Patienten wurden während des stationären Aufenthalts mit Amoxicillin/Clavulansäure, Enrofloxacin und Infusionstherapie behandelt und konnten nach 2 bzw. 3 Tagen entlassen werden. Die Chemotherapie wurde in reduzierter Dosis fortgeführt bzw. bei einem Patient auf Wunsch des Besitzers abgebrochen.

Cyclophosphamid verursachte einem Patienten eine sterile hämorrhagische Zystitis mit makroskopischer Hämaturie. Die bakteriologische Untersuchung des Urins des kastrierten Rüden war negativ. Therapeutisch wurden eine Schmerzmedikation mit Meloxicam und Metamizol und die prophylaktische Gabe von Amoxicillin/Clavulansäure vorgenommen. Bei diesem Patienten wurde im weiteren Verlauf des „12-Wochen-DVG-Protokolls“ Cyclophosphamid durch Chlorambucil ersetzt.

Alle Hunde, die Cyclophosphamid erhielten, bekamen begleitend Furosemid. Bei einem Hund, der vorberichtlich für Zystitiden anfällig war, wurde zusätzlich zur Prophylaxe das „12-Wochen-DVG-Protokoll““ so abgewandelt, dass dem Patienten Cyclophosphamid im Wechsel mit Chlorambucil verabreicht wurde.

Akute Arrhythmien wurden einmalig während einer Doxorubicin-Infusion unter Herzauskultation und Pulspalpation festgestellt. Eine sofortige Unterbrechung der Infusion führte direkt zu einer Normalisierung der klinischen Befunde des Patienten. Im umgehend aufgezeichneten Elektrokardiogramm konnten keine Auffälligkeiten mehr festgestellt werden. Die Doxorubicingabe wurde an diesem Tag dennoch nicht weiter fortgesetzt. Klinische Anzeichen einer Kardiomyopathie traten bei keinem der Patienten während des Initialprotokolls auf. Bei 2 Hunden, ein Dobermann und ein Dobermann-Mischling, die vor Therapiebeginn schon im Herzultraschall Anzeichen einer DCM aufwiesen, wurde Doxorubicin durch Epirubicin ersetzt.

Bei 15 Patienten (12,2\%), überwiegend Terrier und Mischlingshunde, traten Fellprobleme in Form von lokal begrenzten Alopezien auf. Diese manifestierten sich im späten Verlauf des „12-Wochen-DVG-“ $(\mathrm{n}=9)$, des „DISC-““ $(\mathrm{n}=4)$ und des „modifizierten DVG-Protokolls“ $(\mathrm{n}=2)$.

Wirksamkeit und Verträglichkeit der „Asparaginase-Monotherapie“": 13 Besitzer haben sich vorweg für eine einmalige oder mehrfache Asparaginase-Injektion/-en entschieden (Tab. 8). Gründe hierfür waren Schwangerschaft der Besitzerin $(n=1)$, Kleinkinder im Haus $(n=$ 
2), das schlechte Allgemeinbefinden des Hundes $(n=7)$ oder unbekannt $(n=3) .2$ Patienten mit „Asparaginase-Monotherapie“ waren in kompletter, 3 in partieller Remission; bei 7 Patienten lag keine Remission (SD oder PD) vor. 2 dieser Patienten wurden wegen ihres schlechten Allgemeinbefindens in der Medizinischen Kleintierklinik euthanasiert. Die übrigen 5 Hunde wurden nicht mehr vorgestellt und den Aussagen der Besitzer entsprechend als remissionslos bewertet. Von einem Patient war der Remissionsstatus unbekannt. Die mediane Überlebenszeit der Hunde betrug 76 Tage. Die beiden Patienten in kompletter Remission überlebten mithilfe wiederholter Asparaginase-Injektionen 150 bzw. 330 Tage. Nebenwirkungen der Therapie traten bei keinem Patienten auf.

\section{Wirksamkeit und Verträglichkeit - Vergleich mit der subjektiven Beurteilung aus Sicht} der Besitzer von Hunden der KC-Gruppe: Aus Sicht der Tierhalter konnte die Chemotherapie bei insgesamt 90 Hunden (73,2\%) eine oder mehrere Besserungen erzielen: die „Besserung des Allgemeinbefindens und der Lebensqualität“ (67mal), die „Verkleinerung der Lymphknoten“ (61mal), die „Lebensverlängerung“ (43mal) und die „Heilung“ (5mal). Ein Besitzer nannte ohne freitextlichen Kommentar „Anderes“. 32 Hunde (26,0 \%) erfuhren „keine Besserung“. Laut Patientendaten waren insgesamt 73 von 84 Hunden mit multizentrischem Lymphom (86,9 \%) in Remission. Die mediane Überlebenszeit der Hunde, die laut Besitzern eine „Lebensverlängerung“ erfuhren lag bei 730 Tagen, die aller übrigen Patienten bei 151 Tagen. 32 Besitzer (26,0 \%) gaben an, dass die Therapie „keine Besserung“ für ihre Hunde erzielen konnte. Bei 17 dieser Patienten wurde keine Remission erreicht, 7 Hunde waren in kompletter, 8 in partieller Remission. Die mediane Überlebenszeit jener Patienten ohne „Besserung“ betrug 32 Tage.

Bei 85 Hunden traten laut Besitzern Nebenwirkungen der Therapie auf. Beim Vergleich dieser Angaben mit den Ergebnissen der Auswertungen anhand der CTCAE-Tabelle fiel folgendes auf: 60 dieser Hundehalter (70,6 \%) empfanden Nebenwirkungen Grad I oder II als „unbedeutend“ und Nebenwirkungen Grad III oder IV als „schwerwiegend“. Bei hämatologischen Toxizitäten (Grad I, II, III) kam es vor, dass diese von den Besitzern nicht als „häufig“ ( $n=17)$ oder als „,schwerwiegend“ $(n=2)$ registriert wurden, solange die Hunde ein ungestörtes Allgemeinbefinden aufzeigten. Klinische Nebenwirkungen (gastrointestinale Nebenwirkungen Grad II) hingegen wurden von 7 Besitzern als „schwerwiegend“ empfunden. Jeweils 8 Besitzer (18,8 \%) kreuzten „unbedeutende“ beziehungsweise „schwerwiegende“ Nebenwirkungen an. Aus der Datenbank dieser Patienten ist zu 
entnehmen, dass weder vorberichtlich noch bei Vorstellung Nebenwirkungen aufgetreten sind. 12 dieser Hunde erreichten keine Remission. Die Besitzer dieser Tiere brachen die Therapie nach $1(n=6), 2(n=3), 3(n=2)$ und $6(n=1)$ Behandlungen $a b$.

80 Besitzer $(65,0 \%)$ waren froh, ihren Hund mit Chemotherapie behandelt haben zu lassen. $29(23,6 \%)$ Besitzer beantworteten diese Frage mit ,ich bin unsicher, weil...“. Freitextlich angegebene Gründe hierfür waren „das Ausbleiben des erhofften Therapieerfolges“ ( $n=12)$, „die große Belastung durch die vielen Therapiesitzungen“ ( Nebenwirkungen der Therapie“ ( $\mathrm{n}=3)$, „der zu späte Therapiebeginn“ $(\mathrm{n}=1)$, „die hohen Kosten“ ( $\mathrm{n}=1)$, und „der ständige Wechsel behandelnder Tierärzte in der Klinikabteilung“ (n $=1)$. 13 Besitzer (10,6\%) bedauerten die Entscheidung zur Therapie. Ein Besitzer machte keine Angaben zu dieser Frage.

Insgesamt waren 15 Hunde der KC-Gruppe (12,2\%) zum Zeitpunkt der Auswertung der Umfrage noch am Leben. 108 Hunde (87,8 \%) waren bereits verstorben. Davon wurden 92 $(74,8 \%)$ aufgrund ihres Lymphoms euthanasiert, bei 16 Hunden $(13,0 \%)$ waren andere Umstände für das Versterben ursächlich.

\section{Analyse der Zufriedenheit mit der Chemotherapie}

Ein Zusammenhang zwischen den aufgetretenen Nebenwirkungen während der Chemotherapie und der Zufriedenheit der Besitzer mit der Chemotherapie ihrer Hunde konnte nicht bestätigt werden $(r=-0,170 ; p=0,069)$. Allerdings bestand ein statistisch signifikanter Zusammenhang zwischen dieser und den Überlebens- (Log Rank $=24,384$, df $=2, p<0,001)$ und Remissionszeiten $(\log \operatorname{Rank}=19,750$ df $=2, p<0,001)$ der Hunde. So waren insbesondere die Besitzer froh darüber, ihr Tier entsprechend behandelt haben zu lassen, deren Hunde längere Remissions- und Überlebenszeiten aufwiesen (Tab. 8).

\section{Diskussion}

Bei der Therapie des kaninen malignen Lymphoms können mit Doxorubicin-haltigen Kombinations-Chemotherapie-Protokollen Remissionsraten zwischen $76 \%$ und $92 \%$ und mediane Überlebenszeiten von rund einem Jahr erreicht werden (Moore et al., 2001; Garrett et al., 2002; Simon et al., 2006).

Soweit bekannt gibt es bisher nur eine Studie, die speziell die Komplikationen eines entsprechenden Protokolls anhand der einheitlichen Bezeichnungsweisen der „Veterinary Cooperative Oncology Group“ (VCOG) evaluierte (Tomiyasu et al., 2010). Inwieweit solche 
Nebenwirkungen den Hund und seinen Besitzer aus dessen subjektiver Sicht belasten, ist bislang allerdings unbekannt.

Das Ziel der vorliegenden Studie war die Evaluierung der Wirksamkeit und Verträglichkeit der palliativen Chemotherapie Lymphom-kranker Hunde insbesondere in Bezug auf Nebenwirkungen der Therapie anhand von Auswertungen mit der CTCAE-Tabelle. Zu Vergleichszwecken erfolgte parallel eine subjektive Beurteilung der Therapie aus Sicht der Besitzer, die somit erstmalig in einer Untersuchung berücksichtigt wurde.

In diese Studie wurden alle an einem malignen Lymphom erkrankten Hunde aufgenommen, die eine oder mehrere Dosen an Chemotherapie erhalten haben und deren Besitzer sich zur Teilnahme an der Studie bereit erklärten.

Die Analyseform basierte auf der „Intention-to-treat““. So fielen alle Hunde von Besitzern, die sich im Voraus für eine volle chemotherapeutische Behandlung entschlossen haben, in die KC-Gruppe - ungeachtet dessen, wie die Medikamente appliziert wurden (i. v. oder oral), welche Protokolle (Kombinations- oder Monotherapie) gewählt wurden und ob die Behandlung schon nach der einleitenden Gabe von Asparaginase abgebrochen wurde. Hierbei wären im Sinne einer besseren Vergleichbarkeit einheitlichere Therapiebedingungen sicherlich wünschenswert gewesen. Nichtsdestotrotz erhielt die Mehrheit der Patienten miteinander vergleichbare Protokolle (,DISC-Protokoll“, „12-Wochen-DVG-Protokoll“, „Doxorubicin-Monotherapie“) (Valerius et al., 1997; Simon et al., 2008; Zenker et al., 2009). 12 Patienten bekamen abweichende Protokolle („modifiziertes DVG-Protokoll“, „orale Chemotherapie“). Berücksichtigt man aber, dass im Verlauf jeder Chemotherapie Lymphomkranker Hunde - aus tierärztlicher Sicht oder aus persönlichen Gründen der Besitzer Anpassungen oder gar Protokolländerungen notwendig sein können, dann lassen sich die Ergebnisse dieser Studie auf die Grundgesamtheit Lymphom-kranker Patienten übertragen (Simon et al., 2006; Chun, 2009).

Die Remissionsrate der Hunde der KC-Gruppe lag bei 83,7 \% mit einer kompletten Remission von $65,0 \%$. Ein Grund für diese vergleichsweise niedrige Rate von Tieren in kompletter Remission liegt sicherlich in den uneinheitlichen Therapiebedingungen, denn einige Patienten erhielten eine Monotherapie oder eine rein orale Therapie mit Alkylanzien. So hatten Hunde, die mit einem Polychemotherapie-Protokoll („12-Wochen-DVG-Protokoll“", „DISC-Protokoll“, „modifiziertes DVG-Protokoll“) behandelt wurden, eine Remissionsrate von $88,0 \%$ (CR 67,6 \%). Diese ist nicht vergleichbar mit den Ergebnissen, von denen Garrett et al. (2002) berichten (CR 92,3\%), liegt aber im mittleren Bereich der Ergebnisse von 
anderen zuvor veröffentlichen Studien (Moore et al., 2001; Simon et al., 2006; Simon et al., 2008; Zenker et al., 2009).

Ein weiterer möglicher Grund für die geringe komplette Remissionsrate der KC-Gruppe ist die Entwicklung multipler Medikamentenresistenzen $(\mathrm{MDR}=$ multiple drug resistance $)$, die durch die häufigen Vorbehandlungen mit Prednisolon bedingt sein könnten. Diese sind vor allem beim malignen Lymphom beschrieben (Moore et al., 1995; Lee et al., 1996).

Weiterhin könnte die Rate durch die Tatsache erklärbar sein, dass 11 Besitzer die Therapie schon nach einer einmaligen Behandlung abbrachen. Zudem lag der Anteil an Tieren, die bereits mit Substage b vorgestellt wurden bei 74,0 \%. Der prozentuale Anteil an Hunden mit gestörtem Allgemeinbefinden der vorher erwähnten Studien hingegen lag bei 39,0\%, 56,2 \% und 63,6 \% (Moore et al., 2001; Simon et al., 2006; Simon et al., 2008). Des Weiteren kann auch der hohe Anteil mediastinaler Lymphome $(n=20)$, die eine ungünstigere Prognose als das multizentrische Lymphom haben, für die geringe komplette Remissionsrate verantwortlich sein (Starrak et al., 1997).

Die Nebenwirkungen der Therapie der Hunde aus der KC-Gruppe waren zumeist mild (Grad I und II) und medizinisch gut zu kontrollieren. Dennoch waren sie in 2 Fällen mit letalen Folgen verbunden. Ein Patient verstarb an den Folgen einer Überdosierung in einer anderen Klinik. Ein weiterer Hund verstarb an den Komplikationen einer Bluttransfusion im Rahmen seiner Sepsis-Behandlung. Andere Studien zeigten ähnliche Mortalitätsraten. In der Studie von Moore et al. (2001) bspw. wurde ein Multi-Chemotherapie-Protokoll ohne Erhaltungsphase evaluiert. Im Therapieverlauf starben 3 von insgesamt 82 Patienten an Sepsis; in der Studie von Simon et al. (2006), die die Therapie von 77 Patienten evaluierte, verstarb ein Patient.

Insgesamt wurden in der hier vorliegenden Studie 6 Fälle $(4,9 \%)$ von Sepsis beobachtet. Bei 2 Patienten waren diese mit Lomustin assoziiert, einem Alkylanz, das zur Therapie des kutanen T-Zell-Lymphoms eingesetzt wurde und für seine myelosuppressive Wirkung bekannt ist (Moore et al., 1999; Kristal et al., 2004).

Obwohl die Sepsis in der Tiermedizin als eine seltene Komplikation der Chemotherapie gilt, besteht einer neuen Studie zufolge bei Hunden mit malignem Lymphom eine größere Gefahr, eine Sepsis zu entwickeln, als bei jenen, die aufgrund eines soliden Tumors chemotherapiert werden (Chun et al., 2007; Sorenmo et al., 2010). Sorenmo und Mitarbeiter (2010) vermuten, dass dies mit der Immunsuppression Lymphom-kranker Hunde in Zusammenhang steht. So erkrankten Lymphom-Patienten vor allem im frühen Therapieverlauf der Induktionsphase, wenn zumeist noch keine Remission erreicht war, insbesondere nach der Gabe von 
Doxorubicin und Vincristin. Eine Immundysfunktion konnte von Fowler und Kollegen (2010) kürzlich bei Hunden mit malignem Lymphom nachgewiesen werden. Obwohl Vincristin längere Zeit als nicht sonderlich nebenwirkungsreich galt, zeigten auch Tomiyasu et al. (2010), dass die Inzidenz schwerwiegender Komplikationen vor allem bei Patienten im fortgeschrittenen Krankheitsstadium nach Vincristingabe höher ist, als bislang vermutet. Zudem ist in der vorliegenden Studie aufgefallen, dass 4 der Sepsis-Patienten ein durchschnittliches Körpergewicht von 12,6 kg (Min.: 8,8 kg; Max.: 21,8 kg) aufwiesen. Hunde mit einem niedrigen Körpergewicht besitzen ein erhöhtes Risiko unter Chemotherapie eine Sepsis zu entwickeln (Sorenmo et al., 2010).

Neben den bereits aufgeführten Komplikationen waren die Nebenwirkungen der Therapie sonst akzeptabel. Die häufigsten Komplikationen waren asymptomatische Neutropenien und gastrointestinale Beschwerden. Keiner der betroffenen Hunde musste aufgrund dieser Nebenwirkungen hospitalisiert werden.

Im Verlauf der Therapie mit Cyclophosphamid trat - obwohl 26 Patienten des „DISCProtokolls“" sogar wöchentlich mit Cyclophosphamid therapiert wurden - nur bei einem Hund eine sterile hämorrhagische Zystitis auf. Bei allen übrigen Hunden konnte die begleitende Verabreichung von Furosemid dieser aber vorbeugen. Furosemid beschleunigt die Ausscheidung des toxischen Cyclophosphamid-Metaboliten, des Acroleins, der sonst eine sterile hämorrhagische Zystitis auslösen kann. Laut Literatur zeigen nur 1,2\% aller mit Cyclophosphamid plus Furosemid behandelten Hunde Symptome einer hämorrhagischen Zystitis (Charney et al., 2003).

Apathie/Lethargie (Grad III) wurde bei einem Hund ein paar Tage nach therapieeinleitender Asparaginasegabe beobachtet ohne Hinweise auf mögliche anaphylaktische Reaktionen, die für L-Asparaginase beschrieben sind (Masetti und Pession, 2009). Dieser Hund war eine Woche später in kompletter Remission und klinisch unauffällig, sodass es wahrscheinlicher ist, diese Beschwerden auf ein Tumor-Lyse-Syndrom zurückzuführen. Zwar berichten nur wenige Studien in der Tiermedizin von Fällen mit Tumor-Lyse-Syndromen, allerdings handelt es sich dabei fast ausschließlich um Lymphom-kranke Hunde unter Chemotherapie (Laing und Carter, 1987; Mylonakis et al., 2007).

Beim Vergleich der Wirksamkeit der Chemotherapie von Hunden der KC-Gruppe fiel folgendes auf: Nur 73,2 \% der Besitzer gaben an, dass die Chemotherapie eine oder mehrere Besserungen erzielen konnte. Aus tierärztlicher Sicht waren 83,7 \% aller Hunde in Remission. Zudem berichteten 61 Besitzer von einer „Verkleinerung der Lymphknoten“. Diese konnte in der Klinik bei 82 Hunden mit multizentrischem Lymphom festgestellt werden. Hier stellt sich 
die Frage, ob manchen Besitzern eine Remission oder speziell eine Verkleinerung der Lymphknoten nicht auffällt oder ob diese aufgrund des langen Befragungszeitraumes in Vergessenheit geraten ist. Womöglich sehen aber auch nicht alle Besitzer eine Remission automatisch als eine Verbesserung an - vor allem wenn weitere Erwartungen keine Erfüllung finden. Betrachtet man beispielsweise die Überlebenszeiten von denjenigen Hunden, deren Besitzer angaben, die Therapie konnte „keine Besserung“ erzielen (mediane Überlebenszeit: 32 Tagen), so kann auch die Enttäuschung von einer unterdurchschnittlichen Überlebenszeit diese Angaben begründen (Bronden et al., 2003). Der Zusammenhang zwischen der Zufriedenheit der Besitzer mit der Chemotherapie ihrer Hunde und den Überlebens- und Remissionszeiten der Tiere unterstützt diese Annahme.

Die Angaben der Besitzer zur Verträglichkeit der Therapie unterschieden sich in folgenden Punkten von denen der Tierärzte: Bei hämatologischen Toxizitäten (Grad I, II, III) kam es vor, dass diese von den Besitzern nicht als „häufig“ ( $n=17)$ oder als „schwerwiegend“ ( $n=$ 2) registriert wurden, solange die Hunde ein ungestörtes Allgemeinbefinden aufzeigten. Dies zeigt, dass Besitzer die Kosten- und Zeitbelastung, die ein Therapieaufschub mit sich bringt, als wenig belastend ansehen und untermauert folgende Vermutung von Bronden et al. (2003), Shaw und Lagoni (2007) und Bowles et al. (2010). Viele Besitzer sehen ihr Haustier als gleichwertiges Familienmitglied, dem sie intensive Therapien ermöglichen, auch wenn diese palliativen Charakter haben.

Ebenso wie in der Studie von Bronden et al. (2003) waren milde gastrointestinale Komplikationen die häufigsten klinische Nebenwirkungen. Zusätzlich hat die vorliegende Studie aufgezeigt, dass gastrointestinale Nebenwirkungen Grad II von einigen Besitzern als „schwerwiegend“ empfunden wurden $(\mathrm{n}=7)$. Dies zeigt, dass auch Störungen, die medizinisch nicht relevant sind, doch zu einer psychischen und physischen Belastung des Tierhalters führen können und daher vorbeugend behandelt werden sollten.

16 Besitzer gaben an, dass bei der Therapie ihrer Hunde Nebenwirkungen auftraten. Aus der Datenbank dieser Patienten ist zu entnehmen, dass weder vorberichtlich noch bei Vorstellung Nebenwirkungen bemerkt wurden. Es ist möglich, dass diejenigen Besitzer, deren Hunde nicht auf die Therapie ansprachen und infolge ihres Tumors eine klinische Verschlechterung erlitten $(n=12)$, diese Verschlechterung als Nebenwirkung der Therapie erachteten.

Ungeachtet den Überlebenszeiten als ein Maß für die Wirksamkeit der Therapie (Bronden et al., 2003) liegt der Nachteil dieser Studie in ihrem retrospektiven Charakter, denn einige Behandlungen lagen bis zu 13 Jahre zurück. In der Literatur wird der Einfluss des Befragungszeitpunktes auf die Patientenzufriedenheit kontrovers diskutiert. Es ist denkbar, 
dass manche Situationen stärker oder schwächer im Gedächtnis haften bleiben, eventuell Verzerrungen der Sichtweise vorliegen und so die Qualität der Antworten möglicherweise beeinflusst wird (Walker und Restuccia, 1984; Priebe und Gruyters, 1993; Tzannes et al., 2008). Dies unterstreicht die Notwendigkeit prospektiver Studien. Die Erkenntnisse und Erfahrungen der vorliegenden Studie könnten für zukünftige Untersuchungen hilfreich sein.

\section{Schlussfolgerung}

Die zytostatische Therapie wurde von den meisten Hunden - so auch aus Sicht der Besitzer gut vertragen. Regelmäßig zu erwartende Nebenwirkungen, die medizinisch nicht relevant erscheinen, wie Durchfall oder Erbrechen, können zu einer Belastung des Tierhalters führen und sollten vorbeugend behandelt werden. Die Dauer der Überlebenszeit ist als wichtiges Kriterium für die Zufriedenheit von Besitzern mit der erhaltenen Therapie - insbesondere bei der Aufklärung von Patienten mit negativen prognostischen Faktoren - zu berücksichtigen. Prospektive Studien können Vorstellungen und Ansichten des Tierarztes und des Besitzers im Vergleich noch genauer ermitteln. Die Ergebnisse helfen dem Praktiker, sich auf eventuelle Abweichungen in der Sichtweise der Besitzer einzustellen, sodass er diese bereits bei Therapiebeginn berücksichtigen kann.

\section{Danksagung}

Wir danken Frau Susanne Braun, Diplom-Psychologin aus dem Center for Leadership and People Management der Ludwig-Maximilians-Universität München für ihre Hilfe bei der Optimierung des Fragebogens.

\section{Literaturverzeichnis}

Abbo A, Lucroy M (2007): Assessment of anemia as an independent predictor of response to chemotherapy and survival in dogs with lymphoma: 96 cases (1993-2006). J Am Vet Med Assoc 231: 1836-42. 
Bowles D, Robson M, Galloway P, Walker L (2010): Owner's perception of carboplatin in conjunction with other palliative treatments for cancer therapy. J Small Anim Pract 51: 10412 .

Boyce K, Kitchell B (2000): Treatment of canine lymphoma with COPLA/LVP. J Am Anim Hosp Assoc 36: 395-403.

Bronden L, Rutteman G, Flagstad A, Teske E (2003): Study of dog and cat owners' perceptions of medical treatment for cancer. Vet Rec 125: 77-80.

Charney S, Bergman P, Hohenhaus A, McKnight J (2003): Risk factors for sterile hemorrhagic cystitis in dogs with lymphoma recieving cyclophosphamide with or without concurrent administration of furosemide: 216 cases (1990-1996). J Am Vet Med Assoc 222: 1388-93.

Chun R, Garrett L, Vail D (2007): Cancer Chemotherapy. In: Withrow SJ, MacEwen EG Small Animal Clinical Oncology, 4th edn., W.B. Saunders Company, Philadelphia, 163-92.

Chun R (2009): Lymphoma: which chemotherapy protocol and why? Top Companion Anim Med 24:157-62.

Couto C, Cullen J, Pedroia V, Turrel J (1984): Central nervous system lymphosarcoma in the dog. J Am Vet Med Assoc 184: 809-13.

Dobson J, Samuel S, Milstein H, Rogers K, Wood J (2002): Canine neoplasia in the UK: estimates of incidence rates from a population of insured dogs. J Small Animal Pract 43: 2406.

Dorn C, Taylor D, Schneider R, Hibbard H, Klauber M (1968): Survey of animal neoplasms in Alameda and Contra Costa Counties, California. II. Cancer morbidity in dogs and cats from Alameda County. J Natl Cancer Inst 40: 307-18.

Dorn C, Taylor D, Schneider R (1970): The epidemiology of canine leukemia and lymphoma. Bibl Haematol 36: 403-15. 
Fontaine J, Bovens C, Bettenay S, Mueller R (2009): Canine cutaneous epitheliotropic Tcell-lymphoma: a review. Vet Comp Oncol 7: 1-14.

Fowler B, Axiak S, DeClue A (29. Oktober - 01. November 2010): Blunted immune response in dogs with neoplesia [abstract]. VCS San Diego

Garrett L, Thamm D, Chun R, Dudley R, Vail D (2002): Evaluation of a 6-month chemotherapy protocol with no maintenance therapy for dogs with lymphoma. J Vet Intern Med 16: 704-9.

Hardy W, Old L (1970): L-asparaginase in the treatment of neoplastic disease of the dog, cat and cow. Recent Results Cancer Res 33: 131-139.

Hirschberger J (2001): Prinzipien der Chemotherapie beim Hund. Tieräztl Prax 29: 20-24.

Keller E, MacEwen E, Rosenthal R, Helfand S, Fox L (1993): Evaluation of prognostic factors and sequential combination chemotherapy with doxorubicin for canine lymphoma. $\mathrm{J}$ Vet Intern Med 7: 289-95.

Kristal O, Rassnick K, Gliatto J, Northrup N, Chretin, J, Morrison-Collister K, Cotter S, Moore A (2004): Hepatotoxicity associated with CCNU (lomustine) chemotherapy in dogs. J Vet Intern Med 18:75-80.

Laing E, Carter R (1987): Acute tumor lysis syndrome following treatment of canine lymphoma. J Am Anim Hosp Assoc 24: 691-696.

Lee J, Hughes C, Fine R, Page, R (1996): P-glycoprotein expression in canine lymphoma: a relevant, intermediate model of multidrug resistance. Cancer 77: 1892-8.

Masetti R, Pession A (2009): First-line treatment of acute lymphoblastic leukemia with pegasparaginase. Biologics 3: 359-68.

Mellanby R, Herrtage M, Dobson J (2003): Owners' assessments of their dog's quality of life during palliative chemotherapy for lymphoma. J Small Anim Pract 44: 100-3. 
Moore A, Leveille C, Reimann K, Shu H, Arias I (1995): The expression of P-glycoprotein in canine lymphoma and its association with multidrug resistance. Cancer Invest 13: 475-9.

Moore A, London C, Wood C, Williams L, Cotter S, L'Heureux D, Frimberger A (1999): Lomustine (CCNU) for the treatment of resistant lymphoma in dogs. J Vet Intern Med 13: 395-398.

Moore A, Cotter S, Rand W, Wood C, Williams L, London C, Frimberger A, L'Heureux D (2001): Evaluation of a discontinuous treatment protocol (VELCAP-S) for canine lymphoma. J Vet Intern Med 15: 348-54.

Mylonakis M, Koutinas A, Papaioannou N, Lekkas S (2007): Acute tumour lysis syndrome in a dog with B-Cell multicentric lymphoma. Aust Vet J 85: 206-8.

Myers N, 3rd, Moore A, Rand W, Gliatto J, Cotter S (1997): Evaluation of a multidrug chemotherapy protocol (ACOPA II) in dogs with lymphoma. J Vet Intern Med 11: 333-9.

Priebe S, Gruyters T (1993): The role of the helping alliance in psychiatric community care. A prospective study. J Nerv Men Dis 181: 552-7.

Shaw J, Lagoni L (2007): End-of-life communication in veterinary medicine: delivering bad news and euthanasia decision making. Veterinary Clinics of North America Small Animal Practice 37: 95-108.

Simon D, Nolte I, Eberle N, Abbrederis N, Killich M, Hirschberger J (2006): Treatment of dogs with lymphoma using a 12-week, maintenance-free combination chemotherapy protocol. J Vet Intern Med 20: 948-54.

Simon D, Moreno S, Hirschberger J, Moritz A, Kohn B, Neumann S, Jurina K, Scharvogel S, Schwedes C, Reinacher M, Beyerbach M, Nolte I (2008): Efficacy of a continuous, multiagent chemotherapeutic protocol versus a short-term single-agent protocol in dogs with lymphoma. J Am Vet Med Assoc 232: 879-85. 
Sorenmo K, Harwood L, King L, Drobatz K (2010): Case-control study to evaluate risk factors for the development of sepsis (neutropenia and fever) in dogs receiving chemotherapy. J Am Vet Med Assoc 236: 650-6.

Squire R, Bush M, Melby E, Neeley L, Yarbrough B (1973): Clinical and pathologic study of canine lymphoma: clinical staging, cell classification and therapy. $\mathbf{J}$ Natl Cancer Inst 51: $565-574$

Starrak G, Berry C, Page R, Johnson J, Thrall D (1997): Correlation between thoracic radiographic changes and remission/survival duration in 270 dogs with lymphosarcoma. Vet Radiol Ultrasound 38: 411-8.

Tomiyasu H, Takahashi M, Fujino Y, Ohno K, Tsujimoto H (2010): Gastrointestinal and Hematologic Adverse Events after Administration of Vincristine, Cyclophosphamide, and Doxorubicin in Dogs with Lymphoma that Underwent a Combination Multidrug Chemotherapy Protocol. J Vet Med Sci Jun 11.

Tzannes S, Hammond MF, Murphy S, Sparkes A, Blackwood L (2008): Owners' perception of their cats' quality of life during COP chemotherapy for lymphoma. J Feline Med Surg 10: 73-81.

Vail D, MacEwen E, Young K (2001): Canine lymphoma and lymphoid leukemias. In: Small Animal Clinical Oncology, 3rd edn., W.B. Saunders Company, Philadelphia, 558-590.

Vail D (2004): Veterinary Co-operative Oncology Group. Vet Comp Oncol 2: 194.

Valerius K, Ogilvie G, Mallinckrodt C, Getzy D (1997): Doxorubicin alone or in combination with asparaginase, followed by cyclophosphamide, vincristine, and prednisone for treatment of multicentric lymphoma in dogs: 121 cases (1987-1995). J Am Vet Med Assoc 210: 512-6.

Walker A, Restuccia J (1984): Obtaining information on patient satisfaction with hospital care: mail versus Telefone. Health Serv Res 19: 291-306. 
L'Heureux D, Gliatto J, Cotter S (1998): A combination chemotherapy protocol (VELCAPL) for dogs with lymphoma. J Vet Intern Med 12: 465-70.

Zenker I, Meichner K, Steinle K, Kessler M, Hirschberger J ("in press"): A 13-week Dose Intensifying Simultaneous Combination Chemotherapy (DISC) Protocol for Malignant Lymphoma in Dogs: 21 Cases. Vet Rec.

Korrespondenzadresse:

Michele Bergmann

Königinstrasse 45

80539 München

E-Mail: nicky.bergmann@googlemail.com

Telefon: $+49(0) 89$ / 97396704

Fax: $+(0) 89 / 2180-5913$

\section{Abbildungs- und Tabellenlegende}

Tab. 1 Auszug aus der CTCAE-Tabelle

Tab. 2 ,12-Wochen-DVG-Protokoll“, Anwendung bei 80 Hunden mit malignem Lymphom

Tab. 3 Dosierung und Applikationsmodus der verwendeten Therapeutika

Tab. 4 Remissionsstatus der Hunde in Abhängigkeit von den Behandlungsprotokollen ( $\mathrm{n}=$ 136)

Tab. 5 Remissionsstatus der Hunde in Abhängigkeit von der anatomischen Form sowie in Abhängigkeit vom Substage $(n=123)$

Tab. 6 Anzahl an Hunden der KC-Gruppe mit Nebenwirkungen auf das Symptom $(n=123)$

Tab. 7 „Asparaginase-Monotherapie“, Anwendung bei 13 Hunden mit malignem Lymphom 
Tab. 8 Einflussnahme der Überlebens- und Remissionszeit der am malignen Lymphom erkrankten und zytostatisch behandelten Hunde auf die Einstellung ihrer Besitzer gegenüber Chemotherapie (statistisch signifikante Unterschiede im Fettdruck) $(\mathrm{n}=122)$

\section{Tabellen}

Tab. 1 Auszug aus der CTCAE-Tabell

\begin{tabular}{|c|c|c|c|}
\hline \multicolumn{2}{|c|}{ Toxizität } & Grad & Definition \\
\hline \multirow{8}{*}{ 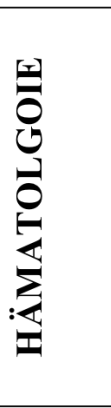 } & \multirow[t]{4}{*}{ Neutropenie } & 1 & $1,5 \times 10^{9} / \mathrm{L}-<\mathrm{LLN}$ \\
\hline & & 2 & $1,0-1,499 \times 10^{9} / \mathrm{L}$ \\
\hline & & 3 & $0,5-0,999 \times 10^{9} / \mathrm{L}$ \\
\hline & & 4 & $<0,5 \times 10^{9} / \mathrm{L}$ \\
\hline & \multirow{4}{*}{$\begin{array}{l}\text { Thrombozyto- } \\
\text { penie }\end{array}$} & 1 & $100 \times 10^{9} / \mathrm{L}-<\mathrm{LLN}$ \\
\hline & & 2 & $50-99 \times 10^{9} / \mathrm{L}$ \\
\hline & & 3 & $25-49 \times 10^{9} / \mathrm{L}$ \\
\hline & & 4 & $<25 \times 10^{9} / \mathrm{L}$ \\
\hline \multirow{8}{*}{ 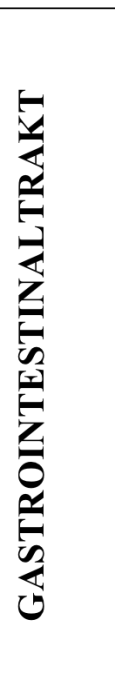 } & \multirow[t]{4}{*}{ Durchfall } & 1 & Kotabsatz $>2 \mathrm{mal} /$ Tag im Vergleich zu sonst \\
\hline & & 2 & $\begin{array}{l}\text { Kotabsatz }>2-6 \mathrm{mal} / \text { Tag im Vergleich zu sonst, } \\
\text { vorübergehender Flüssigkeitsersatz notwendig ( }<24 \mathrm{Std} .)\end{array}$ \\
\hline & & 3 & $\begin{array}{l}\text { Kotabsatz }>6 \mathrm{mal} / \mathrm{Tag} \text { im Vergleich zu sonst, Inkontinenz, } \\
\text { eingeschränkte ADL, intravenöse } \\
\text { Flüssigkeitstherapie/stationäre Aufnahme notwendig ( }>24 \\
\text { Std.) }\end{array}$ \\
\hline & & 4 & Lebensbedrohlicher Zustand (hämodynamischer Kollaps) \\
\hline & \multirow[t]{4}{*}{ Erbrechen } & 1 & $<3$ Episoden in $24 \mathrm{Std}$ \\
\hline & & 2 & $\begin{array}{l}\text { 3-5 Episoden in } 24 \text { Std., }<3 \text { Episoden/Tag für }>2 \text { Tage und } \\
<5 \text { Tage, vorübergehender Flüssigkeitsersatz notwendig } \\
\text { (<24 Std.) }\end{array}$ \\
\hline & & 3 & $\begin{array}{l}>5 \text { Episoden in } 24 \text { Std., Erbrechen }>4 \text { Tage, intravenöse } \\
\text { Flüssigkeitstherapie oder PPN/TPN notwendig ( }>24 \text { Std.) }\end{array}$ \\
\hline & & 4 & Lebensbedrohlicher Zustand (hämodynamischer Kollaps) \\
\hline \multirow{8}{*}{ 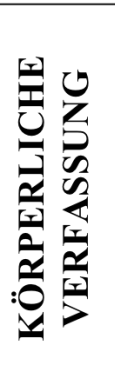 } & \multirow[t]{4}{*}{ Lethargie } & 1 & Milde Lethargie im Vergleich zu sonst \\
\hline & & 2 & Lethargie mit geringfügig eingeschränkter $\mathrm{ADL}$ \\
\hline & & 3 & ADL eingeschränkt, ambulante Unterstützung notwendig \\
\hline & & 4 & Keine ADL möglich \\
\hline & \multirow[t]{4}{*}{ Fieber } & 1 & $1^{\circ} \mathrm{C}$ über ULN \\
\hline & & 2 & $1-2^{\circ} \mathrm{C}$ über ULN \\
\hline & & 3 & $2-3^{\circ} \mathrm{C}$ über ULN \\
\hline & & 4 & $>3^{\circ} \mathrm{C}$ über ULN \\
\hline
\end{tabular}

LLN = Lower limit of normal; ULN = Upper limit of normal; ADL = activities of daily living (eating, sleeping, defecating and urinating)

Tab. 2 „12-Wochen-DVG-Protokoll“, Anwendung bei 80 Hunden mit malignem Lymphom

\begin{tabular}{|c|c|c|c|c|c|}
\hline Woche $^{1}$ & $\begin{array}{c}\text { L-Aspara- } \\
\text { ginase }\end{array}$ & Vincristin* & $\begin{array}{c}\text { Cyclophosphamid } \\
\text { + Furosemid* }\end{array}$ & Doxorubicin & $\begin{array}{c}\text { Prednisolon für } \\
\text { 3 Tage }\end{array}$ \\
\hline 1 & $\mathrm{X}$ & & & & $\mathrm{X}$ \\
\hline
\end{tabular}




\begin{tabular}{|c|c|c|c|c|c|}
\hline 2 & & $\mathrm{X}$ & & $\mathrm{X}$ \\
\hline 3 & & & $\mathrm{X}$ & $\mathrm{X}$ \\
\hline 4 & & & & $\mathrm{X}$ & $\mathrm{X}$ \\
\hline 5 & & $\mathrm{X}$ & $\mathrm{X}$ & $\mathrm{X}$ \\
\hline 6 & & & $\mathrm{X}$ & $\mathrm{X}$ \\
\hline 7 & & & & $\mathrm{X}$ & $\mathrm{X}$ \\
\hline 8 & & & & $\mathrm{X}$ & $\mathrm{X}$ \\
\hline 9 & & & $\mathrm{X}$ & $\mathrm{X}$ \\
\hline 10 & & $\mathrm{X}$ & $\mathrm{X}$ & $\mathrm{X}$ \\
\hline 11 & & & & & $\mathrm{X}$ \\
\hline 12 & & & & & $\mathrm{X}$ \\
\hline 13 & & & & & $\mathrm{X}$ \\
\hline
\end{tabular}

*Für das modifizierte DVG-Protokoll (kosten- und zeitsparende Variante) Vincristin durch Cyclophosphamid p. o. und Cyclophosphamid durch Chlorambucil p. o. ersetzen.

${ }^{1}$ Therapie verschieben (meist um 3 Tage) bei Neutrophilen $<3000 / \mu 1$ oder Thrombozyten $<$ 100 000/ $\mu 1$. Bei gutem Allgemeinbefinden und Neutrophilen $<2000 / \mu 1$ Therapie verschieben und antibiotische Behandlung (12,5 mg/kg $2 \times \mathrm{tgl}$. Amoxicillin/Clavulansäure für 5 Tage). Bei schlechtem Allgemeinbefinden und/oder Fieber parenterale, am besten intravenöse Antibiotikagabe (Amoxicillin/Clavulansäure und Enrofloxacin), und zusätzlich unterstützende stationäre Therapie wie für Sepsis.

Tab. 3 Dosierung und Applikationsmodus der verwendeten Therapeutika 


\begin{tabular}{|c|c|c|}
\hline Medikament & Dosierung & Anmerkung \\
\hline Vincristin & $0,7 \mathrm{mg} / \mathrm{m}^{2}$ i. v. & als Bolus streng i. v. \\
\hline Vinblastin & $2 \mathrm{mg} / \mathrm{m}^{2}$ i. v. & als Bolus streng i. v. \\
\hline L-Asparaginase & $400 \mathrm{IU} / \mathrm{kg}$ s. c. & $\begin{array}{c}\text { Inj. in s. c. } 0,9 \% \text { iges NaCl-Depot; } \\
15 \mathrm{Minuten} \text { vor Injektion } \\
0,2 \mathrm{mg} / \mathrm{kg} \text { Dexamethason s. c. }\end{array}$ \\
\hline Cyclophosphamid & $\begin{array}{l}200 \mathrm{mg} / \mathrm{m}^{2} \text { i. v. oder } 250 \mathrm{mg} / \mathrm{m}^{2} \\
\text { p. o. }\end{array}$ & $\begin{array}{c}\text { vormittags applizieren, damit } \\
\text { toxische Metaboliten nicht über } \\
\text { Nacht in der Harnblase verweilen } \\
+ \text { Furosemid }\end{array}$ \\
\hline Doxorubicin & $\begin{array}{c}30 \mathrm{mg} / \mathrm{m}^{2} \text { i. v. } \\
(<10 \mathrm{~kg} \mathrm{KM}: 1 \mathrm{mg} / \mathrm{kg} \mathrm{KM})\end{array}$ & $\begin{array}{c}\text { streng i. v. über } 30 \mathrm{~min} \\
\text { Dauertropfinfusion mit } 0,9 \% \\
\mathrm{NaCl} \text { verdünnt }(1: 10) ; \text { evtl. } \\
15 \text { Minuten vor Infusion } 0,2 \mathrm{mg} / \mathrm{kg} \\
\text { Dexamethason i. v. }\end{array}$ \\
\hline Prednisolon & $2 \mathrm{mg} / \mathrm{kg}$ p. o. & $\begin{array}{l}\text { mit dem Tag der Chemotherapie } \\
\text { beginnend } 3 \text { Tage lang täglich }\end{array}$ \\
\hline Lomustin & $60-90 \mathrm{mg} / \mathrm{m}^{2}$ p. o. & $\begin{array}{c}\text { alle } 3 \text { Wochen; BB-Kontrolle an } \\
\text { Tag } 7 \text { und an Tag } 21\end{array}$ \\
\hline Chlorambucil & $12,5 \mathrm{mg} / \mathrm{m}^{2}$ p. o. & $\begin{array}{c}\text { Je an } 2 \text { aufeinander folgenden } \\
\text { Tagen }\end{array}$ \\
\hline Furosemid & $0,5 \mathrm{mg} / \mathrm{kg} 2 \times$ tgl. p. o. & für 2 Tage Therapie-begleitend \\
\hline
\end{tabular}


Tab. 4 Remissionsstatus der Hunde in Abhängigkeit von den Behandlungsprotokollen ( $\mathrm{n}=$ 136)

\begin{tabular}{|c|c|c|c|c|c|c|}
\hline & \multicolumn{5}{|c|}{ Chemotherapieprotokolle } & \multirow[b]{2}{*}{$\begin{array}{l}\text { Asparaginase- } \\
\text { Monotherapie }\end{array}$} \\
\hline & DVG & DISC & $\begin{array}{l}\text { Orale } \\
\text { Chemo- } \\
\text { therapie }\end{array}$ & $\begin{array}{c}\text { Modifi- } \\
\text { ziertes } \\
\text { DVG- } \\
\text { Protokoll }\end{array}$ & $\begin{array}{l}\text { Doxoru- } \\
\text { bicin- } \\
\text { Monothera- } \\
\text { pie }\end{array}$ & \\
\hline Remissionen & 67 & 26 & 6 & 2 & 2 & 5 \\
\hline davon CR & 51 & 20 & 5 & 2 & 2 & 2 \\
\hline davon PR & 16 & 6 & 1 & - & - & 3 \\
\hline $\begin{array}{c}\text { Keine } \\
\text { Remission }\end{array}$ & 13 & - & 4 & - & 3 & 7 \\
\hline Gesamt (n) & 80 & 26 & 10 & 2 & 5 & 13 \\
\hline
\end{tabular}

Tab. 5 Remissionsstatus der Hunde der KC-Gruppe in Abhängigkeit von der anatomischen Form sowie in Abhängigkeit vom Substage $(\mathrm{n}=123)$

\begin{tabular}{|c|c|c|c|c|c|}
\hline & CR & PR & $\begin{array}{c}\text { Keine } \\
\text { Remission }\end{array}$ & Gesamt & $\begin{array}{c}\text { Mediane } \\
\text { Ubberlebenszeit } \\
\text { in Tagen }\end{array}$ \\
\hline Multizentrisch & $62(73,8 \%)$ & $11(13,1 \%)$ & $11(13,1 \%)$ & $84(100 \%)$ & 373 \\
\hline Mediastinal & $11(55,0 \%)$ & $6(30,0 \%)$ & $3(15,0 \%)$ & $20(100 \%)$ & \multirow{2}{*}{117} \\
\cline { 1 - 4 } Gastrointestinal & $2(22,2 \%)$ & $4(44,5 \%)$ & $3(33,3 \%)$ & $9(100 \%)$ & \multirow{2}{*}{$10(100 \%)$} \\
\hline Extranodal & $5(50,0 \%)$ & $2(20,0 \%)$ & $3(30,0 \%)$ & 324 \\
\hline Substage a & $27(84,4 \%)$ & $2(6,2 \%)$ & $3(9,4 \%)$ & $32(100 \%)$ & 247 \\
\hline Substage b & $53(58,2 \%)$ & $21(23,1 \%)$ & $17(18,7 \%)$ & $91(100 \%)$ & \\
\hline
\end{tabular}

Tab. 6 Anzahl an Hunden der KC-Gruppe mit Nebenwirkungen auf das Symptom $(\mathrm{n}=123)$

\begin{tabular}{|l|c|c|c|c|}
\hline Organsystem & Gesamt & Grad I, II & Grad III, IV & Keine Toxizität \\
\hline Neutropenie & $48(39,0 \%)$ & $42(34,1 \%)$ & $13(10,6 \%)$ & $75(61,0 \%)$ \\
\hline Thrombozytopenie & $14(11,4 \%)$ & $11(8,9 \%)$ & $3(2,4 \%)$ & $109(88,6 \%)$ \\
\hline Gastrointestinal & $36(29,3 \%)$ & $36(29,3 \%)$ & - & $87(70,7 \%)$ \\
\hline Apathie/Lethargie & $5(4,1 \%)$ & $4(3,3 \%)$ & $1(0,8 \%)$ & $118(95,9 \%)$ \\
\hline Fieber/Sepsis & $8(6,5 \%)$ & $3(2,4 \%)$ & $5(4,1 \%)$ & $115(93,5 \%)$ \\
\hline
\end{tabular}




\begin{tabular}{|l|c|c|c|c|}
\hline Zystitis & $1(0,8 \%)$ & $1(0,8 \%)$ & - & $122(99,2 \%)$ \\
\hline Akute Arrythmien & $1(0,8 \%)$ & $1(0,8 \%)$ & - & $122(99,2 \%)$ \\
\hline Alopezie & $15(12,2 \%)$ & $15(12,2 \%)$ & - & $108(87,8 \%)$ \\
\hline
\end{tabular}

Tab. 7 „Asparaginase-Monotherapie“, Anwendung bei 13 Hunden mit malignem Lymphom

\begin{tabular}{|c|c|c|c|c|}
\hline Tag & 1 & 2 & 3 & \multirow{4}{*}{$\begin{array}{l}\text { Erneute Gaben bei } \\
\text { Rezidiv mit erhöhtem } \\
\text { Risiko auf } \\
\text { anaphylaktische } \\
\text { Reaktionen möglich }\end{array}$} \\
\hline Hexadreson & $\mathrm{X}$ & & & \\
\hline L-Asparaginase & $X$ & & & \\
\hline Prednisolon & & $\mathrm{X}$ & $\mathrm{X}$ & \\
\hline
\end{tabular}

Tab. 8 Einflussnahme der Überlebens- und Remissionszeit der am malignen Lymphom erkrankten Hunde der KC-Gruppe auf die Zufriedenheit ihrer Besitzer mit der Chemotherapie (statistisch signifikante Unterschiede im Fettdruck) $(\mathrm{n}=122)$

\begin{tabular}{|c|c|c|c|c|}
\hline & \multicolumn{3}{|c|}{$\begin{array}{c}\text { "Welche Aussage repräsentiert am besten Ihre Gefühle } \\
\text { gegenüber Chemotherapie heute?“" }\end{array}$} & \multirow[b]{2}{*}{ p } \\
\hline & $\begin{array}{l}\text { „Ich bin froh, meinen } \\
\text { Hund behandelt haben } \\
\text { zu lassen“" }\end{array}$ & $\begin{array}{l}\text { "Ich bedauere es, } \\
\text { meinen Hund } \\
\text { behandelt haben zu } \\
\text { lassen“ }\end{array}$ & $\begin{array}{l}\text { „Ich bin } \\
\text { unsicher" }\end{array}$ & \\
\hline $\begin{array}{l}\text { Mediane } \\
\text { Überlebenszeit in } \\
\text { Tagen }\end{array}$ & 393 & 30 & 200 & $<\mathbf{0 , 0 0 1}$ \\
\hline $\begin{array}{l}\text { Mediane } \\
\text { Remissionszeit in } \\
\text { Tagen }\end{array}$ & 230 & 9 & 67 & $<\mathbf{0 , 0 0 1}$ \\
\hline
\end{tabular}




\section{DISKUSSION}

Bei der Therapie des malignen Lymphoms handelt es sich um eine in erster Linie palliative Behandlung (ETTINGER, 2003). Obwohl in der Literatur viele Angaben zu verschiedenen Chemotherapie-Protokollen vorliegen, gibt es bisher nur eine Studie, die die Lebensqualität von Hunden mit malignem Lymphom unter Chemotherapie krankheitsspezifisch berücksichtigt (MELLANBY et al., 2003). Erfahrungsberichte aus der Perspektive deutscher Hundehalter existieren diesbezüglich bislang noch nicht. Haustiere nehmen kulturell einen unterschiedlichen Stellenwert ein, sodass von unterschiedlichen Erwartungen der Halter an die medizinische Versorgung ihrer Tiere auszugehen ist, insbesondere im Rahmen einer Tumorbehandlung. Dies macht hierzulande eine entsprechende Analyse erforderlich.

Ziel war es deshalb, den Erfolg der palliativen Chemotherapie Lymphom-kranker Hunde insbesondere in Bezug auf ihre Lebensqualität $\mathrm{zu}$ evaluieren, einen Überblick über die Einstellungen betroffener Hundebesitzer gegenüber Chemotherapie zu bekommen und herauszufinden, welche Faktoren für die Besitzer bei der Einschätzung der Lebensqualität ihrer Tiere sowie für ihre Gesamtbewertung der Therapie eine entscheidende Rolle spielten. Zusätzlich wurden die Wirksamkeit und die Verträglichkeit der Chemotherapie anhand von Remissionsstatus, Remissions- und Überlebenszeiten sowie den einheitlichen Bezeichnungsweisen der „Veterinary Co-operative Oncology Group“ evaluiert und den Beobachtungen der Hundebesitzer gegenübergestellt (VAIL, 2004). Der Vergleich dieser Auswertungen mit der subjektiven Beurteilung der Therapie aus Sicht der Hundehalter zeigt darüber hinaus, inwiefern diese von der tierärztlichen Sicht abweicht.

\subsection{Material und Methoden}

In diese Studie wurden alle an einem malignen Lymphom erkrankten Hunde aufgenommen, die eine oder mehrere Dosen an Chemotherapie erhalten haben und deren Besitzer sich zur Teilnahme an der Studie bereit erklärten. Die Analyseform basierte auf der „Intention-to-treat“. So fielen alle Hunde von Besitzern, die sich im Voraus für eine volle chemotherapeutische Behandlung entschlossen haben, in die Gruppe Kombinations-Chemotherapie (KC-Gruppe) - 
ungeachtet dessen, wie die Medikamente appliziert wurden (i. v. oder oral), welche Protokolle (Kombinations- oder Monotherapie) gewählt wurden und ob die Behandlung schon nach der einleitenden Gabe von Asparaginase abgebrochen wurde. Hierbei wären im Sinne einer besseren Vergleichbarkeit einheitlichere Therapiebedingungen sicherlich wünschenswert gewesen. Nichtsdestotrotz erhielt die Mehrheit der Patienten miteinander vergleichbare Protokolle (,DISCProtokoll“, ,12-Wochen-DVG-Protokoll“, , „Doxorubicin-Monotherapie“) (VALERIUS et al., 1997; SIMON et al., 2008; ZENKER et al., 2009). 12 Patienten bekamen abweichende Protokolle („modifiziertes DVG-Protokoll“, „orale Chemotherapie“). Berücksichtigt man aber, dass im Verlauf jeder Chemotherapie Lymphom-kranker Hunde - aus tierärztlicher Sicht oder aus persönlichen Gründen der Besitzer - Anpassungen oder gar Protokolländerungen notwendig sein können, dann lassen sich die Ergebnisse dieser Studie auf die Grundgesamtheit Lymphom-kranker Patienten übertragen (SIMON et al., 2006; CHUN, 2009).

Zur Bewertung der Therapie aus Sicht der Besitzer wurde eine schriftliche Befragung vorgenommen. Eine Befragung per Telefon, wie sie Mellanby und Mitarbeiter (2003) durchführten, hätte womöglich mehr beantwortete Fragebogen erbracht. Dennoch wurde die schriftliche Befragung dem Interviewverfahren vorgezogen. Sie hatte den Vorteil, dass die Hundebesitzer nicht unter Zeitdruck standen. Zusätzlich konnte eine hohe Anonymität gewährleistet werden und Antworten im Sinne der sozialen Erwünschtheit ließen sich so vermeiden (RUPPANER, 1972; MELLANBY et al., 2002).

Der Nachteil dieser Studie liegt in ihrem retrospektiven Charakter, denn einige Behandlungen lagen bis zu 13 Jahre zurück. In der Literatur wird der Einfluss des Befragungszeitpunktes auf die Patientenzufriedenheit kontrovers diskutiert (WALKER \& RESTUCCIA, 1984; PRIEBE \& GRUYTERS, 1993). Denkbar ist, dass manche Situationen stärker oder schwächer im Gedächtnis haften bleiben, eventuell verzerrte Sichtweisen vorliegen und dies die Qualität der Antworten beeinflusst (WALKER \& RESTUCCIA, 1984; PRIEBE \& GRUYTERS, 1993; TZANNES et al., 2008). TZANNES und Mitarbeiter (2008) konnten keinen statistisch signifikanten Zusammenhang zwischen dem Zeitpunkt der Diagnose am malignen Lymphom erkrankter Katzen und der retrospektiven Bewertung der Lebensqualität durch die Besitzer nachweisen. Inwiefern sich dies auf die 
Validität ihrer Daten auswirkt, wird nicht diskutiert. BOWLES und Mitarbeiter (2010) sehen einen Validitätsnachweis in dem Vergleich der Besitzerangaben mit den Krankenakten der Patienten. Aus Sicht des Autors der hier vorliegenden Studie können auf diese Weise Einschätzungen zwar vorgenommen werden, doch ist zu bedenken, dass die subjektive Beurteilung der Therapie durch den Besitzer generell von der tierärztlichen Sicht abweichen könnte. Zudem stellt sich die Frage, ob es für Tierbesitzer womöglich schwierig ist, zwischen Nebenwirkungen der Therapie und krankheitsbedingten Symptomen $\mathrm{zu}$ unterscheiden. Die Möglichkeit einer eingeschränkten Erinnerung der Besitzer sowie potentiell abweichende Sichtweisen unterstreichen die Notwendigkeit prospektiver Studien, in denen die Beobachtungen der Hundebesitzer denen des Tierarztes gegenübergestellt werden. Die Erkenntnisse und Erfahrungen der vorliegenden Studie könnten für solch zukünftige Studien hilfreich sein.

\subsection{Besitzerumfrage}

Die Rücklaufquote des Fragebogens betrug 59,4\% und findet sich somit im unteren Bereich von zuvor veröffentlichten Lebensqualitätsumfragen in der onkologischen Veterinärmedizin (BRONDEN et al., 2003; MELLANBY et al., 2003; TZANNES et al., 2008; BOWLES et al., 2010). Ein Grund hierfür ist sicherlich die zum Teil schon lange zurückliegende Chemotherapie. Dennoch stellt sich die Frage, ob diese niedrige Rücklaufquote eine Unzufriedenheit etwa mit der durchgeführten Therapie widerspiegelt und ob Besitzer, deren Hunde erfolgreich behandelt wurden, womöglich motivierter waren, den Fragebogen zu beantworten (ASCH et al., 1997; EDWARDS et al., 2007). Die unterschiedliche Resonanz zeigt allerdings, dass vielfältige Teilnehmer vertreten waren und lässt somit auf repräsentative Ergebnisse schließen (MELLANBY et al., 2003; BOWLES et al., 2010).

85 Besitzer (73,3 \%) gaben an, dass die Chemotherapie ihres Hundes mit Nebenwirkungen einherging. Auch wenn der mehrheitliche Teil der Besitzer diese als „selten“ und „unbedeutend“ einstufte, waren sie dennoch neben dem Remissionsstatus als signifikanter Faktor für die Beurteilungen der Lebensqualität der Hunde unter Chemotherapie entscheidend. So konnte nur bei 64 Hunden $(53,3 \%)$ eine Steigerung der Lebensqualität erreicht werden, obwohl es bei 90 Hunden zu einer Besserung der Symptome kam. Diese Ergebnisse sind nicht 
vergleichbar mit den Erfolgen, von denen MELLANBY und Mitarbeiter (2003) berichten. Dabei ist aber zu berücksichtigen, dass in der vorliegenden Studie alle an einem malignen Lymphom erkrankten Hunde mit zytostatischer Therapie aufgenommen wurden, unabhängig von anatomischem Stadium oder eventueller Vorbehandlung mit Glukokortikoiden. Zudem lag der Anteil an Patienten mit Substage $b$ in der vorliegenden Studie weit über dem in der Studie von MELLANBY und Mitarbeitern (2003). Das eigene Patientengut wies somit einen deutlich höheren Anteil an Faktoren auf, die bekanntlich mit einer schlechteren Prognose einhergehen (COUTO et al., 1984; KELLER et al., 1993; LEE et al., 1996; FONTAINE et al., 2009; RASSNICK et al., 2009). Zusätzlich fielen in der vorliegenden Studie bei der Auswertung der Lebensqualität widersprüchliche Angaben von 15 Besitzern (12,5 \%) auf. Diese schätzen die Lebensqualität ihres Hundes vor und während der Chemotherapie zwar als gleichbleibend ein, gaben weiter unten im Fragebogen jedoch an, dass ihre Erwartungen an die Chemotherapie unter anderem durch eine „Verbesserung des Allgemeinbefindens und der Lebensqualität“ ihres Tieres erfüllt wurden.

Folgende Erklärungen lassen sich hierfür in Betracht ziehen:

Zum einen ist es denkbar, dass die Antwortmöglichkeiten nach Notenpunkten keine Feinabstimmung zuließ und sich die Lebensqualität der Hunde während der Chemotherapie im Vergleich zur Situation davor nur geringfügig veränderte, sodass diese als gleichbleibend gewertet wurde. Möglicherweise haben aber auch Schwankungen der Lebensqualität unter Chemotherapie die Beurteilung schwierig gestaltet.

Hier stellt sich die Frage, ob eine einmalige Bewertung der Lebensqualität unter Therapie ausreichend war. Um die Lebensqualität möglichst genau zu evaluieren, müssen Befragungen prospektiv durchgeführt werden. Die therapiebegleitende Beurteilung der Lebensqualität sollte zudem konstant erfolgen und ggf. durch quantitative Erhebungen ergänzt werden (z. B. das Verhältnis von „guten“ und „schlechten Tagen“ zwischen den jeweiligen Therapiesitzungen).

Zusammenfassend lässt dich feststellen, dass sich die Lebensqualität der meisten Hunde durch die Therapie besserte. So lag die mediane Bewertung der Lebensqualität zum Zeitpunkt der Diagnosestellung bei ,3“ und ist somit als „mittelmäßig“ zu betrachten. Während der Chemotherapie verbesserte sich dieser 
Wert auf „2“ und ist demnach als „gut“ zu bewerten.

Insgesamt war der Großteil der Besitzer (65,0\%) im Nachhinein zufrieden mit der palliativen Chemotherapie ihres Hundes und 90 Besitzer (73,2\%) würden sich heute erneut für eine solche Therapie entscheiden. Dies bestätigt die Ergebnisse anderer Umfragen in der veterinärmedizinischen Onkologie (VON WETHERN et al., 1999; BRONDEN et al., 2003; MELLANBY et al., 2003; TZANNES et al., 2008; BOWLES et al., 2010). Zusätzlich zeigte die vorliegende Studie, dass sich vor allem Besitzer, deren Hunde sehr lange Remissions- und Überlebenszeiten erreichten, erneut zu einer Chemotherapie entschließen würden, unabhängig von den Nebenwirkungen der Behandlung. Diese Ergebnisse untermauern die Vermutungen von TZANNES und Mitarbeitern (2008) und BOWLES und Mitarbeitern (2010): Besitzer tolerieren in gewisser Weise eine Reduktion der Lebensqualität ihrer Hunde, solange deren Leben durch die Behandlung verlängert werden kann.

\subsection{Wirksamkeit der Chemotherapie}

Die Remissionsrate der Hunde der KC-Gruppe lag bei 83,7 \% mit einer kompletten Remission (CR) von 65,0 \%. Ein Grund für diese vergleichsweise niedrige Rate von Tieren in kompletter Remission liegt sicherlich in den uneinheitlichen Therapiebedingungen, denn einige Patienten erhielten eine Monotherapie oder eine rein orale Therapie mit Alkylanzien. So hatten Hunde, die mit einem Polychemotherapie-Protokoll (,12-Wochen-DVG-Protokoll“, „DISCProtokoll“, „modifiziertes DVG-Protokoll“) behandelt wurden, eine Remissionsrate von 88,0\% (CR 67,6\%). Diese ist nicht vergleichbar mit den Ergebnissen, von denen Garrett und Mitarbeiter (2002) berichten (CR 92,3\%), liegt aber im mittleren Bereich der Ergebnisse von anderen zuvor veröffentlichen Studien (MOORE et al., 2001; SIMON et al., 2006; SIMON et al., 2008; ZENKER et al., 2009). Ein weiterer möglicher Grund für die geringe komplette Remissionsrate der KC-Gruppe ist die Entwicklung multipler Medikamentenresistenzen, die durch die häufigen Vorbehandlungen mit Prednisolon bedingt sein könnten. Diese sind vor allem beim malignen Lymphom beschrieben (MOORE et al., 1995; LEE et al., 1996).

Weiterhin könnte die Rate durch die Tatsache erklärbar sein, dass 11 Besitzer die 
Therapie schon nach einer einmaligen Behandlung abbrachen. Zudem lag der Anteil an Tieren, die bereits mit Substage b vorgestellt wurden, bei 74,0 \%. Der prozentuale Anteil an Hunden mit gestörtem Allgemeinbefinden der vorher erwähnten Studien hingegen lag bei 39,0 \%, 56,2 \% und 63,6 \% (MOORE et al., 2001; SIMON et al., 2006, SIMON et al., 2008). Des Weiteren kann auch der hohe Anteil mediastinaler Lymphome $(n=20)$, die eine ungünstigere Prognose als das multizentrische Lymphom haben, für die geringe komplette Remissionsrate verantwortlich sein (STARRAK et al., 1997).

\subsection{Verträglichkeit der Chemotherapie}

Die Nebenwirkungen der Therapie der Hunde aus der KC-Gruppe waren zumeist mild (Grad I und II) und medizinisch gut zu kontrollieren. Dennoch waren sie in 2 Fällen mit letalen Folgen verbunden. Ein Patient verstarb an den Folgen einer Überdosierung in einer anderen Klinik. Ein weiterer Hund verstarb an den Komplikationen einer Bluttransfusion im Rahmen seiner Sepsis-Behandlung. Andere Studien zeigten ähnliche Mortalitätsraten. In der Studie von MOORE und Mitarbeitern (2001) beispielsweise wurde ein Multi-Chemotherapie-Protokoll ohne Erhaltungsphase evaluiert. Im Therapieverlauf starben 3 von insgesamt 82 Patienten an Sepsis; in der Studie von SIMON und Mitarbeitern (2006), die die Therapie von 77 Patienten evaluierte, verstarb ein Patient.

Insgesamt wurden in der hier vorliegenden Studie 6 Fälle (4,9 \%) von Sepsis beobachtet. Bei 2 Patienten waren diese mit Lomustin assoziiert, einem Alkylanz, das zur Therapie des kutanen T-Zell-Lymphoms eingesetzt wurde und für seine myelosuppressive Wirkung bekannt ist (MOORE et al., 1999; KRISTAL et al., 2004).

Obwohl die Sepsis in der Tiermedizin als eine seltene Komplikation der Chemotherapie gilt, besteht einer neuen Studie zufolge bei Hunden mit malignem Lymphom eine größere Gefahr, eine Sepsis zu entwickeln, als bei jenen, die aufgrund eines soliden Tumors chemotherapiert werden (CHUN et al., 2007; SORENMO et al., 2010). SORENMO und Mitarbeiter (2010) vermuten, dass dies mit der Immunsuppression Lymphom-kranker Hunde in Zusammenhang steht. So erkrankten Lymphom-Patienten vor allem im frühen Therapieverlauf der Induktionsphase, wenn zumeist noch keine Remission erreicht war, insbesondere nach der Gabe von Doxorubicin und Vincristin. Eine Immundysfunktion konnte 
von FOWLER und Mitarbeitern (2010) kürzlich bei Hunden mit malignem Lymphom nachgewiesen werden. Obwohl Vincristin längere Zeit als nicht sonderlich nebenwirkungsreich galt, zeigten auch TOMIYASU und Mitarbeiter (2010), dass die Inzidenz schwerwiegender Komplikationen vor allem bei Patienten im fortgeschrittenen Krankheitsstadium nach Vincristingabe höher ist, als bislang vermutet. Zudem ist in der vorliegenden Studie aufgefallen, dass 4 der 6 Sepsis-Patienten ein durchschnittliches Körpergewicht von 12,6 kg (Min.: 8,8 kg; Max.: 21,8 kg) aufwiesen. Hunde mit einem niedrigen Körpergewicht besitzen ein erhöhtes Risiko unter Chemotherapie eine Sepsis zu entwickeln (SORENMO et al., 2010).

Neben den bereits aufgeführten Komplikationen waren die Nebenwirkungen der Therapie sonst akzeptabel. Die häufigsten Komplikationen waren asymptomatische Neutropenien und gastrointestinale Beschwerden. Keiner der betroffenen Hunde musste aufgrund dieser Nebenwirkungen hospitalisiert werden. Im Verlauf der Therapie mit Cyclophosphamid trat - obwohl 26 Patienten des „DISC-Protokolls“ sogar wöchentlich mit Cyclophosphamid therapiert wurden nur bei einem Hund eine sterile hämorrhagische Zystitis auf. Bei allen übrigen Hunden konnte die begleitende Verabreichung von Furosemid dieser aber vorbeugen. Furosemid beschleunigt die Ausscheidung des toxischen Cyclophosphamid-Metaboliten, des Acroleins, der sonst eine sterile hämorrhagische Zystitis auslösen kann. Laut Literatur zeigen nur 1,2 \% aller mit Cyclophosphamid plus Furosemid behandelten Hunde Symptome einer hämorrhagischen Zystitis (CHARNEY et al., 2003).

Apathie/Lethargie (Grad III) wurde bei einem Hund ein paar Tage nach therapieeinleitender Asparaginasegabe beobachtet ohne Hinweise auf mögliche anaphylaktische Reaktionen, die für L-Asparaginase beschrieben sind (MASETTI \& PESSION, 2009). Dieser Hund war eine Woche später in kompletter Remission und klinisch unauffällig, sodass es wahrscheinlicher ist, diese Beschwerden auf ein Tumor-Lyse-Syndrom zurückzuführen. Zwar berichten nur wenige Studien in der Tiermedizin von Fällen mit Tumor-Lyse-Syndromen, allerdings handelt es sich dabei fast ausschließlich um Lymphom-kranke Hunde unter Chemotherapie (LAING \& CARTER, 1987; MYLONAKIS et al., 2007). 


\subsection{Wirksamkeit und Verträglichkeit - Vergleich mit der subjektiven Beruteilung aus Sicht der Besitzer}

Beim Vergleich der Wirksamkeit der Chemotherapie von Hunden der KC-Gruppe fiel folgendes auf: Nur 73,2 \% der Besitzer gaben an, dass die Chemotherapie eine oder mehrfache Besserungen erzielen konnte. Aus tierärztlicher Sicht waren $83,7 \%$ aller Hunde in Remission. Zudem berichteten 61 Besitzer von einer „Verkleinerung der Lymphknoten“. Diese konnte in der Klinik bei 82 Hunden mit multizentrischem Lymphom festgestellt werden. Hier stellt sich die Frage, ob manchen Besitzern eine Remission oder speziell eine Verkleinerung der Lymphknoten nicht auffällt oder ob diese aufgrund des langen Befragungszeitraumes in Vergessenheit geraten ist. Womöglich sehen aber auch nicht alle Besitzer eine Remission automatisch als eine Verbesserung an - vor allem wenn weitere Erwartungen keine Erfüllung finden. Betrachtet man beispielsweise die Überlebenszeiten von denjenigen Hunden, deren Besitzer angaben, die Therapie konnte „keine Besserung“ erzielen (mediane Überlebenszeit: 32 Tagen), so kann auch die Enttäuschung von einer unterdurchschnittlichen Überlebenszeit diese Angaben begründen (BRONDEN et al., 2003). Der Zusammenhang zwischen der Zufriedenheit der Besitzer mit der Chemotherapie ihrer Hunde und den Überlebens- und Remissionszeiten der Tiere unterstützt diese Annahme.

Die Angaben der Besitzer zur Verträglichkeit der Therapie unterschieden sich in folgenden Punkten von denen der Tierärzte: Bei hämatologischen Toxizitäten (Grad I, II, III) kam es vor, dass diese von den Besitzern nicht als „häufig“ (n $=17)$ oder als ,schwerwiegend“ $(\mathrm{n}=2)$ registriert wurden, solange die Hunde ein ungestörtes Allgemeinbefinden aufzeigten. Dies zeigt, dass Besitzer die Kostenund Zeitbelastung, die ein Therapieaufschub mit sich bringt, als wenig belastend ansehen und untermauert folgende Vermutung von BRONDEN und Mitarbeitern (2003), SHAW und LAGONI (2007) und BOWLES und Mitarbeitern (2010). Viele Besitzer sehen ihr Haustier als gleichwertiges Familienmitglied, dem sie intensive Therapien ermöglichen, auch wenn diese palliativen Charakter haben.

Ebenso wie in der Studie von BRONDEN und Mitarbeitern (2003) waren milde gastrointestinale Komplikationen die häufigsten klinischen Nebenwirkungen. Zusätzlich hat die vorliegende Studie aufgezeigt, dass gastrointestinale 
Nebenwirkungen Grad II von einigen Besitzern als „schwerwiegend“ empfunden wurden $(n=7)$. Dies zeigt, dass auch Störungen, die medizinisch nicht relevant sind, doch zu einer psychischen und physischen Belastung des Tierhalters führen können und daher vorbeugend behandelt werden sollten.

16 Besitzer gaben an, dass bei der Therapie ihrer Hunde Nebenwirkungen auftraten. Aus der Datenbank dieser Patienten ist $\mathrm{zu}$ entnehmen, dass weder vorberichtlich noch bei Vorstellung Nebenwirkungen bemerkt wurden. Es ist möglich, dass diejenigen Besitzer, deren Hunde nicht auf die Therapie ansprachen und infolge ihres Tumors eine klinische Verschlechterung erlitten $(n=12)$, diese Verschlechterung als Nebenwirkung der Therapie erachteten.

\subsection{Schlussfolgerung}

Die zytostatische Therapie wurde von den meisten Hunden - so auch aus Sicht der Besitzer - gut vertragen. Regelmäßig zu erwartende Nebenwirkungen, die medizinisch nicht relevant erscheinen, wie Durchfall oder Erbrechen, können zu einer Minderung der Lebensqualität des Patienten sowie zu einer Belastung des Tierhalters führen und sollten daher vorbeugend behandelt werden. Die Dauer der Überlebenszeit ist als wichtiges Kriterium für die Zufriedenheit von Besitzern mit der erhaltenen Therapie ebenso für die erneute Therapiewahl zu berücksichtigen, insbesondere bei der Aufklärung von Patienten mit negativen prognostischen Faktoren.

Die Erfassung der Lebensqualität muss therapiebegleitend und konstant erfolgen. Nur so kann sie bei der Auswahl geeigneter Chemotherapie-Protokolle helfen und zusätzlich dem Besitzer und Tierarzt die Entscheidung für den weiteren Verlauf der Therapie erleichtern. Dies erfordert die Entwicklung geeigneter Messinstrumente, die zusätzlich die Qualität der tierärztlichen Betreuung berücksichtigen. Hierzu könnte der in dieser Studie verwendete Fragebogen nach entsprechenden Modifikationen für zukünftige Umfragen nützlich sein. Prospektive Studien können zusätzlich Vorstellungen und Ansichten des Tierarztes und des Besitzers im Vergleich noch genauer ermitteln. Die Ergebnisse helfen dem Praktiker, sich auf eventuelle Abweichungen in der Sichtweise der Besitzer einzustellen, sodass er diese bereits bei Therapiebeginn berücksichtigen kann. 


\section{ZUSAMMENFASSUNG}

Bei Hunden mit malignem Lymphom wird die Chemotherapie in erster Linie palliativ zur Erhaltung oder Verbesserung der Lebensqualität und zur Lebensverlängerung eingesetzt. Erfahrungsberichte aus der Perspektive deutscher Hundehalter existieren diesbezüglich bislang nicht. Hundebesitzer, deren Tiere in den letzten 13 Jahren zur Chemotherapie in der Medizinischen Kleintierklinik vorgestellt worden waren, wurden retrospektiv mittels eines Fragebogens bezüglich Krankheitsverlauf und Therapie des malignen Lymphoms ihrer Hunde befragt. Mithilfe statistischer Tests wurden Faktoren erfasst, die für die Besitzer bei der Einschätzung der Lebensqualität ihrer Tiere sowie für ihre Gesamtbewertung der Therapie eine entscheidende Rolle spielten. Objektive Parameter der Chemotherapie, wie Überlebens-, Remissionszeiten und Nebenwirkungen wurden der Datenbank, dem Klinikverwaltungsprogramm Vetera (G\&P Software, Eltville, Deutschland) entnommen und den Beobachtungen der Hundebesitzer gegenübergestellt. Nebenwirkungen wurden anhand der Common Terminology Criteria for Adverse Events (CTCAE) ausgewertet (VAIL, 2004). 123 Besitzer (59,4\%) beantworteten den Fragebogen. Bei 64 Hunden (53,3\%) ließ sich aus Sicht der Besitzer mit Chemotherapie eine Verbesserung der Lebensqualitäts erreichen. Nur bei 24 Hunden (20,0 \%) kam es zu einer Verschlechterung der Lebensqualität, die in direktem Zusammenhang mit dem Remissionsstatus und Nebenwirkungen der Chemotherapie stand. Der Großteil der Besitzer (65,0\%) war zufrieden mit der Chemotherapie und 90 Besitzer (73,2 \%) würden sich erneut für eine solche Behandlung entscheiden, wobei insbesondere die Lebensverlängerung ein wichtiges Entscheidungskriterium darstellte. Die Remissionsrate der Hunde lag bei 83,7 \% (65,0 \% komplette Remission, 18,7 \% partielle Remission). Die mediane Überlebenszeit betrug 275 Tage. 69 Patienten (56,1 \%) zeigten laut Datenbank hämatologische $(\mathrm{n}=52)$ und/oder klinische Nebenwirkungen $(\mathrm{n}=49)$. Bei 48 Hunden (39,0 \%) waren diese mild (Grad I und II), bei 21 Patienten schwerwiegend (Grad III und IV). 85 Besitzer (69,1\%) berichteten von Nebenwirkungen. 60 Besitzer (70,6 \%) empfanden Nebenwirkungen Grad I, II als „unbedeutend“, Nebenwirkungen Grad III, IV als „schwerwiegend“. Klinische, banale gastrointestinale Nebenwirkungen Grad II wurden von einigen Besitzern 
als ,schwerwiegend“ empfunden $(\mathrm{n}=7)$.

Die Ergebnisse der vorliegenden Studie sind dem praktizierenden Tierarzt eine große Hilfe in der Therapieentscheidung und der Tierhalterberatung bei Lymphom-kranken Hunden. 


\section{SUMMARY}

Chemotherapy in dogs with lymphoma is administered predominantly palliative for preservation or improvement of quality of life and for life extension. To date there are no studies about the opinions of German owners of dogs which had received chemotherapy. Therefore the owners of dogs that underwent chemotherapy at the Clinic of Small Animal Medicine, University of Munich during the last 13 years were queried about their dogs' course of disease and therapy by using a questionnaire in a retrospective study. With the aid of statistical tests the essential factors were assessed, which the owners deemed important for estimation of their dogs' quality of life and for assessment of therapy. Objective parameters, such as survival time, remission duration and adverse events were extracted from the clinic data base 'Vetera' (G\&P Software, Eltville, Germany) and compared with the owners' observations. Adverse events were graded according to the CTCAE-scale (Common Terminology Criteria for Adverse Events) (VAIL, 2004). A total of 123 owners (59.4\%) responded to the questionnaire. Quality of life was improved in 64 dogs (53.3\%) during chemotherapy. In only 24 dogs $(20.0 \%)$ a decline in quality of life was reported, that directly correlated with remission status and adverse events. The majority of the owners $(65.0 \%)$ was satisfied with the results of chemotherapy and 90 owners $(73.2 \%)$ would allow treatment of their animal with chemotherapy again; for this decision prolonged survival was an important factor. The overall remission rate of dogs undergoing chemotherapy was $83.7 \%$ (65.0\% complete remission, $18.7 \%$ partial remission). Median survival time was 275 days. According to the clinic data base 69 patients $(56.1 \%)$ showed haematologic $(n=52)$ and/or clinical adverse events $(n=48)$. Among 48 dogs adverse events were mild (grade I and II), among 21 patients they were serious (grade III und IV). From the owners' perspective, therapy led to improvement in 90 dogs (73.2\%). Eighty-five owners (69.1\%) reported about adverse events. Sixty owners (70.6\%) felt grade I, II toxicoses to be minor to negligible, while grade III, IV toxicoses were considered serious complications. Clinical, banal gastrointestinal toxicoses grade II were also regarded as "severe" $(\mathrm{n}=7)$.

The results of the present survey greatly assist the practicing veterinary in his therapy decisions as well as in counseling the owners of dogs with lymphoma. 


\section{LITERATURVERZEICHNIS}

Abbo AH, Lucroy MD. Assessment of anemia as an independent predictor of response to chemotherapy and survival in dogs with lymphoma: 96 cases (19932006). J Am Vet Med Assoc. 2007; 231: 1836-42.

Asch DA, Jedrziewski MK, Christakis NA. Response rates to mail surveys published in medical journals. J Clin Epidemiol. 1997; 50: 1129-36.

Badia X, Herdmann M. The importance of health-related quality-of-life data in determining the value of drug therapy. Clin Ther. 2001; 23: 168-75.

Baskin CR, Couto CG, Wittum TE. Factors influencing first remission and survival in 145 dogs with lymphoma: a retrospective study. J Am Anim Hosp Assoc. 2000; 36: 404-9.

Bergman PJ. Mechanisms of anticancer drug resistance. Vet Clin North Am Small Anim Pract. 2003; 33: 651-67.

Bernhard J, Lowy A, Mathys N, Hermann R, Hürny C. Health related quality of life: a changing construct? Qual Life Res. 2004; 13: 1187-97.

Bowles DB, Robson MC, Galloway PE, Walker L. Owner's perception of carboplatin in conjunction with other palliative treatments for cancer therapy. $\mathrm{J}$ Small Anim Pract. 2010; 51: 104-12.

Bristow MR, Sageman WS, Scott RH, Bellingham ME, Bowden RE, Kernof RS, Snidow GH, Daniels JR. Acute and chronic cardiovascular effects of doxorubicin in the dig: the cardiovascular pharmacology of drug-induce histamine-release. $\mathrm{J}$ Cardiovasc Pharmacol. 1980; 2: 487-515.

Bronden LB, Rutteman GR, Flagstad A, Teske E. Study of dog and cat owners' perceptions of medical treatment for cancer. Vet Rec. 2003; 152: 77-80.

Brooks MB, Matus RE, Leifer CE, Patnaik AK. Use of splenectomy in the management of lymphoma in dogs: 16 cases (1976-1985). J Am Vet Med Assoc. 1987; 191: 1008-10.

Carter RF, Valli VE, Lumsden JH. The cytology, histology and prevalence of cell types in canine lymphoma classified according to the National Cancer Institute 
Working Formulation. Can J Vet Res. 1986; 50: 154-64.

Carter RF, Harris CK, Withrow SJ, Valli VEO, Susaneck SJ. Chemotherapy of canine lymphoma with histopathological correlation: doxorubicin alone compared to COP as first treatment regimen. J Am Anim Hosp Assoc. 1987; 23: 587-96.

Chabanne L, Bonnefont C, Bernaud J, Rigal D. Clinical applications of flow cytometry and cell immunophenotyping to companion animals (dog and cat). Methods Cell Sci. 2000; 22: 199-207.

Chabner BA, Myers CE. Antitumor antibiotics. In: DeVita VT, Hellman S, Rosenberg SA, editors. Cancer: principles and practice of oncology. 4th ed. Philadelphia: J.B. Lippincott Co; 1993. p. 374-84.

Charney SC, Bergman PJ, Hohenhaus AE, McKnight JA. Risk factors for sterile hemorrhagic cystitis in dogs with lymphoma recieving cyclophosphamide with or without concurrent administration of furosemide: 216 cases (1990-1996). J Am Vet Med Assoc. 2003; 222: 1388-93.

Chun R, Garrett LD, Vail DM. Cancer Chemotherapy. In: Withrow SJ, MacEwen EG, editors. Small Animal Clinical Oncology. 4th ed. Philadelphia, PA: W.B. Saunders Company; 2007. p. 163-92.

Chun R. Lymphoma: which chemotherapy protocol and why? Top Companion Anim Med. 2009; 24: 157-62.

Couto CG, Cullen J, Pedroia V, Turrel JM. Central nervous system lymphosarcoma in the dog. J Am Vet Med Assoc. 1984; 184: 809-13.

Couto GC. Canine lymphomas: Something old, something new. Comp Cont Edu. 1985; 7: 291-302.

Couto CG. Management of complications of cancer chemotherapy. Vet Clin North Am Small Anim Pract. 1990; 20: 1037-54.

Crow SE, Theilen GH, Madewell BR, Weller RE, Henness AM. Cyclophosphamide-induced cystitis in the dog and cat. J Am Vet Med Assoc. 1977; 171: 259-62.

Culmsee K, Simon D, Mischke R, Nolte I. Possibilities of flow cytometric analysis for immunophenotypic characterization of canine lymphoma. J Vet Med 
A Phisiol Pathol Clin Med. 2001; 48: 199-206.

Day MJ. Review of thymic pathology in 30 cats and 36 dogs. J Small Anim Pract. 1997; 38: 393-403.

Decorti G, Klugmann FB, Candussio L, Furkani A, Scarcia V, Baldini L. Uptake of Adriamycin by rat and mouse mast cells and correlation with histamine release. Cancer Res. 1989; 49: 1921-6.

Dickinson RM. Canine lymphosarcoma: overcoming diagnostic obstacles and introduction to the latest diagnostic techniques. Can Vet J. 2008; 49: 305-8.

Dobson JM, Samuel S, Milstein H, Rogers K, Wood JLN. Canine neoplasia in the UK: estimates of incidence rates from a population of insured dogs. J Small Animal Pract. 2002; 43: 240-6.

Dorn CR, Taylor DO, Hibbard HH. Epizootiologic characteristics of canine and feline leukemia and lymphoma. Am J Vet Res. 1967; 28: 993-1001.

Dorn CR, Taylor DO, Schneider R, Hobbard HH, Klauber MR. Survey of animal neoplasms in Alameda and Contra Costa Counties, California. II. Cancer morbidity in dogs and cats from Alameda County. J Natl Cancer Inst. 1968; 40: 307-18.

Dorn CR, Taylor DO, Schneider R. The epidemiology of canine leukemia and lymphoma. Bibl Haematol. 1970; 36: 403-15.

Duncan JR, Prasse KW. Cytology of canine cutaneous round cell tumors. Mast cell tumor, histiocytoma, lymphosarcoma and transmissible venereal tumor. Vet Pathol. 1979; 16: 673-9.

Edwards P, Roberts I, Clarke M, DiGuiseppi C, Pratap S, Wenzt R, Kwan I, Cooper R. Methods to increase response rates to postal questionnaires. Cochrane Database Syst Rev. 2007: 18: MR00008.

Ettinger SN. Principles of treatment for canine lymphoma. Clin Tech Small Anim Pract. 2003; 18: 92-7.

Fan TM. Lymphoma updates. Vet Clin North Am Small Anim Pract. 2003; 33: 455-71.

Fontaine J, Bovens C, Bettenay S, Mueller RS. Canine cutaneous epitheliotropic 
T-cell-lymphoma: a review. Vet Comp Oncol. 2009; 7: 1-14.

Fournel-Fleury C, Ponce F, Felman P, Blavier A, Bonnefont C, Chabanne L, Marchal T, Cadore JL, Goy-Thollot I, Ledieu D, Ghernati I, Magnol JP. Canine T-cell lymphomas: a morphological, immunological, and clinical study of 46 new cases. Vet Pathol. 2002; 39: 92-109.

Fowler B, Axiak S, DeClue A. Blunted immune response in dogs with neoplesia [abstract]. VCS. San Diego; 29. Oktober - 1. November 2010.

Fry MM, Vernau W, Pesavento PA, Bromel C, Moore PF. Hepatosplenic lymphoma in a dog. Vet Pathol. 2003; 40: 556-62.

Garrett LD, Thamm DH, Chun R, Dudley R, Vail DM. Evaluation of a 6-month chemotherapy protocol with no maintenance therapy for dogs with lymphoma. J Vet Intern Med. 2002; 16: 704-9.

Gibson D, Aubert I, Woods JP, Abrams-Ogg A, Kruth S, Wood RD, Bienzle D. Flow cytometric immunophenotype of canine lymph node aspirates. J Vet Intern Med. 2004; 18: 710-7.

Greenlee PG, Filippa DA, Quimby FW, Patnaik AK, Calvano SE, Matus RE, Kimmel M, Hurvitz AI, Lieberman PH. Lymphoma in dogs. A morphologic, immunologic, and clinical study. Cancer. 1990; 66: 480-90.

Gross TL, Ihrke PJ, Walder EJ, Affolter VK, editors. Skin Diseases of the Dog and Cat, Clinical and Histopathologic Diagnosis, 2nd ed. Oxford: Blackwell Science; 2005.

Gunnars B, Nygren P, Glimelius B. Assessment of quality of life during chemotherapy. Acta Oncol. 2001; 40: 175-84.

Hammer AS. Prevention and treatment of chemotherapy complications. In: Kirk RW, Bongura JD, editors. Current Veterinary Therapy XI Small animal practice. Philadelphia: WB Saunders Co; 1992. p. 409-14.

Hardy W, Old L. L-asparaginase in the treatment of neoplastic disease of the dog, cat and cow. Recent Results Cancer Res. 1970; 33: 131-9.

Hartmann K, Kuffer M. Karnofsky's score modified for cats. Eur J Med Res. 1998; 3: 95-8. 
Hayes HM, Tarone RE, Cantor KP, Jessen CR, McCurnin DM, Richardson RC. Case control study of canine malignant lymphoma: Positive association between 2,4 dichlorophenoxyacetic acid herbicides. J Natl Cancer Inst. 1991; 83: 1226-31.

Hirschberger J, Dorsch R, Kaspar A, Link M, Meuser C, Neuerer F, Nussbaum K, Schafhauser T, Stocke N, Wieland S. Nebenwirkungen der Chemotherapie beim Hund. Mehrkomponenten-Chemotherapie des kaninen malignen Lymphoms. Tierärztl Prax. 2000; 28: 164-9.

Kaldrymidou E, Papaioannou N, Poutahidis T, Karayannopoulou M, Gruys E, Toliou T, Tsangaris T. Malignant lymphoma in nasal cavity and paranasal sinuses of a dog. J Vet Med A Physiol Pathol Clin Med. 2000; 47: 457-62.

Karnofsky D, Burchenal J. The clinical evaluation of chemotherapeutic agents in cancer. In: MacLeod CM, editor. Evaluation of chemotherapeutic agents. New York: Columbia Press; 1949. p. 191-205.

Khanna C, LundEM, Redic KA, Hayden DW, Bell FW, Goulland EL, Klausner JS. Randomized controlled trial of doxorubicin versus dactinomycin in a multiagent protocol for treatment of dogs with malignant lymphoma. J Am Vet Med Assoc. 1998; 213: 985-90.

Keller ET, MacEwen EG, Rosenthal RC, Helfand SC, Fox LE. Evaluation of prognostic factors and sequential combination chemotherapy with doxorubicin for canine lymphoma. J Vet Intern Med. 1993; 7: 289-95.

Keller RL, Avery AC, Burnett RC, Walton JA, Olver CS. Detection of neoplastic lymphocytes in peripheral blood of dogs with lymphoma by polymerase chain reaction for antigen receptor gene rearrangement. Vet Clin Pathol. 2004; 33: 1459.

Kiupel M, Teske E, Bostock D. Prognostic factors for treated canine malignant lymphoma. Vet Pathol. 1999; 36: 292-300.

Kristal O, Rassnick K, Gliatto J, Northrup N, Chretin, J, Morrison-Collister K, Cotter S, Moore A. Hepatotoxicity associated with CCNU (lomustine) chemotherapy in dogs. J Vet Intern Med. 2004; 18: 75-80.

Laing E, Carter R. Acute tumor lysis syndrome following treatment of canine lymphoma. J Am Anim Hosp Assoc. 1987; 24: 691-6. 
Lee JJ, Hughes CS, Fine RL, Page RL. P-glycoprotein expression in canine lymphoma: a relevant, intermediate model of multidrug resistance. Cancer. 1996; 77: $1892-8$.

Lennert K, Feller AC. Histopathologie der Non-Hodgkin-Lymphome, 2nd ed. Berlin: Springer Verlag; 1990.

MacEwen EG, Brown NO, Patnaik AK, Hayes AA, Passe S. Cyclic combination chemotherapy of canine lymphosarcoma. J Am Vet Med Assoc. 1981; 178: 117881.

Madewell BR. Canine lymphoma. Vet Clin North Am Small Anim Pract. 1985; 15: $709-15$.

Madewell BR, Thesen GH. Haematopoietic neoplasms, sarcomas and related conditions, Part IV: Canine. In: Theilen GH, Madewell BR, editors. Veterinary Cancer Medicine, 2nd ed. Philadelphia, PA: Lea and Febiger; 1987. p. 392-407.

Masetti R, Pession A. First-line treatment of acute lymphoblastic leukemia with pegasparaginase. Biologics. 2009; 3: 359-68.

Mauldin GE, Fox PR, Patnaik AK, Bond BR, Mooney SC, Matus RE. Doxorubicin-induced cardiotoxicosis. Clinical features in 32 dogs. J Vet Intern Med. 1992; 6: 82-8.

McMillan FD. Quality of life in animals. J Am Vet Med Assoc. 2000; 216: 190410.

McMillan FD. Quality of life concerns in animal shelters - part 2: Why is it important and how do we measure it? NAVC Conference. 2009; 1486-8.

Meleo KA. The role of radiotherapy in the treatment of lymphoma and thymoma. Vet Clin North Am Small Anim Pract. 1997; 27: 115-219.

Mellanby RJ, Herrtage ME, Dobson JM. Treatment of canine Lymphoma by veterinarians in first opinion practice in England. J Small Anim Pract. 2002; 43: 198-202.

Mellanby RJ, Herrtage ME, Dobson JM. Owners' assessments of their dog's quality of life during palliative chemotherapy for lymphoma. J Small Anim Pract. 2003; 44: 100-3. 
Miniscalco B, Guglielmino R, Morello E, Tarducci A, Geuna M. Clinical usefulness of peripheral blood lymphocyte subsets in canine lymphoma. Vet Res Comm. 2003; 27 Suppl 1: 407-9.

Moore PF, Olivry T, Naydan D. Canine cutaneous epitheliotropic lymphoma (mycosis fungoides) is a proliferative disorder of CD8+ T cells. Am J Pathol. 1994; 144: 421-9.

Moore A, Leveille C, Reimann K, Shu H, Arias I. The expression of Pglycoprotein in canine lymphoma and its association with multidrug resistance. Cancer Invest. 1995; 13: 475-9.

Moore A, London C, Wood C, Williams L, Cotter S, L'Heureux D, Frimberger A. Lomustine (CCNU) for the treatment of resistant lymphoma in dogs. J Vet Intern Med. 1999; 13: 395-8.

Moore AS, Cotter SM, Rand WM, Wood CA, Williams LE, London CA, Frimberger, AE, L'Heureux DA. Evaluation of a discontinuous treatment protocol (VELCAP-S) for canine lymphoma. J Vet Intern Med. 2001; 15: 348-54.

Morrison WB. Cancer in Dogs and Cat, Medical and Surgical Management. 2nd edn., Jackson: Teton NewMedia, 2001. p. 641-70.

Morrison WB. Non-Cutaneous Lymphoma. In: Morrison WB, editor. Lymphoma in Dogs and Cats. Jackson: Teton NewMedia; 2005. p. 1-96.

Moldovanu G, Friedman M, Miller DG. Treatment of canine malignant lymphoma with surgery and chemotherapy. J Am Vet Med Assoc. 1996; 148: 153-6.

Müller S. Immunhistologische Untersuchungen an malignen Lymphomen des Hundes - Zelltypisierung und Bestimmung der Proliferations- und Apoptosefraktion [dissertation]. Hannover: Tierärzliche Hochschule; 1998.

Mylonakis M, Koutinas A, Papaioannou N, Lekkas S. Acute tumour lysis syndrome in a dog with B-Cell multicentric lymphoma. Aust Vet J. 2007; 85: 206-8.

Nagel ML. Komplikationen während und nach der Chemotherapie beim Hund. Tierärztl Prax. 2003; 31: 35-8. 
Northrup NC, Rassnick KM, Snyder LA, Stone MS, Kristal O, Cotter SM, Moore AS. Neutropenia associated with vincristine and L-asparaginase induction chemotherapy for canine lymphoma. J Vet Intern Med 2002; 16: 570-5.

Ogilvie GK, Moore AS. Paraneoplastic Syndromes. In: Ogilvie GK, editor. Managing the veterinary cancer patient. Trenton, New Jersey: Veterinary Learning Systems; 1995. p. 197-222.

Osoba D. The Quality of Life Committee of the Clinical Trials Group of the National Cancer Institute of Canada: organization and functions. Qual Life Res. 1992; 1: 211-8.

Owen LN. TNM classification of tumors of domestic animals. 1st ed. Geneva, Switzerland: World Health Organization; 1980. p. 46-7.

Parodi A, Wyers M, Paris J. Incidence of canine lymphoid leukosis: age, breed and sex distribution - results of a necropsy survey. Bibl Haematol. 1968; 30: 2637.

Patrick DL, Deyo RA. Generic and desease-specific measures in assessing health status and quality of life. Med Care. 1989; 27: 217-32.

Peterson JL, Couto CG, Hammer AS, Ayl RD. Acute sterile hemorrhagic cystitis after a single intravenous administration of cyclophosphamide in three dogs. J Am Vet Med Assoc. 1992; 201: 1572-3.

Piek CJ, Rutteman GR, Teske E. Evaluation of the results of a L-asparaginasebased continuous chemotherapy protocol versus a short doxorubicin-based induction chemotherapy protocol in dogs with malignant lymphoma. Vet Q. 1999; 21: 44-9.

Pizzo PA, Young RC. Infection in the cancer patient. In: DeVita VT, Hellman S, Rosenberg SA, editors. Cancer principles and practice of oncology. 2nd ed. Philadelphia: JB Lippincott Co; 1985. p. 1963-99.

Ponce F, Magnol JP, Ledieu D, Marchal T, Turinelli V, Chalvet-Monfray K, Fournel-Fleury C. Prognostic significance of morphological subtypes in canine malignant lymphomas during chemotherapy. Vet J. 2004; 167: 158-66.

Price GS, Page RL, Fischer BM, Levine JF, Gerig TM. Efficacy and toxicity of doxorubicin/cyclophosphamide maintenance therapy in dogs with multicentric 
lymphosarcoma. J Vet Intern Med. 1991; 5: 259-62.

Priebe S, Gruyters T. The role of the helping alliance in psychiatric community care. A prospective study. J Nerv Men Dis. 1993; 181: 552-7.

Rassnick KM, Moore AS, Collister KE, Northrup NC, Kristal O, Chretin JD, Bailey DB. Efficacy of combination chemotherapy for treatment of gastrointestinal lymphoma in dogs. J Vet Intern Med. 2009; 23: 317-22.

Rosenthal RC. Epidemiology of canine lymphosarcoma. Comp Cont Edu. 1984; 4: 855-60.

Rowinsky EK. Antimicrotubule Agents. In: Chabner BA, Longo DL, editors. Cancer Chemotherapy \& Biotherapy. Principles and Practice, 4th ed. Philadelphia, PA: Lippincott Williams \& Wilkins; 2006. p. 237-83.

Ruppaner R. Measurement of disease in animal populations based on interviews. J Am Vet Med Assoc. 1972; 161: 1033-8.

Ruslander DA, Gebhard DH, Tompkins MB, Grindem CB, Page RL. Immunophenotypic characterization of canine lymphoproliferative disorders. In Vivo. 1997; 11: 169-72.

Ruslander D. Komplikationen der Chemotherapie. In: Kessler M, Herausgeber: Kleintieronkologie. Diagnose und Therapie von Tumorerkrankungen bei Hunden und Katzen. Berlin: Parey Buchverlag; 1999. p. 156-67.

Scott M. Muller and Kirk's Small Animal Dermatology 6th ed. Philadelphie, PA: W.B. Saunders Company; 2001: 1330-40.

Shaw J, Lagoni L. End-of-life communication in veterinary medicine: delivering bad news and euthanasia decision making. Vet Clin North Am Small Anim Pract. 2007; 37: 95-108.

Simon D, Nolte I, Eberle N, Abbrederis N, Killich M, Hirschberger J. Treatment of dogs with lymphoma using a 12-week, maintenance-free combination chemotherapy protocol. J Vet Intern Med. 2006; 20: 948-54.

Simon D, Moreno S, Hirschberger J, Moritz A, Kohn B, Neumann S, Jurina K, Scharvogel S, Schwedes C, Reinacher M, Beyerbach M, Nolte I. Efficacy of a continuous, multiagent chemotherapeutic protocol versus a short-term single- 
agent protocol in dogs with lymphoma. J Am Vet Med Assoc. 2008; 232: 879-85.

Sorenmo KU, Harwood LP, King LG, Drobatz KJ. Case-control study to evaluate risk factors for the development of sepsis (neutropenia and fever) in dogs receiving chemotherapy. J Am Vet Med Assoc. 2010; 236: 650-6.

Squire RA, Bush M, Melby EC, Neeley LM, Yarbrough B. Clinical and pathologic study of canine lymphoma: clinical staging, cell clasification, and therapy. J Natl Cancer Inst. 1973; 51: 565-74.

The WHOQOL-Group: Development of the World Health Organization WHOQOL-BREF quality of life assessment. Psychol Med. 1998; 28: 551-8.

Theunissen NC, Vogels TG, Koopman HM, Verrips GH, Zwinderman KA, Verloove-Vanhorick SP, Wit JM. The proxy problem: child report versus parent report in health-related quality of life research. Qual Life Res. 1998; 7: 387-97.

Teske E. Canine malignant lymphoma: A review and comparison with human non-Hodgkin's lymphoma. Vet Quart 1994; 16: 209-19.

Teske E, Van Heerde P, Ruttemann GR, Kurzman ID, Moore PF, MacEwen EG. Prognostic factors for treatment of malignant lymphoma in dogs. J Am Vet Med Assoc. 1994; 205: 1722-8.

Tomiyasu H, Takahashi M, Fujino Y, Ohno K, Tsujimoto H. Gastrointestinal and Hematologic Adverse Events after Administration of Vincristine, Cyclophosphamide, and Doxorubicin in Dogs with Lymphoma that Underwent a Combination Multidrug Chemotherapy Protocol. J Vet Med Sci. 2010; Jun 11.

Tzannes S, Hammond MF, Murphy S, Sparkes A, Blackwood L. Owners 'perception of their cats'quality of life during COP chemotherapy ror lymphoma. J Feline Med Surg. 2008; 10: 73-81.

Vail DM, Kisseberth WC, Obradovich JE, Moore FM, London CA, MacEwen EQ, Ritter MA. Assessment of potential doubling time (Tpot), argyrophilic nucleolar organizer regions (AgNOR), and proliferating cell nuclear antigen (PCNA) as predictors of therapy response in canine non-Hodgkin's lymphoma. Exp Hematol. 1996; 24: 807-15.

Vail DM, MacEwen EG, Young KM. Canine lymphoma and lymphoid leukemias. In: Withtrow SJ, MacEwen EG, editors. Small Animal Clinical Oncology, 3rd ed. 
Philadelphia, PA: W.B. Saunders Company; 2001. p. 558-90.

Vail DM. Veterinary Co-operative Oncology Group. Vet Comp Oncol. 2004; 2: 194.

Vail DM, Young KM. Canine lymphoma and lymphoid leukemia. In: Withrow SJ, MacEwen EG, editors. Small Animal Clinical Oncology, 4th ed. Philadelphia, PA: W.B. Saunders Company; 2007. p. 699-733.

Valerius K, Ogilvie G, Mallinckrodt C, Getzy D. Doxorubicin alone or in combination with asparaginase, followed by cyclophosphamide, vincristine, and prednisone for treatment of multicentric lymphoma in dogs: 121 cases (19871995). J Am Vet Med Assoc. 1997; 210: 512-6.

Valerius KD, Ogilvie GK, Fettman MJ, Walton JA, Richardson K, Powers BE, McNiel EA, Rogers QR. Comparison of the effects of asparaginase administered subcutaneously versus intramuscularly for treatment of multicentric lymphoma in dogs receiving doxorubicin. J Am Vet Med Assoc. 1999; 214: 353-6.

Valli VE, Vernau W, De Lorimier LP, Grahams PS, Moore PF. Canine indolent nodular lymphoma. Vet Pathol. 2006; 43: 241-56.

Van Vleet JF, Ferrans VJ. Clinical observations, cutaneous lesions, and hematologic alterations in chronic adriamycin intoxication in dogs with and without vitamin E and selenium supplementation. Am J Vet Res. 1980; 41: 691-9.

Vonderhaar MA, Morrison WB. Lymphosarcoma. In: Morrison WB, editor. Cancer in dogs and cats: medical and surgical management. 2nd ed. Jackson: Teton NewMedia; 2002. p. 641-70.

Von Wethern CJ, Horst C, Schwarz G. Zur Gliedmaßenamputation bei Hund und Katze: Eine Besitzerbefragung. Kleintierpraxis. 1999; 44: 169-76.

Walker A, Restuccia J. Obtaining information on patient satisfaction with hospital care: mail versus Telefone. Health Serv Res. 1984; 19: 291-306.

Winnicka A, Jagielski D, Hoffmann-Jagielska M, Lechowski R. Cytometric evaluation of peripheral blood lymphocytes in dogs with lymphoma during chemotherapy. J Vet Med A Physiol Pathol Clin Med. 2002; 49: 303-6.

Wojciechowska JI, Hewson CJ. Quality-of-life assessment in pet dogs. J Am Vet 
Med Assoc. 2005; 226: 722-8.

Working Formulation. [No authors listed] National Cancer Institute sponsored study of classifications of non-Hodgkin's lymphomas: summary and description of a working formulation for 53 clinical usage. The Non-Hodgkin's Lymphoma Pathologic Classification Project. Cancer. 1982; 49: 2112-35.

Yazbek KV, Fantoni DT. Validity of a health-related quality-of-life scale for dogs with signs of pain secondary to cancer. J Am Vet Med Assoc. 2005; 226: 1354-8.

Yeates J, Main D. Assessment of companion animal quality of life in veterinary practice and research. J Small Anim Pract. 2009; 50: 274-81.

Zemann BI, Moore AS, Rand WM, Mason G, Ruslander DM, Frimberger AE, WoodCA, L'Heureux DA, Gliatto J, Cotter SM. A combination chemotherapie protocol (VELCAP-L) for dogs with lymphoma. J Vet Intern Med. 1998; 12: 46570.

Zenker I, Meichner K, Steinle K, Kessler M, Hirschberger J. A 13-week Dose Intensifying Simultaneous Combination Chemotherapy (DISC) Protocol for Malignant Lymphoma in Dogs: 21 Cases. Vet Rec. "in press“. 


\section{ANHANG}

\subsection{Besitzeranschreiben}

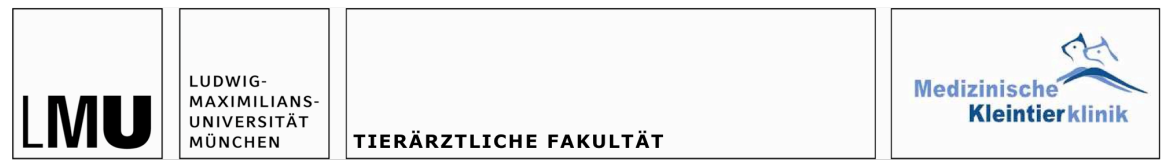

Medizinische Kleintierklinik • Veterinärstr. 13 • 80539 München An:
Johannes Hirschberger

Prof. Dr. Dr. habil.,
Diplomate ECVIM-CA

(Internal Medicine \& Oncology)

hon. Diplomate ECVCP

(Clinical Pathology)

Telefon $+49(0) 89 / 2180-2640$ elefax $+49(0) 89 / 2180-2640$ hirschberger@lmu.de

München, 02.02.2011

Sehr geehrte/r Frau/Herr

Im Rahmen einer tiermedizinischen Doktorarbeit der Tierärztlichen Fakultät

München führen wir eine Umfrage zur Chemotherapie des malignen Lymphoms des Hundes bei betroffenen Hundebesitzern durch.

Sie helfen uns mit der Umfrage, besser einschätzen zu können, ob das eigentliche Ziel der Chemotherapie bei Tieren - nämlich die Verbesserung und der Erhalt der Lebensqualität tatsächlich den Erwartungen gemäß erfüllt wird. Neben unserem wissenschaftlichen Interesse hoffen wir, dass anderen Tierbesitzern Ihre Erfahrungen zu gute kommen.

Die Geheimhaltung Ihrer persönlichen Daten ist absolut gewährleistet. Ihre Angaben zu Ihrem Patienten werden von uns statistisch ausgewertet. Eine Zusammenfassung der Ergebnisse würden wir Ihnen selbstverständlich gerne zukommen lassen.

Die Beantwortung des vierseitigen Fragebogens dauerte im Probedurchlauf 10 Minuten. Sollten beim Ausfüllen des Fragebogens Probleme auftreten, melden Sie sich bitte bei:

Prof. Dr. Dr. habil. Johannes Hirschberger; Email: hirschberger@Imu.de oder NickyBergmann; Email: nicky.bergmann@googlemail.com; Tel: 0163/3690071

Wir freuen uns, wenn Sie uns den ausgefüllten Fragebogen zukommen lassen. Einen frankierten Rückumschlag legen wir bei.

Vielen Dank!

Prof. Dr. Johannes Hirschberger

\begin{tabular}{|c|c|c|}
\hline $\begin{array}{l}\text { Lehrstuhl für Innere Medizin der } \\
\text { kleinen Haustiere und Heimtiere der } \\
\text { Ludwig-Maximilians-Universität }\end{array}$ & $\begin{array}{l}\text { Öffentliche Verkehrsmittel: U-Bahn } \\
\text { U-Bahn: Linie } 3 \text { und } 6 \\
\text { Haltestelle: "Universität" } \\
\text { Telefon: }+49 \text { (0)89 } 2180-2650 \\
\text { Telefax:+49 }(0) 892180-6240\end{array}$ & $\begin{array}{l}\text { Dienstgebäude: Königinstr. } 16 \\
\text { Klinik: Veterinärstr. } 13 \\
80539 \text { München } \\
\text { info@medizinische-kleintierklinik.de }\end{array}$ \\
\hline
\end{tabular}




\subsection{Fragebogen zur Chemotherapie}




Hatten Sie im Vorfeld schon einmal engen Kontakt zu Personen/Tieren, die Chemotherapie erhalten haben?

$\square \mathrm{Ja}$

$\square$ Nein

Wenn ja, in welchem Bezug standen Sie dazu?

$\square$ Ich selbst/ ein Familienmitglied/ein enger Freund habe/hat Chemotherapie erhalten.

$\square$ Ein anderes Haustier, das ich kenne, hat Chemotherapie erhalten.

$\square$ Ich hatte/habe beruflich damit zu tun.

$\square$ Dazu möchte ich mich nicht äußern.

Welche Aspekte haben Ihrer Meinung nach gegen eine Chemotherapie gesprochen? (mehrere Antwortmöglichkeiten können angekreuzt werden)

$\square$ Ich hatte keine Einwände.

$\square$ Die hohe Belastung meines Hundes durch Nebenwirkungen.

$\square$ Das hohe Alter meines Hundes.

$\square \mathrm{Zu}$ hohe Kosten.

$\square$ Emotionale Aspekte.

$\square$ Ethische Grundsätze.

$\square$ Die Meinungen von Menschen aus meinem Umfeld.

$\square$ Keine Antwort trifft zu.

\section{Erwartungen}

\begin{tabular}{|c|c|c|c|}
\hline \multicolumn{4}{|c|}{$\begin{array}{l}\text { Wie hat Sie Ihr betreuender Onkologie-Tierarzt über Chemotherapie bei Tieren } \\
\text { aufgeklärt? }\end{array}$} \\
\hline $\begin{array}{l}\text { Prognose } \\
\text { Nebenwirkungen } \\
\text { Kosten }\end{array}$ & $\begin{array}{l}\square \quad 1 \text { (gut) } \\
\square 1 \text { (gut) } \\
\square \quad 1 \text { (gut) }\end{array}$ & $\begin{array}{l}\square 2 \text { (mittel) } \\
\square 2(\text { mittel) } \\
\square 2 \text { (mittel) }\end{array}$ & $\begin{array}{l}\square \quad 3 \text { (schlecht) } \\
\square 3 \text { (schlecht) } \\
\square 3 \text { (schlecht) }\end{array}$ \\
\hline
\end{tabular}

Nachdem Sie von den Onkologie-Tierärzten aufgeklärt wurden....

Warum haben Sie sich dazu entschlossen, Ihren Hund mit Chemotherapie behandeln zu lassen?

$\square$ Meiner Meinung nach war Chemotherapie die beste Therapie, die meinem Hund zur Verfügung stand.

$\square$ Ich war unsicher, wollte die Chemotherapie aber versuchen.

$\square$ Aus anderen Gründen:......

\section{Welches Gefühl hatten Sie, als Ihr Hund die 1. Chemotherapie erhalten hatte?}

$\square$ erwartungsvoll

$\square$ zweifelnd

$\square$ skeptisch

$\square$ neutral 
Welche Vorteile haben Sie von der Chemotherapie erwartet? (mehrere Antwortmöglichkeiten)

$\square$ Dass sich die Lymphknoten meines Hundes verkleinern.

$\square$ Dass sich das Allgemeinbefinden und die Lebensqualität verbessern (keine

Schmerzen, Interesse an der Umwelt, Appetit).

$\square$ Dass mein Hund mit Therapie länger leben wird, als ohne.

$\square$ Dass mein Hund vollständig geheilt wird.

$\square$ Ich habe überhaupt keine Besserung erwartet

$\square$ Anderes:

Welche Nebenwirkungen haben Sie von der Chemotherapie erwartet? (mehrere Antwortmöglichkeiten)

$\square$ Haarausfall

$\square$ Gewichtsverlust

$\square$ Ein schlechtes Allgemeinbefinden

$\square$ Durchfall, Erbrechen

$\square$ Fieber

$\square$ Ich habe keine Nebenwirkungen erwartet.

$\square$ Anderes:.

\section{Chemotherapie}

\section{Welche Ihrer Erwartungen konnten durch die Chemotherapie erfüllt werden?}

$\square$ Die Lymphknoten sind kleiner geworden.

$\square$ Das Allgemeinbefinden und die Lebensqualität haben sich verbessert.

$\square$ Mein Hund hat länger gelebt als erwartet.

$\square$ Mein Hund wurde vollständig geheilt.

$\square$ Es ist keine Besserung aufgetreten.

$\square$ Anderes:.

\section{Nebenwirkungen der Chemotherapie traten während der gesamten} Behandlungsdauer...?

$\square$ keine auf.

$\square$ selten auf. Sie waren

$\square$ unbedeutend.

$\square$ schwerwiegend.

$\square$ häufig auf. Sie waren

$\square \quad$ unbedeutend.

$\square$ schwerwiegend.

Wie schätzen Sie die Lebensqualität ein, die Ihr Hund mit Chemotherapie während der gesamten Behandlungsdauer hatte?

$\square 1$ (sehr gut) $\square 2$ (gut) $\square 3$ (mittel) $\square 4$ (schlecht) $\square 5$ (sehr schlecht)


Wie hat Ihr Umfeld (Nachbar, andere Hundebesitzer...) reagiert, als sie von der Chemotherapie Ihres Hundes gehört haben? (mehrere Antwortmöglichkeiten)

$\square$ positiv:

$\square$ negativ:.

Wurde die Therapie vorzeitig abgebrochen?

$\square$ Nein

$\square \mathrm{Ja}$, mein Hund hat nicht mehr auf die Chemotherapie angesprochen.

$\square$ Ja, die Nebenwirkungen waren zu stark.

$\square \mathrm{Ja}$, die Kosten wurden zu hoch.

$\square$ Ja, der Zeitaufwand war zu hoch.

$\square \mathrm{Ja}:$

Welche Aussage repräsentiert am besten Ihre Gefühle gegenüber Chemotherapie heute?

$\square$ Ich bin froh, meinen Hund behandelt haben zu lassen.

$\square$ Ich bedauere es, meinen Hund behandelt haben zu lassen.

$\square$ Ich bin unsicher, weil:.

Würden Sie sich heute wieder dafür entscheiden Ihr Tier/ eines Ihrer Tiere mit Chemotherapie behandeln zu lassen?

\section{$\square \mathrm{Ja}$}

$\square$ Nein, weil:

Lebt Ihr am malignen Lymphom erkrankter Hund noch? Wenn nicht, warum und seit wann nicht mehr?

$\square \mathrm{Ja}$

$\square$ Nein:

Haben Sie weitere Anmerkungen? 


\section{DANKSAGUNG}

Mein ganz besonderer Dank geht an Herrn Univ. Prof. Dr. Johannes Hirschberger, meinem Doktorvater und Betreuer für die Überlassung des interessanten Themas und für die jederzeit gewährte, engagierte wissenschaftliche und freundliche Unterstützung sowie seine herzliche Art.

Weiter möchte ich mich bei der gesamten Medizinischen Kleintierklinik bedanken: ich durfte ein tolle Zeit genießen.

Ich danke meinen lieben Eltern, die jederzeit für mich da waren.

Zazie und Marcus: Danke, dass Ihr immer für mich da seid. 